\title{
Internal Control Quality as an Explanatory Factor of Tax Avoidance
}

by

\author{
Andrew M. Bauer
}

\author{
A thesis \\ presented to the University of Waterloo \\ in fulfillment of the \\ thesis requirement for the degree of \\ Doctor of Philosophy \\ in \\ Accounting
}

Waterloo, Ontario, Canada, 2011

(C) Andrew M. Bauer 2011 


\section{AUTHOR'S DECLARATION}

I hereby declare that I am the sole author of this thesis. This is a true copy of the thesis, including any required final revisions, as accepted by my examiners.

I understand that my thesis may be made electronically available to the public. 


\begin{abstract}
Internal control disclosures mandated by section 404 of the Sarbanes-Oxley Act (SOX) are designed to provide information about a firm's financial reporting quality and in doing so may offer information on firm-specific tax planning activities. Internal control weaknesses disclosed under SOX are frequently related to a firm's tax function (Ge and McVay, 2005; Gleason, Pincus and Rego, 2010) and thus raise the question of whether or not these frequent problems affect corporate tax avoidance.

In this thesis, I test hypotheses that tax-related disclosures, particularly those that contain company-level internal control weaknesses (ICWs), provide information with respect to long-run tax avoidance. Furthermore, I test hypotheses that the combination of internal control quality and aggressive tax avoidance aid in assessing shareholder returns. To conduct these tests, I collect and construct firm-level SOX disclosure data from 2004 to 2006 across 1,286 publicly-owned corporations. I begin with an empirical analysis of the association between tax avoidance and firm-level ICWs and generally find that the presence of tax ICWs and company-level tax ICWs constrain long-run tax avoidance. For firms with low cash constraints however, company-level tax ICWs appear to lead to an increase in tax avoidance. Nevertheless, subsequent analysis of monthly abnormal returns implies that the stock market reacts negatively to the disclosure of company-level tax ICWs, regardless of whether or not tax aggressiveness is also present.

This thesis contributes to the literature by documenting the first evidence that internal control disclosures provide information regarding firm-level tax planning. Although the number of internal control weakness disclosures is decreasing over time, the availability of these SOX disclosures represents a previously unavailable opportunity to examine and further understand
\end{abstract}


internal governance mechanisms within the firm and their influence on tax planning. In addition, this thesis further corroborates prior literature that argues for the importance of the pervasiveness of internal control weaknesses by showing that the pervasive, company-level tax internal control weaknesses are associated with tax avoidance and lower shareholder returns.

Finally, my dissertation implies that the presence of tax internal control weaknesses constrains tax avoidance and thus a focus on improving internal controls could help improve the tax planning function. However, my firm-level analysis also implies that effective tax planning is a sustainable process and thus a firm and its stakeholders may require several periods before the full benefits of these improvements are realized. 


\section{ACKNOWLEDGEMENTS}

I am especially grateful for the consistent advice, mentorship and encouragement of my supervisor, Ken Klassen. His efforts have had an immeasurable influence not only on my dissertation, but more importantly on my development as an academic scholar and colleague.

I am also grateful for the feedback and direction provided by the other members of my dissertation committee: Jee-Hae Lim, Alan Macnaughton and Anindya Sen. I must further thank Alan Macnaughton and Anindya Sen for their excellent mentorship throughout my studies. I would also like to express my gratitude to Cristi Gleason for acting as my external examiner and for providing wonderful insight on this thesis. This dissertation has also benefited from the thoughtful comments of Dan Amiram, Joseph Cheng, Sarah Cheung, Joseph Comprix, Michael Donohoe, Pete Lisowsky, Andrew Oldham, and particularly James Chyz, as well as countless helpful individuals at various conferences and workshops.

To the many faculty and staff whom have impacted my life positively since my earliest days at the University of Waterloo, thank you. I note a special thank you to Anthony Atkinson, Patricia O’Brien, Alan Webb, Christine Wiedman and Tony Wirjanto for their guidance and support during my doctoral studies, and to Howard Armitage, a source of great inspiration.

To my fellow doctoral students, your support and camaraderie made the early struggles manageable and the later successes possible. Darren Henderson, Yutao Li, Adam Presslee, and especially Louise Hayes have also been vital to the completion of this thesis. Finally, to my brother and closest colleague Tim Bauer, although it is strange that we keep following a similar path, I am never disappointed that we do. For all the long nights, heated debates, gentle encouragement and, most importantly, candid honesty, I am truly grateful. 


\section{DEDICATION}

To my family and friends, especially my wife Melanie and my daughter Ava: thank you for your love and encouragement. 


\section{TABLE OF CONTENTS}

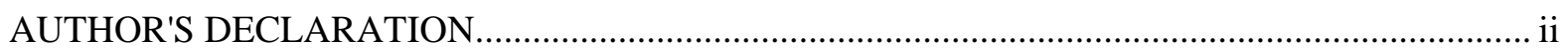

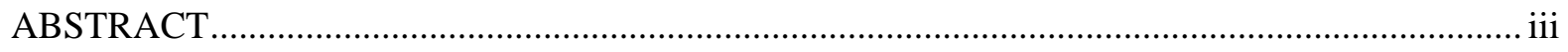

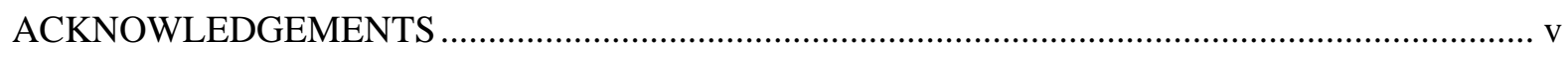

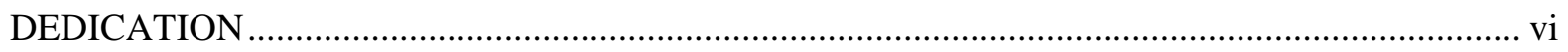

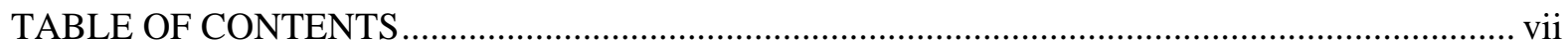

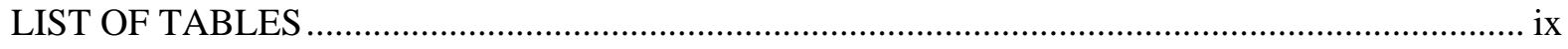

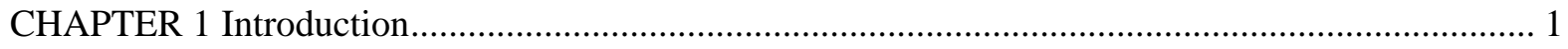

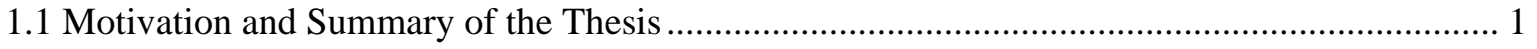

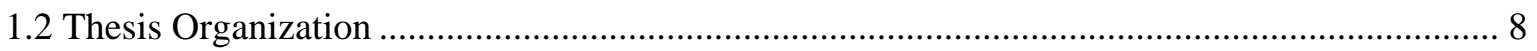

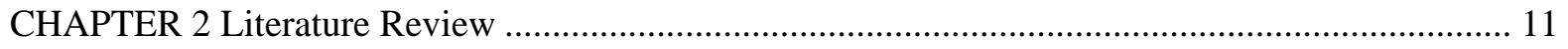

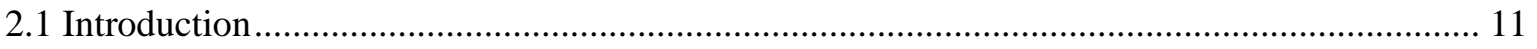

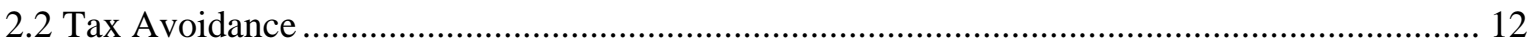

2.3 Internal Control Disclosures under Sarbanes-Oxley Regulations............................................ 18

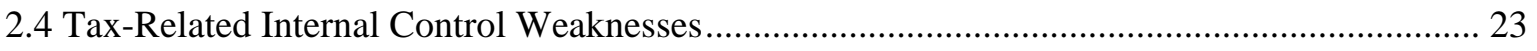

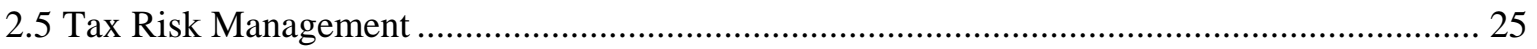

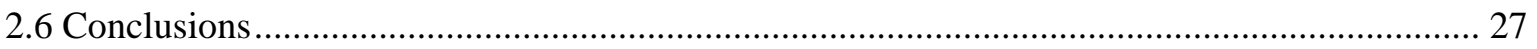

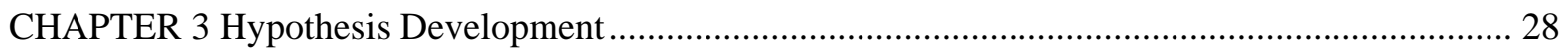

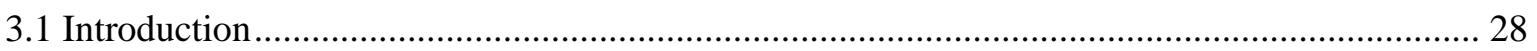

3.2 Internal Control Quality and Tax Avoidance.................................................................... 29

3.3 Pervasiveness of Internal Control Weaknesses and Tax Avoidance....................................... 31

3.4 Internal Control Quality, Tax Avoidance and Stock Return Performance .............................. 34

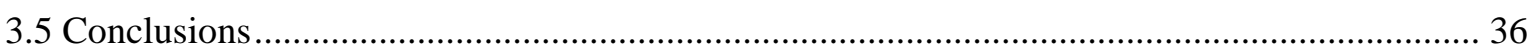

CHAPTER 4 Sample Selection and Research Design............................................................... 37

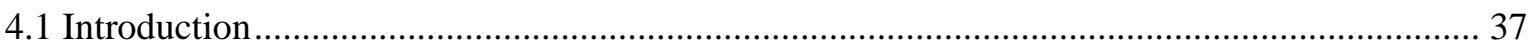

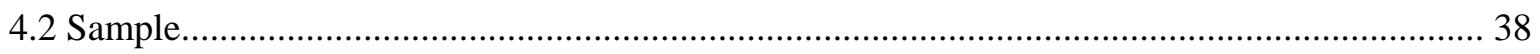

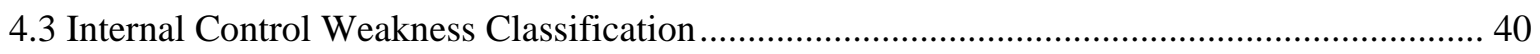

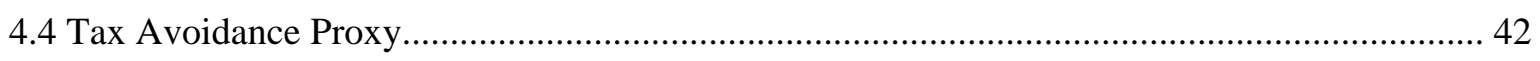

4.5 Empirical Models - Tax Avoidance and Internal Control Quality ....................................... 45

4.6 Empirical Models - Stock Returns, Tax Avoidance and Internal Control Quality ................... 52

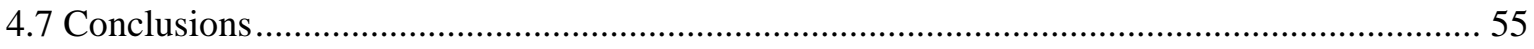

CHAPTER 5 Empirical Analysis - Tax Avoidance and Internal Control Quality ............................. 56 


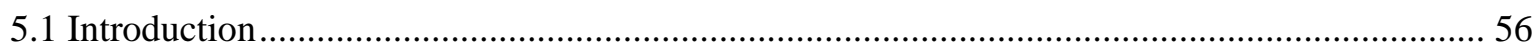

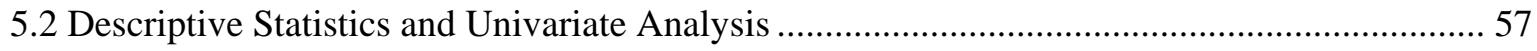

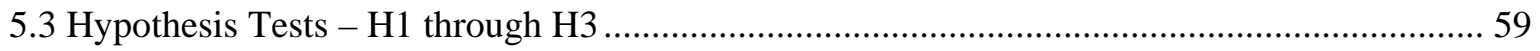

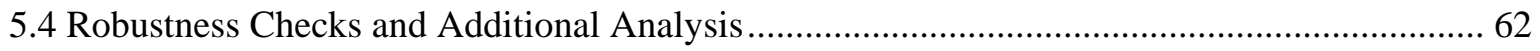

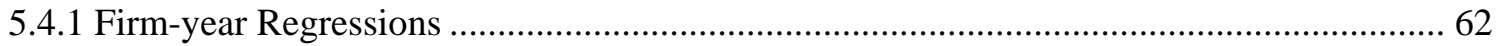

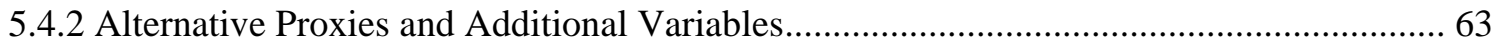

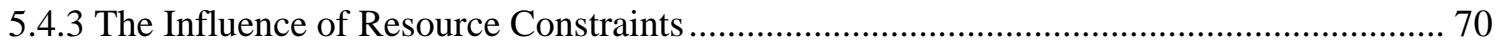

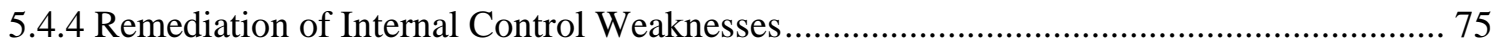

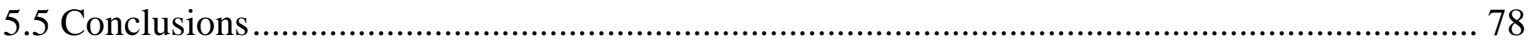

CHAPTER 6 Empirical Analysis - Stock Returns and the Influence of Tax Avoidance and Internal

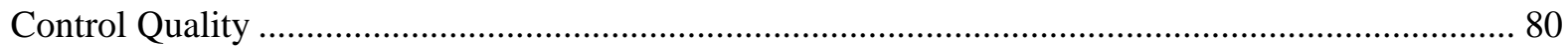

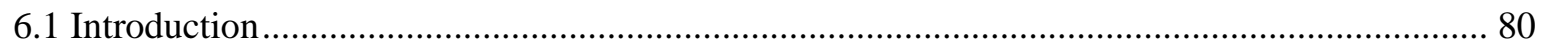

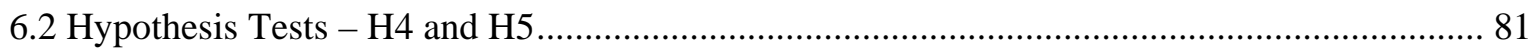

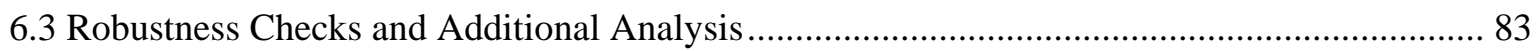

6.3.1 Alternative Internal Control Weakness Variables and Alternative Sample Periods ............ 83

6.3.2 Alternative Tax Avoidance Proxies .................................................................................... 85

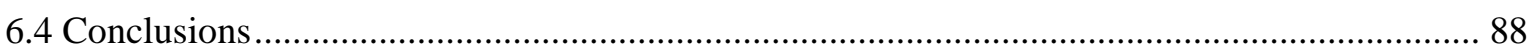

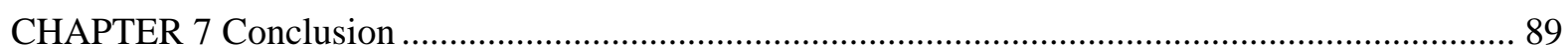

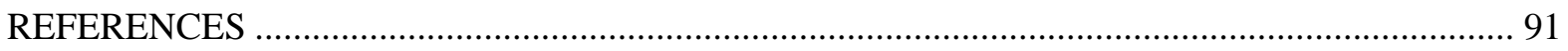

APPENDIX A Doyle et al. (2007a) Material Weakness Classification Scheme................................ 97

APPENDIX B Material Weakness Classification Scheme (Based on Hammersley et al., 2008) ....... 98

APPENDIX C Examples of Tax-Related Material Weakness Disclosures ..................................... 100

APPENDIX D Table D.1 - Determination of a Parsimonious Model of Tax Avoidance.................. 101 


\section{LIST OF TABLES}

Table 1 Sample, Industry and Weakness Composition ................................................................... 105

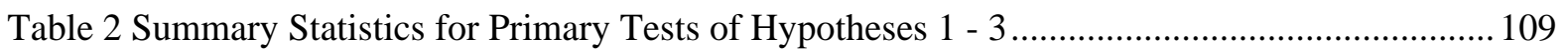

Table 3 Summary Statistics by Group for Primary Tests of Hypotheses 1 - 3 (Average Values Only)

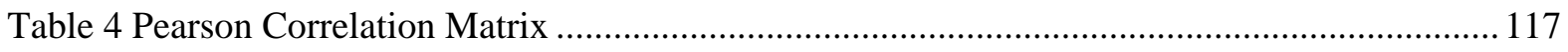

Table 5 Firm Analysis of Tax Avoidance \& Internal Control Weaknesses .....................................118

Table 6 Firm-Year Analysis of Tax Avoidance \& Internal Control Weaknesses using Overlapping

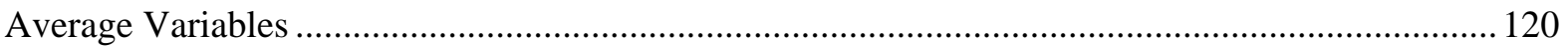

Table 7 Summary Statistics for Variables in Section 5.4 Robustness Tests .................................... 122

Table 8 Analysis of Tax Avoidance \& Internal Control Weaknesses with BTD Proxies .................. 127

Table 9 Firm Analysis of Tax Avoidance with Alternative Internal Control Weakness Categorizations

Table 10 Firm Analysis of Tax Avoidance, Internal Control Weaknesses and Corporate Governance

Table 11 Analysis of Tax Avoidance, Internal Control Weaknesses \& Resource Constraint Factors

Table 12 Analysis of Tax Avoidance and the Interaction between Internal Control Weaknesses \& Resource Constraints

Table 13 Analysis of Tax Avoidance \& Remediation of Internal Control Weaknesses

Table 14 Summary Statistics for Variables in Chapter 6 Tests

Table 15 Analysis of Abnormal Stock Returns Conditional on Tax Aggressiveness and Company-

Level Tax-Related Internal Control Quality

Table 16 Analysis of Abnormal Stock Returns Conditional on Tax Aggressiveness and General/Tax-

Related Internal Control Quality

Table 17 Analysis of Abnormal Stock Returns Conditional on Tax Aggressiveness and Company-

Level Tax-Related Internal Control Quality (12 months preceding and following 2004-2006 SOX period)

Table 18 Analysis of Abnormal Stock Returns Conditional on Alternative Tax Aggressiveness

Proxies and Company-Level Tax-Related Internal Control Quality . 



\section{CHAPTER 1}

\section{INTRODUCTION}

\subsection{Motivation and Summary of the Thesis}

In this dissertation I examine how internal governance mechanisms affect a firm's capacity for strategic tax planning. More specifically, I investigate a possible relation between a firm's system of internal control and long-run corporate tax avoidance. Tax planning encompasses the strategies that a firm uses to lower the present value of its income tax payments (Rego, 2003) and long-run tax avoidance reflects the outcome of this planning over a sustained time period. According to Doss and Jonas (2004), a system of internal controls contains the policies and procedures that ensure the effectiveness of operations and the attainment of business objectives, and thus by extension internal controls represent an underlying component that facilitates tax planning.

Tax planning is not typically publicly observable. However, empirical constructs of tax avoidance allow researchers to infer the extent of a firm's tax planning activities. As discussed more fully in Chapters 2 and 4, long-run tax avoidance can be measured using five-year average Cash ETR following Dyreng, Hanlon and Maydew (2008). Similarly, internal control systems are proprietary but recent changes to financial statement disclosure regulations in the United States provide a window to examine publicly-available information regarding the quality of these internal mechanisms.

The Sarbanes-Oxley Act (SOX), enacted in 2002, requires companies to provide opinions about the effectiveness of their internal controls and to identify significant problem areas as part of an initiative to ensure the credibility of financial statements. Although SOX was designed with financial reporting quality in mind, the disclosure of internal control weaknesses (ICWs) 
within the tax function are frequent under SOX (Ge and McVay, 2005; Quimby and Pearce, 2006), with reports citing that $20 \%$ or more of weaknesses in SOX disclosures are tax-related (European Audit Committee Leadership Network, 2005; Elgood, 2006). Given the extent of these reported issues in the tax function, I examine whether these disclosed tax-related internal control weaknesses provide information about firm-level, long-run tax avoidance. Furthermore, I examine whether the combination of tax-specific internal control disclosures and tax avoidance provide relevant information for assessing shareholder returns.

At least two reasons explain why a relation between tax-specific internal control disclosures and tax avoidance may exist. First, firms must consider tax risk to effectively address tax issues and opportunities. This process includes integrated assessments of internal control aspects and operational aspects of risk (Wunder, 2009). By assessing the firm's tax-related internal controls a manager can improve the overall tax risk management strategy. Failure to document controls, maintain documentation, or communicate across divisions reflects poor internal processes that could result in missed tax planning opportunities or reassessments by tax authorities that follow poorly conducted tax planning. In summary, weak tax-related internal controls can directly reduce the effectiveness of a firm's tax planning function. Second, such internal control weaknesses can also suggest the presence of financial constraints. Financial constraints influence firms to allocate fewer resources to strategic tax planning. The point is that, either directly or indirectly, firms with weak tax-related internal controls may avoid less tax.

On the other hand, recent studies suggest that for firms that operate in environments that allow significant management discretion, earnings management and aggressive tax avoidance are positively correlated, as found by Frank, Lynch, and Rego (2009a) and Wilson (2009). If tax ICWs result in an environment that is conducive to discretionary activities, then earnings 
management and aggressive tax avoidance could occur, as suggested by anecdotal evidence that argues that firms involved in significant accounting scandals, i.e. Enron and WorldCom, jointly set income-increasing and tax-decreasing objectives (US Congress, 2003; McGill and Outslay, 2004). As described more fully in Chapter 2, concurrent evidence by Gleason, Pincus and Rego (2010) is consistent with earnings management occurring in an environment with tax ICWs. Whether the presence of tax ICWs is also associated with more tax avoidance has not been empirically demonstrated and is thus the subject of Hypothesis 1.

To further clarify the relation between tax-related ICWs and tax planning activities, I separate tax-related ICWs into account-level and company-level components, consistent with studies by Doyle, Ge and McVay (2007a and 2007b) and Hammersley, Myers and Shakespeare (2008). These studies argue that the pervasiveness of the weakness determines whether or not it influences overall firm behaviour. Doyle et al. (2007a and 2007b) interpret their findings as evidence that account-level ICWs lead to unintentional errors that are unrelated to lower accruals quality. Consequently, my Hypothesis 2 states that tax avoidance is unrelated to account-level tax weaknesses because unintentional tax misstatements do not benefit active tax planning.

As described in Chapter 2, prior research observes that company-level ICWs are more likely for firms with financial risk, resource constraints and various personnel issues, consistent with less effective tax planning for firms with "competency" issues. Company-level ICWs are also associated with lower accruals quality, earnings management and can reflect a "tone at the top" that results in management override and inadequate oversight, consistent with an environment that would be conducive to risky tax minimization because of "integrity" issues. Thus Hypothesis 3 states in the null form that company-level ICWs could have either a negative 
or positive association with tax avoidance because competency issues and integrity issues have opposing relations with tax avoidance.

The next step in my hypothesis development is to consider the relative stock return performance of firms conditional on how aggressively they avoid tax and the quality of their internal control systems. As Wilson (2009) describes, effective tax planning can lead to the creation of wealth for shareholders but ineffective tax planning can lead to "managerial opportunism” and ultimately wealth destruction. Weak internal controls may also be associated with ineffective tax planning. If firms lack the capacity or resources for strategic tax planning they will have difficulty creating positive returns for shareholders. Furthermore, the use of more discretionary activities in the presence of tax-related ICWs suggests managerial opportunism and lower abnormal returns, even when more tax is avoided. On the other hand, I expect that tax aggressive firms with strong tax-related internal controls will provide positive abnormal returns to shareholders. In Chapter 3, I present these hypotheses in the null form, consistent with my earlier arguments. Hypothesis 4 states that firms with weak tax-related internal controls do not underperform firms with strong internal controls, and Hypothesis 5 states that among firms with weak tax-related internal controls, there is no difference between firms that are tax aggressive and firms that are not tax aggressive.

Chapter 4 describes a unique unbalanced panel dataset that I construct from multiple sources and use to evaluate my hypotheses. Basic material weakness disclosure data from Audit Analytics is matched with detailed, manually-collected material weakness information obtained from company $10-\mathrm{K}$ filings in EDGAR. The combined material weakness data is then matched to firm-level accounting information from Compustat. The resulting panel dataset allows for control 
of unobserved heterogeneity that could affect coefficient estimates. For my shareholder returns analysis, I further match this dataset with Fama-French risk factors and $C R S P$ stock return data.

In Chapter 5, I report the tests of the relation between tax avoidance and tax-related ICWs. The ordinary least squares (OLS) regression analysis, with Cash ETR as the dependent measure, reveals that the coefficient on overall tax ICWs is positive. The positive coefficient is consistent with the argument that tax ICWs correlate with less tax avoidance. After separating the weaknesses into account-level and company-level components, I show that account-level tax ICWs are unrelated to tax avoidance but company-level tax ICWs, like overall tax ICWs, are positively associated with my dependent measure, Cash ETR. These findings continue to hold in rolling average regressions, annual regressions using the Manzon-Plesko (2002) book-tax difference (BTD) measure as the dependent variable, regressions with alternative internal control weakness classification methods and regressions that control for the strength of corporate governance. Overall my results support prior research on the importance of pervasive internal control weaknesses and extend this literature to suggest that they negatively influence the ability to plan and minimize taxes effectively.

The main results also suggest a strong direct effect of resource constraints on tax avoidance. The coefficient on one of the two proxies of resource constraints indicates an eighteen percentage point increase in five-year average Cash ETR for firms with consecutive, cumulative accounting losses. Drawing on supplemental factor analysis that provides a single resource constraint factor and interactions between this factor and tax ICWs, coefficient estimates reveal that firms with tax ICWs and low constraints avoid more tax on average than firms without ICWs but the negative association between tax ICWs and tax avoidance is strengthened for firms with high constraints. 
In additional supplemental analysis I investigate the influence of internal control weakness remediation on tax avoidance. In annual specifications of my empirical model, the presence of remediation is associated with higher levels of tax avoidance. In other words, tax planning appears to improve after ICWs are remediated. However, further analysis with overlapping, annual regressions of average variables implies that these improvements occur in the short-term and that it likely requires several periods until a subsequent improvement in longrun tax planning occurs.

Chapter 6 presents the analysis of stock return performance. In these tests, I estimate abnormal returns from the Fama-French (1993) four-factor model. I find that tax aggressive firms with strong internal control systems have positive abnormal returns. Consistent with my expectations and contrary to my hypothesis stated in the null form, I document a negative association between company-level tax-related ICWs and stock returns. This negative association holds in regressions with out-of-sample and in-sample measurement of tax aggressiveness and regressions with any type of ICW as well as general tax ICWs. The negative association is weaker in regressions with the Manzon-Plesko (2002) measure of book-tax differences as a proxy for tax aggressiveness. The negative association does not hold in regressions before or after my sample period or in regressions with the Wilson (2009) measure of tax shelter participation as a proxy for tax aggressiveness. Furthermore, my tests fail to reject Hypothesis 5 and thus do not provide evidence that this negative association increases for firms that are tax aggressive.

My research makes the following contributions. First, the specific link between internal controls and tax avoidance has not been shown previously and thus my research extends our understanding of how internal governance influences tax planning. I demonstrate that the high 
incidence of tax-related material weakness disclosures is correlated with less tax avoidance. Such evidence answers the call by Graham (2008) for more research that examines why firms do not pursue tax benefits more aggressively. Second, this evidence implies that company-level internal control disclosures provide information other than on financial reporting quality and thus corroborates the conjectures in the extant literature that company-level ICWs affect management's ability to control their overall operations. Third, I show that tax-related ICWs are associated with lower stock performance such that tax aggressive and non-tax aggressive firms with weak tax controls under-perform tax aggressive firms with strong tax controls. This evidence extends the research on the shareholder benefits of tax aggressiveness and implies that weak internal governance reduces these benefits.

Finally, this research provides a new component to the growing SOX-related tax literature. SOX-related tax research has generally focused on auditor independence, knowledge spill-over and non-audit fees (Maydew and Shackelford, 2007; Gleason and Mills, 2007; Cook, Huston and Omer, 2008; and Elder, Harris and Zhou, 2008). Elder et al. (2008) consider the influence of auditor independence and tax consulting on tax and other internal control weaknesses but they do not consider tax avoidance, while Cook et al. (2008) investigate the association between auditor-provided tax services and tax planning (using changes in effective tax rates or ETR) but they do not consider internal control disclosures. Bedard and Graham (2011) focus on the determinants of tax internal control deficiencies, both publicly and privately disclosed. My dissertation suggests that disclosed issues in the tax function constrain tax planning and any related shareholder returns, and thus recognition and remediation of such issues as a result of SOX regulation is a benefit to the firm and its stakeholders. 
My dissertation contrasts in several ways with concurrent research of Gleason et al. (2010), which investigates the influence of general tax weaknesses on earnings management via reductions in ETR. First, they examine tax ICWs and financial reporting aggressiveness, not tax avoidance. Second, Gleason et al. (2010) do not identify the pervasiveness of tax ICWs and thus their results could be stronger if company-level ICWs are distinguished. Third and finally, their results are consistent with tax ICWs allowing managers to engage in tax-related earnings management on average in the short-run, while my results are consistent with less long-run tax avoidance on average in the presence of tax ICWs.

\subsection{Thesis Organization}

This dissertation is organized into five main chapters, excluding this introduction and a conclusion. Chapter 2 presents a review of the literature relevant to this dissertation. This review includes separate discussions of tax avoidance and internal control disclosures and weaknesses, as well as specific discussions of tax-related internal control weaknesses and a link between internal controls and tax planning. This review emphasizes the lack of empirical research on tax avoidance and internal controls.

Chapter 3 develops the thesis hypotheses, which are motivated by the frequency that taxrelated internal control weaknesses are disclosed under SOX regulation and the resulting potential implications of this disclosed information. The first set of three hypotheses examines the influence of tax-related internal control weaknesses on tax avoidance, both in general and when the pervasiveness of the internal control weakness is considered. Recognizing the implication of pervasive, company-level internal control weaknesses for the tax function, the

second set of two hypotheses examines the joint influence of internal control quality and aggressive tax avoidance on stock return performance. 
Chapter 4 details the sample selection procedure and the specific empirical models designed to test each of my hypotheses. This chapter reports the construction of my panel dataset and the firm-level measures of tax avoidance and internal control weaknesses that are critical for my subsequent empirical analysis. The first two empirical models are intended to estimate the influence of general, account-level and company-level tax-related internal control weaknesses on the rate of taxes paid (i.e. Cash ETR) for S\&P 1500 firms that file a SOX report. The third empirical model is intended to examine the abnormal stock returns associated with binary rankings of a firm's Cash ETR estimate and internal control quality. Overall, the purpose of these tests is to show that long-run tax planning is influenced by tax-related internal control weaknesses and that the stock market reacts to the combination of these two factors.

Chapter 5 reports results from the empirical analysis of Hypotheses 1 through 3 regarding the relation between long-run tax avoidance and tax-related internal control weaknesses. The primary evidence in this chapter is from empirical tests that use firm-level, average values of the dependent and independent variables. Implicit in this analysis of the panel dataset is the smoothing of within-firm variation using these firm-level, average values. Furthermore, this chapter includes sensitivity analysis that reports results from overlapping, annual regressions of average variables used to identify the empirical models. This sensitivity analysis also includes tests designed to determine whether alternative tax avoidance proxies, the classification method of account-level and company level ICWs, the inclusion of corporate governance measures, the influence of resource constraints, or remediation of internal control weaknesses affect the results and inferences relating to Hypotheses 1 through 3.

Chapter 6 reports results from the empirical analysis of Hypotheses 4 and 5 regarding the potential joint influence of aggressive tax avoidance and internal control quality on shareholder 
returns. The tests use cross-sectional variation from a Fama-French four factor model to compare the monthly abnormal returns for four groups of firms that result from the interaction of tax aggressive/non-tax aggressive and strong/weak internal control indicators. Additional analysis tests the robustness of the results to alternative internal control weakness variables, sample periods and tax aggressiveness proxies.

Finally, Chapter 7 concludes by providing a summary of the evidence in and the main conclusions of the dissertation. 


\section{CHAPTER 2 \\ LiterATURE REVIEW}

\subsection{Introduction}

In this chapter I introduce extant research that is relevant to my dissertation. Two main themes are apparent in my work: tax avoidance and internal control quality. The first part of this review describes how the literature defines, measures and empirically examines tax avoidance, an outcome of strategic tax planning. The second part of this review begins with a general discussion of the importance of Sarbanes-Oxley (SOX) regulation for internal control research and concludes with a specific discussion of internal control research with respect to taxes. The third and final part of this review introduces the concept of tax risk management, a concept which could help to integrate the previously unexplored connection between tax avoidance and internal control quality.

This chapter is intended to provide a review of the main themes of this paper, and thus subsequent chapters may introduce additional research that is important to the concepts being discussed in those particular chapters. This chapter is divided into six sections, including this introduction and a conclusion.

Section 2.2 begins by defining tax avoidance and explaining why the broad concept of tax avoidance is suitable for my context. This section also identifies proxies of tax avoidance that are commonly explored by researchers and the traditional determinants of tax avoidance that are associated with these proxies. Finally, this section reviews recent studies that consider new relations between tax avoidance and its underlying factors, as well as a brief discussion of the implications of tax avoidance for shareholder returns. 
Section 2.3 summarizes the disclosure requirements under SOX 302 and SOX 404 and the firm characteristics that are typically associated with the presence of material internal control weaknesses. This section follows with a discussion of the dichotomy of pervasiveness that is common in the literature and explains how firm characteristics can differ depending on whether an internal control weakness relates to company-level issues or account-level issues. This review also details literature that examines the outcomes that result from internal control weaknesses and how certain negative outcomes can be mitigated by the process of remediation.

Section 2.4 examines the extant literature that specifically investigates tax-related internal control weaknesses. This review reveals two main points: (1) despite a high frequency of disclosed issues in the tax function, tax-related internal control research is sparse, and; (2) extant research has not yet attempted to triangulate the themes of tax avoidance and internal control quality.

Section 2.5 begins with a discussion of the concepts of tax risk and tax risk management and follows with a description of the links between tax risk management, internal control assessments and strategic tax planning. Section 2.6 concludes with a summary of the chapter.

\subsection{Tax Avoidance}

Rego (2003, p.808) defines tax planning as: “[a reduction of] the present value of tax payments”. Thus in a general sense tax planning is a strategy of minimizing taxes. Effective tax planning seeks to minimize taxes but only to the extent that such planning maximizes after-tax returns (Scholes, Wolfson, Erickson, Maydew, and Shevlin, 2009). ${ }^{1}$

Beginning with Scholes and Wolfson (1992), modern concepts of tax planning have been explored. Recently, Hanlon and Heitzman (2010) delineate concepts of tax avoidance - including

\footnotetext{
${ }^{1}$ Their definition of effective tax planning requires consideration of the three components of the 'Scholes-Wolfson' paradigm: all parties, all taxes and all costs.
} 
tax aggressiveness, tax sheltering and tax evasion - as degrees of tax reductions that result from tax planning, and often the bounds of these concepts overlap. In a broad sense, tax avoidance is a term that suggests a firm is avoiding taxes by all means, which may or may not include tax aggressiveness, tax sheltering or tax evasion (Dyreng et al., 2008). Furthermore, tax avoidance firms are often considered to be tax aggressive when they report a tax rate that is significantly lower than the prevailing statutory rates (Dyreng et al., 2008). Frank et al. (2009a, p.468) define tax aggressiveness as “downward manipulation of taxable income through tax planning that may or may not be considered fraudulent tax evasion". 2 Tax sheltering is a specific type of tax planning that is considered aggressive and often to represent evasion (Wilson, 2009). Tax evasion, therefore, defines an area of aggressive tax planning that circumvents the law.

Ultimately, tax avoidance could be considered to be synonymous with tax aggressiveness. The former is typically associated with broad descriptions of tax planning, the latter with extreme descriptions of tax planning. Consistent with the Hanlon and Heitzman (2010) discussion of the inter-related terms tax avoidance, tax planning and tax aggressiveness, I refer to tax avoidance throughout this dissertation unless I write aggressive tax avoidance or tax aggressiveness specifically. In this regard I attempt to remain neutral towards a large crosssection of the literature.

Turning to the extant research, a number of different proxies are used to capture tax planning or tax avoidance because actual tax planning is unobservable from publicly available information. Gupta and Newberry (1997), Mills et al. (1998), Rego (2003) and Ayers, Jiang and Laplante (2009) use effective tax rates (ETR), generally estimated as current tax expense divided by pre-tax book income. Mills et al. (1998) also measure investments in tax planning using

\footnotetext{
${ }^{2}$ While some researchers would argue that tax planning does not include tax evasion, which is fraudulent reporting of activities for tax purposes, empirical analysis cannot distinguish these activities and so are often included in the broader classification.
} 
proprietary data on tax department salaries and fees paid for external tax consulting (legal, accounting, etc.).

While these two measures represent traditional proxies, more recent research has relied on alternative measures of tax avoidance, such as book-tax differences (BTDs). In general, BTD measures require an estimate of taxable income to be subtracted from pre-tax income, where taxable income is often defined as current tax expense grossed-up at the statutory tax rate. However, Desai and Dharmapala (2006), Frank, Lynch and Rego (2009a and 2009b) and Wilson (2009) each estimate more sophisticated BTD proxies. In the following three paragraphs, I describe each of these measures more fully.

Desai and Dharmapala (2006) construct a discretionary or residual BTD that adjusts for earnings management. They regress the annual domestic BTD measure of Manzon and Plesko (2002) on annual total accruals estimates from Healy (1985). Desai and Dharmapala (2006) argue that their correction for accounting accruals results in an estimated residual value that represents the discretionary, tax shelter component of a firm's BTD.

Frank et al. (2009a and 2009b) also develop an annual discretionary BTD based on empirical regressions that rely specifically on permanent BTDs rather than total BTDs. In other words, temporary deferred tax expense is removed from their BTD proxy. They then regress this permanent $B T D$ on what they argue are non-discretionary items that are unrelated to tax aggressiveness, such as intangible assets, state taxes, change in net operating losses and lagged permanent $B T D$. The residual from this regression is a discretionary permanent difference otherwise known as DTAX (Frank et al., 2009a).

Wilson (2009) begins with a standard estimate of BTD as pre-tax income minus grossedup current tax expense. However, he focuses on tax shelter activity and accordingly adjusts the 
$B T D$ estimate for the value of tax benefits derived from tax sheltering. Wilson (2009) calculates the grossed-up federal tax savings from tax shelter activity based on financial statement information collected for known tax shelter participants. In addition, Wilson (2009) uses the standard $B T D$ estimate to help identify his model of tax shelter participation. I will describe this predictive model of tax shelter participation in greater detail in Chapter 6 .

Cash ETR is another recently developed proxy that researchers use to measure tax avoidance (Dyreng, Hanlon and Maydew, 2008 and 2010). Like ETR, Cash ETR is a tax rate estimate based on financial statement information. However, Cash ETR includes taxes paid in the numerator and pre-tax income adjusted for extraordinary items and discontinued operations in the denominator. More importantly, Cash ETR is meant to be an average of values over several periods so as to smooth out the measurement error resulting from timing differences in installments, refunds, tax settlements, etc. I will discuss the estimation method of Cash ETR in greater detail in Chapter 4.

Several recent studies compare the relative effectiveness and aggressiveness of these proxies when investigating different aspects of tax avoidance (e.g. Frank et al., 2009a; Rego and Wilson, 2010; Chen, Chen, Cheng and Shevlin, 2010). Frank et al. (2009a) show that their DTAX measure performs as well or better than other $B T D$ measures in their various tests that examine a relation between tax aggressiveness and financial reporting aggressiveness. Rego and Wilson (2010) show that their tests of association between senior management compensation and tax aggressiveness are robust to using measures of Cash ETR, DTAX, and tax sheltering as independent variables. Chen et al (2010) show a consistent result that closely-held firms exhibit less aggressive tax avoidance than widely-held firms, regardless of how they measure tax avoidance (ETR, Cash ETR, Manzon-Plesko BTD, Desai-Dharmapala residual BTD). However, 
as Hanlon and Heitzman (2010) argue, not all tax avoidance measures are suited for every tax avoidance context. In Chapter 4, I discuss why I use the Dyreng et al. (2008) measure of Cash ETR as my primary proxy for tax avoidance in my dissertation.

Within the tax avoidance literature researchers use these proxies to investigate the firm characteristics that drive tax planning. The common explanatory variables tested include size, profitability, foreign operations, leverage and intensity (capital, R\&D, etc.), and thus these determinants can be control variables in my empirical regression analysis. The literature is mixed on the association between size and these various measures of tax avoidance. Mills et al. (1998), using investments in tax planning, and Dyreng et al. (2008), using Cash ETR, show that larger firms avoid more tax. Using ETR measures, Zimmerman (1983) and Rego (2003) show that larger firms avoid less tax, a finding corroborated by Frank et al. (2009a) using BTD proxies. These negative associations are generally attributed to the influence of political pressure. Gupta and Newberry (1997), on the other hand, find no relation between size and ETR-based tax avoidance proxies.

Evidence on the influence of profitability on tax avoidance is also mixed. Rego (2003) and Frank et al. (2009a) show that more profitable firms avoid more tax when ETR and BTD proxies are used. Gupta and Newberry (1997) again find the opposite result using ETR. Dyreng et al. (2008), using Cash ETR as a proxy for tax avoidance, report results consistent with Gupta and Newberry (1997). Generally the evidence regarding foreign operations is consistent across these studies and proxies: more foreign operations or foreign income leads to greater levels of tax avoidance.

Beyond firm characteristics, recent research on tax avoidance focuses on new relations. Dyreng et al. (2010) investigate the influence of management characteristics on ETR and Cash 
ETR proxies of tax avoidance using a sample of firms where the manager (CEO or CFO) has switched from one firm to another. Their model develops a method to estimate the influence of "manager" fixed-effects on tax avoidance. They show that CEOs and CFOs have a significantly positive influence on tax avoidance. Robinson, Sikes and Weaver (2010) use survey data to form a prediction model of a firms' choice to structure their internal tax department as a profit center or a cost center. Consistent with their theoretical predictions, they show that firms with tax departments as profit centers have lower ETRs. They do not find an association with Cash ETR, however. Finally, as described previously in this section, Chen et al. (2010) document a negative relation between aggressive tax avoidance and closely-held firms.

Finally, some research has examined the stock returns to shareholders that are associated with aggressive tax avoidance. Hanlon and Slemrod (2009) investigate the market's reaction to press releases that inform the public of a firm's involvement in a tax shelter. Using event study methodology and cumulative abnormal returns over a 3-day announcement window, they find a decline in stock price for firms with news reports linking them to tax shelter activity. Wilson (2009) extends the findings of Hanlon and Slemrod (2009) and examines the joint influence of corporate governance quality and known tax shelter participation on abnormal market returns. I describe his method in greater detail in subsequent chapters of this dissertation. Wilson (2009) observes that both actual and predicted tax shelter firms with strong corporate governance outperform actual and predicted tax shelter firms with weak corporate governance. Thus tax shelter firms with strong corporate governance in his model avoid the price declines documented by Hanlon and Slemrod (2009), and in fact generate wealth for shareholders.

Frank et al. (2009b) examine the stock market reactions to firms that are considered to be aggressive for both financial and tax purposes. Using size-adjusted twelve-month buy-and-hold 
returns as a dependent variable, Frank et al. (2009b) provide evidence that the market typically rewards firms with aggressive reporting. They do find that aggressive firms in the time period from 1995-1999 experience lower abnormal returns in the years following that period. Overall, the market appears to attach a premium to firms that are jointly aggressive for financial reporting and tax purposes in their sample period.

\subsection{Internal Control Disclosures under Sarbanes-Oxley Regulations}

Internal control disclosures are required under Sections 302 and 404 of the SarbanesOxley Act. Section 302 became effective for fiscal years ending after August 29, 2002 for all SEC registrants. Section 404 became effective for fiscal years ending after November 15, 2004 for accelerated filers, and for years ending on or after December 15, 2007 for management assessment of the effectiveness of internal control and December 15, 2008 for the auditor's attestation report. In addition to differences in their effective dates, these two sections of SOX differ in regards to who assesses the effectiveness of internal controls. Although Sections 302 and 404 require management to certify that they have evaluated the effectiveness of their internal controls over disclosures and financial reporting, respectively, Section 404 further requires the auditor/public accountant to attest to the assessment of internal controls. Doyle et al. (2007a) conclude that some material weakness disclosures under SOX 302 are, in effect, voluntary. To avoid issues regarding "voluntary" disclosures I investigate SOX 404 disclosures only with this dissertation. However, I do comment on the results of both SOX 302 and 404 studies in this section.

The availability of SOX internal control disclosures has spawned a series of archivalempirical research papers that examine firms with poor internal control quality. The disclosures provide a set of previously unavailable qualitative information that researchers have quantified in 
an effort to understand the factors that give rise to poor internal controls. Two papers at the forefront of this investigation of determinants of internal control weaknesses (ICWs) are Doyle et al (2007a) and Ashbaugh-Skaife et al. (2007).

Doyle et al. (2007a) investigate material internal control weakness disclosures from SOX 302 and SOX 404. A material internal control weakness represents a significant deficiency or a series of significant deficiencies that could result in material financial misstatement and thus is the most severe type of deficiency in SOX disclosures. Ashbaugh-Skaife et al. (2007) focus on all types of deficiencies, material or not, and restrict their investigation to SOX 302 disclosures in the pre-SOX 404 period. $^{3}$ Both studies use logistic regressions to investigate the association of internal control weaknesses with firm characteristics, including size, financial health, reporting complexity, rapid growth, restructuring and corporate governance. ${ }^{4}$ In general, both studies show that ICWs are more likely for firms that are smaller, financially weaker, more complex, growing rapidly, and/or undergoing restructuring. Both papers also state that firms with ICWs have likely fewer resources available for internal control.

Doyle et al. (2007a) further sub-classify these internal control weaknesses into accountlevel and company-level categories. Doyle et al. (2007b), Chan et al. (2008), Hammersley et al (2008) and Goh (2009) also rely on similar sub-classifications. ${ }^{5}$ According to Doyle et al.

\footnotetext{
${ }^{3}$ Doyle et al. (2007a) refer to internal control weaknesses or ICWs while Ashbaugh-Skaife et al. (2007) refer to internal control deficiencies or ICDs. Having stated that Ashbaugh-Skaife et al. (2007) investigate deficiencies with varying levels of severity, for expositional purposes I use the term ICWs only.

${ }^{4}$ Doyle et al. (2007a) also include age as a determinant of interest and Ashbaugh-Skaife et al. (2007) include auditor variables, the incidence of restatements and the potential for litigation.

${ }^{5}$ In theory, all of these studies are interested in how serious or pervasive an internal control weakness is. However, the individual studies may refer to these concepts using different terminology. Doyle et al. (2007a and 2007b) refer to pervasiveness and how easily one can "audit around" an ICW, borrowing terminology put forth by Moody's Investor Services (Doss and Jonas 2004). Doyle et al. (2007a and 2007b) dichotomize the term into account-level i.e. less pervasive and company-level i.e. more pervasive. Goh (2009) uses identical classifications. Chan et al. (2008) refer to account-level and company-level ICWs as specific and general ICWs, respectively. Finally, Hammersley et al. (2008) use the terms auditability and seriousness, and like Doyle et al. (2007a and 2007b), they base their terminology on Moody's "audit around" concept. Instead of account-level and company-level ICWs,
} 
(2007a), account-level internal control weaknesses include incorrectly recorded balances and improper application of accounting principles. On the other hand, Doyle et al. (2007a) and Hammersley et al. (2008) state that company-level internal control weaknesses reflect issues in the company's overall control environment and thus by their nature have a much more pervasive effect on the company's operations.

Doyle et al. (2007a) document that specific firm characteristics differ across these two types of weaknesses. Account-level internal control weaknesses are more likely for firms that are larger, older, financially healthier, more complex and growing more rapidly. Company-level internal control weaknesses are more likely for firms that are smaller, younger and at greater financial risk. Again, resource constraints are considered a significant issue for the firms with company-level internal control weaknesses.

The availability of SOX disclosures allows researchers to study the determinants of internal control weaknesses but it also allows researchers to investigate the implications of having a weak system of internal control. In the following paragraphs, I will discuss various studies that examine associations between internal control weaknesses and subsequent financial outcomes, namely shareholder returns and earnings quality.

Hammersley et al. (2008) examine market reactions to the disclosure of SOX 302 internal control weaknesses. Particularly relevant to my thesis, they investigate the market reactions to the severity or pervasiveness of those weaknesses. Hammersley et al. (2008) show that the market reacts negatively to internal control weakness disclosures and that it reacts more negatively to disclosures as the pervasiveness of the weaknesses increases. The authors conclude

Hammersley et al. (2008) refer to "more auditable" and "less auditable” ICWs, respectively. In my dissertation, I choose to use the terms pervasiveness, account-level and company-level. 
that these SOX disclosures are informative to investors and thus influence market revisions of firm value.

Corroborating these results, Beneish, Billings and Hodder (2008) show that the market reacts negatively to disclosures of SOX 302 internal control weaknesses, and that the 3-day cumulative abnormal returns surrounding these disclosures are more negative for firms with company-level ICWs. For non-accelerated filers, they typically find more negative reactions, as well as a negative market reaction to account-level ICWs. They do not find a market reaction to SOX 404 disclosures, however, regardless of ICW pervasiveness or type of filer. Beneish et al. (2008) conjecture that the lack of market reaction to SOX 404 disclosures could be due to the independent confirmation from the auditor's report, the typically stronger firm-level attributes of SOX 404 filers, or the noise induced by the clustering of SOX 404 filings.

With respect to earning quality, Ashbaugh-Skaife et al. (2008) suggest that weak internal controls lead to both unintentional errors and intentional misstatement, both of which reflect inaccurate accruals and therefore lower accruals quality. In cross-sectional tests, they show that firms disclosing SOX 404 internal control weaknesses have lower accruals quality. In withinfirm tests, they document that firms that remediate internal control weaknesses have a subsequent improvement in accruals quality. Furthermore, Ashbaugh-Skaife et al. (2008) provide evidence that ICWs are associated with both large positive and large negative accruals. Therefore, they conclude that the bias in accruals is more likely related to unintentional errors rather than intentional misstatement.

Doyle et al. (2007b) also provide evidence that ICWs lead to lower accruals quality in cross-sectional tests. In general, the negative relation between ICWs and accruals quality exists only for SOX 302 disclosures. However, when internal control weaknesses are classified at the 
account-level and the company-level, this negative relation also exists for SOX 404 disclosures. Although they make no conclusion about whether lower accruals quality results from unintentional or intentional errors, Doyle et al. (2007b, p.1146) concede that certain companylevel weaknesses could "facilitate earnings management". Overall this study provides further evidence that pervasiveness is critical to understanding the impact of an ICW on firm-level outcomes.

Contrary to Ashbaugh-Skaife et al. (2008), Chan et al. (2008) provide modest evidence consistent with earnings management and intentional misstatement in their cross-sectional study of SOX 404 disclosures and earnings quality. Like Doyle et al. (2007b), Chan et al. (2008) find that firms with company-level weaknesses have lower earnings quality than firms with accountlevel weaknesses. Furthermore, firms with company-level weaknesses appear to bias earnings upwards. As I discuss in the next section, Gleason et al. (2010) also provide evidence consistent with upwards earnings management in the presence of tax-specific ICWs. Thus the extant literature consistently shows that internal control weaknesses are associated with lower earnings quality, however it cannot yet be concluded whether lower earnings quality is a product of unintentional errors or, more seriously, earnings management.

Finally, although the disclosure of an internal control weakness can suggest that various issues, such as lower earnings quality, exist within a firm, the aforementioned study by Ashbaugh-Skaife et al. (2008) suggest that these issues can be mitigated through subsequent improvements in the problem areas. Typically, SOX disclosures contain a section where management discusses the steps they plan to undertake or the plans currently underway to remediate internal controls weaknesses. In addition to Ashbaugh-Skaife et al. (2008), Feng, Li, and McVay (2009) compare firms that report ICWs in two consecutive years to firms that 
remediate their ICWs by the second of the two years. They also include a benchmark set of firms that do not report any ICWs in the two-year period. Feng, Li, and McVay (2009) find that failing to remediate internal control weaknesses are firms that are also less likely to provide timely, precise and relatively frequent management guidance.

\subsection{Tax-Related Internal Control Weaknesses}

A recent report issued by Deloitte (2011) suggests that although material weakness disclosures continue to show an overall decline, tax-related issues remain the most prevalent of all internal control weaknesses. Even with overall declines and planned remediation, the report comments that remediation efforts are an on-going process for firms and that many organizations still have much room for improvement in their tax function. The empirical literature also shows a significantly high incidence of disclosed weaknesses within the tax function under SOX (Ge and McVay, 2005). Gleason et al. (2010) document that as of June 2007 more than one-third of reports included in Audit Analytics indicate tax ICWs.

Nevertheless, analysis of tax-related internal control weaknesses within the academic literature is sparse. Elder et al. (2008) examine a relation between auditor-provided tax services and internal control weaknesses (both tax-related and other) and provide some evidence that suggests that a negative relation between auditor-provided tax services and internal control weaknesses is indicative of a lack of auditor independence. However, Elder et al. (2008) attempt to understand the factors that give rise to tax-related ICWs and I view internal control systems as an underlying part of a firm's tax function. Thus I investigate the role of tax-related internal control weaknesses as a determinant, rather than a result, of firm-level activities.

Like Elder et al. (2008), Bedard and Graham (2011) also focus on the determinants of tax-related internal control deficiencies. In their research, Bedard and Graham (2011) use a 
proprietary dataset of internal control disclosures that are privately known to the firm and its auditor. Several findings in their research support the importance of further investigating the implications of tax-related internal control weaknesses. First, publicly disclosed tax issues are far less frequent than privately disclosed tax issues. Thus inferences drawn from SOX disclosures are just the "tip of the iceberg". Second, more than $80 \%$ of the tax issues identified in the Bedard and Graham sample are determined by auditors. Without SOX regulation, one could argue that many tax issues would likely still exist undetected. This evidence therefore further suggests that SOX regulation provides an opportunity to investigate internal governance of the tax function. Third, resource constraints contribute to the disclosure of tax internal control deficiencies.

Concurrent research by Gleason et al. (2010) investigates the implications of tax-related internal control weaknesses and looks specifically at the relation between tax ICWs and earnings management. They report that in the year prior to disclosing a tax ICW, firms with such weaknesses are more likely to reduce their ETR from the third to fourth quarter to meet or beat earnings benchmarks than firms without such weaknesses. Thus evidence in this study suggests that firms with tax ICWs engage in upwards earnings management, consistent with the relation between general ICWs and earnings management reported by Chan et al. (2008).

In related research, the prior literature on book-tax differences argues and provides evidence that a larger book-tax discrepancy is indicative of discretionary behaviour, such as earnings management or aggressive tax planning (e.g., Gleason and Mills, 2002; Dhaliwal et al., 2004; Blouin and Tuna, 2007; Frank et al., 2009a; Frank et al., 2009b). Gleason et al. (2010) do not test a $B T D$ measure but their findings on tax-related earnings management support the general theme of this research stream. However, these book-tax difference studies do not 
consider the influence of tax ICWs, and Gleason et al. (2010) are silent on the implications of tax ICWs for tax avoidance.

Finally, Gleason et al. (2010) show that the remediation of internal control weaknesses subsequent to their initial disclosure is associated with decreases in tax-accrual earnings management and ETR persistence, consistent with the benefits of remediation reviewed in the previous section. Remediation is implicitly relevant to my thesis because I investigate long-run tax planning. Although internal control weaknesses can be remediated from one year to the next, I argue in subsequent chapters that tax planning is a sustainable process that cannot be easily changed. Furthermore, Bedard and Graham (2011) find that tax deficiencies are more likely to be unremediated at year-end than non-tax deficiencies. Thus it is an open empirical question whether, in the same way that remediation appears to have an immediate influence on earnings management activities, the identification and improvement of a tax-related internal control weakness can have an immediate influence on tax planning outcomes.

\subsection{Tax Risk Management}

The ability of a firm to successfully avoid a higher level of taxes paid relates in part to the certainty or uncertainty of its tax plans. In other words, tax avoidance relates to tax risk. A universal definition of tax risk is elusive but Arlinghaus (1998) provides a reasonable one: "the likelihood that a tax outcome differs from what is expected, due to a variety of reasons, for example, the judicial process, changes in the law, changes in business assumptions, an increased intensity of audits, and uncertainty in the interpretation of the law; and any action emanating from the tax function that subjects the company to adverse publicity.”

Managing tax risk requires well-functioning internal controls. A framework of tax risk management adapted from the Committee of Sponsoring Organizations of the Treadway 
Commission (COSO) states that there are seven areas of tax risk that a firm must manage (PricewaterhouseCoopers, 2004), which implies integration of internal control assessment and tax planning. Specifically, these seven risks fall into two sub-categories, specific and generic, which map into the Arlinghaus (1998) definition of tax risk. Specific risk areas include: transactional risk (e.g., acquisitions, mergers); operational risk (e.g., new business ventures, new operating models, new operating structure); compliance risk (e.g., weak records and controls, data integrity issues, legislative changes), and; financial accounting risk (e.g., changes in systems and policies). Generic risk areas include: portfolio risk (e.g., combination of any of the risks); management risk (e.g., changes in personnel, new/inexperienced resources), and; reputational risk (e.g., revenue authority investigation, press comment, legal actions). Each risk area is relevant to internal control policies because, as Wunder (2009, p.16) states, the COSO framework represents “"the gold standard' for assessing internal controls.”

SOX disclosures that accompany a firm's year-end audit are a valuable source for assessing tax risk management within the tax function because public companies "must include in their annual financial reports an assessment of the effectiveness of [their] internal controls” (Wunder, 2009, p.16; emphasis added). Ineffective internal controls imply ineffective tax risk management. Furthermore, audit standards (e.g., SAS No. 55, AICPA 1988) state that internal controls help to achieve entity objectives, thereby implying that internal control procedures for the tax function go beyond the reporting of tax elements in the financial statements. Tax-related internal control disclosures could provide information about tax reporting and tax operations. Thus successful strategic tax planning and tax avoidance may require a strong process that identifies and analyzes tax risk as well as executes the resultant tax plans. 


\subsection{Conclusions}

In summary, this chapter reviews research that investigates the relation between commonly identified factors, such as size and profitability, and several proxies for tax avoidance. The more recent research investigates the influence of less commonly identified factors, such as family ownership, on tax avoidance as well as the influence of tax avoidance on shareholder returns. However, tax researchers have yet to consider the implications that underlying systems of internal controls could have on corporate tax avoidance.

This chapter also reviews extant literature that identifies firm characteristics and management incentives that are associated with the likelihood of disclosing a weakness in internal control. Several studies in this review argue that the relation between firm characteristics and weaknesses depends on whether a weakness is at the account-level or the company-level. Researchers also consider the role of internal control weaknesses in evaluating accruals quality and earnings management. In certain select cases, research examines the determinants of tax internal control weaknesses as well as earnings management and auditor independence for firms with tax-related internal control weaknesses. Given their relative high frequency however, tax internal control weaknesses appear to be an under-investigated area of research and thus provide a fruitful avenue for corporate tax avoidance research. 


\section{CHAPTER 3 \\ HYPOTHESIS DEVELOPMENT}

\subsection{Introduction}

This chapter develops testable hypotheses that build on the themes reviewed in the previous chapter. The chapter begins by providing arguments that relate concepts of internal control quality to strategic tax planning and explaining how tax-related internal control weaknesses could either negatively or positively influence corporate tax avoidance. These arguments move from a discussion of general tax internal control weaknesses to a discussion of specific account-level and company-level tax internal control weaknesses. Continuing with the theme of pervasive internal control weaknesses, this chapter provides arguments regarding the shareholder wealth effects that result from the joint influence of tax avoidance and companylevel tax internal control weaknesses. All hypotheses are stated in the null form.

Section 3.2 of this chapter relates tax internal control weaknesses in general to tax avoidance. Hypothesis 1 is determined by contrasting management's capacity or competency for strategic tax planning with management's integrity and any resulting discretionary tax planning activities. Section 3.3 expands on this comparison and presents Hypotheses 2 and 3 regarding the importance of pervasiveness and how account-level and company-level tax internal control weaknesses could influence tax avoidance.

Section 3.4 develops hypotheses regarding the influence of internal control quality and aggressive tax avoidance on shareholder returns. I argue that weak internal control quality signals wealth destruction and that when paired with aggressive tax avoidance, the destruction of wealth increases. Hypotheses 4 and 5 state these predictions in the null form. Section 3.5 concludes with a summary of the chapter. 


\subsection{Internal Control Quality and Tax Avoidance}

The frequent incidence of tax-related internal control weaknesses is documented in the previous chapter. Given that SOX was designed with financial reporting quality in mind, one would expect tax-related internal control disclosures to provide information about financial reporting quality. Of relevance to this thesis, however, is whether these frequent disclosures provide information about management's capacity for strategic tax planning. One concept discussed in the previous chapter that relates internal control to tax planning capacity is tax risk management because tax risk management relies on integrated assessments of operational, financial and internal control risks, among others. A weak tax risk management process could reflect weak tax-related internal controls and thus firms with tax-related internal control weaknesses would have a diminished capacity for tax planning compared to firms with strong tax-related internal controls.

Determining nexus or permanent establishment for tax purposes is an example of a tax issue with significant risk for multijurisdictional and multinational firms. When a firm has a physical or technical presence (i.e. employees, sales, offices, etc.) in a particular jurisdiction (i.e. state, country, etc.) then it is considered to have nexus or permanent establishment and thus must ensure that it remits the appropriate taxes to the relevant tax authorities. Anecdotally, as organizational structures increase in complexity, it becomes more difficult for a manager to adequately assess the related costs and risks. Furthermore, transfer pricing and the maintenance of contemporaneous documentation is a significant concern among firms (Wunder, 2009). Transfer pricing requires the establishment of internal policies to assign costs between organizational units, and tax authorities require firms to maintain a specific and significant amount of documentation to justify the costs that are chosen. These arguments and anecdotes imply the need for firms to set strong internal controls at the outset of their activities in order to 
ensure and sustain successful tax strategies in the long-run. Weak risk assessment or a lack of policies and documentation reflect ICWs that imply greater likelihood of reassessment by tax authorities or missed opportunities, ultimately resulting in higher taxes paid in the long-run.

The prior literature discussed in Chapter 2 also suggests that the availability of resources for various firm-level functions has a significant influence on the likelihood of internal control weaknesses, including in the tax function. Thus this review suggests that one of the contributing factors to ineffective tax planning is the resources a firm is able to allocate to its tax function, including internal controls considerations. Regardless of the specific reason to forego tax planning opportunities, firms with weak tax-related internal controls could avoid less tax than firms with strong tax-related internal controls.

Alternatively, tax internal controls may not relate directly to the effectiveness of the tax planning function, but may relate more directly to the checks and balances within it. The "tone at the top” of a firm may reflect poor management integrity such as management override, evidence of fraud and inadequate communication/oversight. In this case, the likelihood of engaging in risky tax minimization strategies may be greater because of senior management's underlying objectives and less invasive oversight. For example, according to McGill and Outslay (2004) WorldCom management would set effective tax rate targets and instruct their tax department to achieve those targets through any means necessary. This approach likely contributed to the significant accounting irregularities and ultimate fraud that was unearthed at WorldCom, resulting in, at that time, the largest bankruptcy filing in the United States and severe penalties subsequently handed down by the Securities and Exchange Commission.

According to Gupta and Laux (2008), accounting practices at companies such as Enron suggest that internal control weaknesses and tax-related deficiencies lead to a larger gap between 
book income and taxable income. Furthermore, the Joint Committee on Taxation reports that Enron management fostered an aggressive corporate culture that would use off-balance sheet structures and off-shore entities to achieve both income-increasing and tax-decreasing objectives (US Congress, 2003). The literature on book-tax differences provides evidence consistent with these arguments. As discussed in Section 2.4 of Chapter 2, a larger book-tax discrepancy can signal earnings management or tax aggressiveness.

The aforementioned research of Gleason et al. (2010) provides evidence of upward earnings management for firms prior to the disclosure of a tax internal control weakness. Furthermore, Wilson (2009) documents that book-tax differences and aggressive financial reporting are significant firm characteristics of tax shelter firms. Taken together, these two studies suggest that in certain circumstances aggressive financial reporting and aggressive tax reporting are positively related, an assertion tested directly in Frank et al. (2009a). Such a positive relation supports the possibility that firms with weak tax-related internal controls can avoid more taxes than firms with strong tax-related internal controls.

Based on the foregoing arguments, the relation between internal control quality and tax avoidance could be positive or negative, thus I propose the following null hypothesis:

H1 $1_{\text {null: }}$ Tax avoidance is unrelated to tax-related internal control weaknesses.

\subsection{Pervasiveness of Internal Control Weaknesses and Tax Avoidance}

In the previous section, internal control weaknesses are discussed in general. However, the literature review of Chapter 2 suggests that the pervasiveness of the internal control weakness matters. Citing comments made by Moody's, Doyle et al. (2007a, p.196) write, "While accountspecific weaknesses are auditable, company-level weaknesses are more difficult to audit around and call into question not only management's ability to prepare accurate financial reports but 
also its ability to control the business.” These comments imply that company-level ICWs are more pervasive and can extend to the operating of the business, but account-level ICWs relate to financial reporting only.

This dichotomization of pervasiveness is important when considering the influence of tax-related internal control weaknesses on corporate tax avoidance. In general, account-level ICWs include incorrectly recorded balances and account-level tax ICWs usually reflect issues such as improperly recorded deferred tax account balances and inaccurate valuation of tax amounts according to GAAP. ${ }^{6}$ Furthermore, the improper recording of amounts can be influenced by the manual information systems and spreadsheets that many organizations use to facilitate financial reporting. These errors give rise to internal control weaknesses disclosed in SOX reports (Boritz, Hayes and Lim, 2010).

Despite the possibility for these recording errors and the inherent complexity of tax accounting that can make it difficult to estimate and evaluate balances, these issues are less pervasive. A firm's auditor can detect recording errors when carrying out their audit procedures. In fact, audit firms offer services to help potential clients assess the integrity and accuracy of their spreadsheet models. ${ }^{7}$ Overall, I expect that account-level ICWs will reflect unsystematic, random errors that will cancel on average in a cross-section of firms or that will be mitigated by audit review, particularly in the long-run. I propose my next hypothesis in the null form:

\section{H2 $2_{\text {null: }}$ Tax avoidance is unrelated to account-level tax internal control weaknesses.}

Company-level ICWs have a significant influence on the firm-level outcomes discussed in Chapter 2, namely accruals quality and earnings management. In addition, Hammersley et al.

\footnotetext{
${ }^{6}$ A further description of a general classification scheme and specific examples of both account-level and companylevel weaknesses are available in Appendices A, B and C.

${ }^{7}$ For example, see information about PricewaterhouseCoopers' procedures for "spreadsheet integrity review" at http://www.pwc.com/cy/en/challenges/spreadsheet-integrity-review.jhtml.
} 
(2008) find that the market reacts more negatively to firms disclosing a company-level ICW in their control environment than to firms disclosing an account-level ICW. This collective evidence strongly suggests that company-level controls are important in understanding the relation between internal control disclosures and tax planning.

As described previously, weaknesses in the control environment include ineffective assessment of tax risk, lack of key personnel for planning and the absence of key procedural controls or documentation. These weaknesses are all at the company-level. Resource constraints are also considered a significant issue for firms with company-level weaknesses in general (Doyle et al., 2007a) and in the tax function (Bedard and Graham, 2011). Companies lacking sufficient procedures or human resources to manage their tax function, or the financial resources to develop procedures or secure expertise, will have difficulty planning effective tax strategies and thus will avoid less tax than firms with stronger controls.

On the other hand, control environment issues may also lead to riskier tax minimization schemes, as described for internal controls more generally. Although Ashbaugh-Skaife et al. (2008) suggest that control weaknesses lead to unintentional errors and not to manipulations, that Chan et al. (2008) find evidence consistent with earnings management for company-level ICWs suggests a failure "to control the business" that leads to intentional manipulations. Previous examples suggest that a corporate culture of management override, fraud and/or inadequate communication or oversight allows tax managers to engage in opportunistic and risky tax minimization or avoidance that is aggressive. Thus tax planning by managers with weak controls could also border on, or cross into, evasion. Therefore I state the following hypothesis in the null form:

H3 $3_{\text {null: }}$ Tax avoidance is unrelated to company-level tax internal control weaknesses. 
A negative relation between tax avoidance and company-level tax ICWs is evidence consistent with competency issues that manifest in inadequate tax risk management procedures or resources leading to less tax avoidance. A positive relation between tax avoidance and company-level tax ICWs is evidence consistent with a lack of controls that reflect integrity issues, allowing opportunities for risky tax strategies and more aggressive tax avoidance by management.

\subsection{Internal Control Quality, Tax Avoidance and Stock Return Performance}

In this section I look to combine internal control quality and aggressive tax avoidance to explore whether investors can use knowledge of such a relation to assess the value of the underlying tax planning. Tax avoidance encompasses activities which may or may not involve wrongdoing; Hanlon and Slemrod (2009) posit that shareholders may be concerned that a firm that will deceive tax authorities is also a firm that will deceive them. By examining the market performance of firms based on tax aggressiveness and internal control quality, I plan to demonstrate that internal control quality helps differentiate between firms that avoid taxes while creating positive returns for shareholders and firms that avoid taxes to the detriment of shareholders.

Agency theory suggests that public corporations continue as going concerns by separating operational decisions from oversight decisions using three mechanisms: decision hierarchies, mutual monitoring systems and boards of directors (Fama and Jensen 1983). Decision hierarchies and mutual monitoring interact to produce organizational policies and procedures that incent managers to develop their human capital value and to achieve company objectives, and to specify performance targets and reward structures. The board of directors monitors management actions and carry the ability to compensate or terminate individuals as a 
result of their performance. Within the policies and procedures is the internal control system of a firm and thus the need for internal controls to achieve firm objectives, including tax planning objectives, is rooted in agency theory.

Consistent with agency theory, managers are aware that firm outputs, including information disclosures, are signals to the market about their firm's operational effectiveness (Fama 1980). Furthermore, these signals inform labour markets about a manager's individual talents and capital markets about a firm's value. Managers understand that public information and any resulting stock price revaluations can affect their future wage revisions (Fama 1980). Thus tax-related internal control disclosures signal information to the market about management's ability to tax plan and the market is free to adjust firm prices accordingly based on their evaluation of the signal.

Wilson (2009) investigates the degree to which actual and predicted tax shelter activity signals "wealth creation for shareholders [or] managerial opportunism". I conjecture that among tax aggressive firms, strong internal control quality is a signal of wealth creation and weak internal control quality is a signal of value destruction. Following from my previous hypotheses, weak tax-related internal controls can create tax avoidance opportunities through discretionary activities and risky tax minimization, but these opportunities are difficult to sustain in the longrun and could reflect integrity issues. Firms with weak tax-related internal controls that are not tax aggressive also create less wealth for shareholders but such an outcome likely results from (1) an inability to comply with the law, (2) foregone opportunities, or (3) resource constraints, but is less likely to result from wealth destroying actions. Thus I predict that although firms with weak tax-related internal controls create less value for their shareholders relative to firms with 
strong tax-related internal controls, this relation is amplified for tax aggressive firms. My formal hypotheses are stated in the null as follows:

H4 $4_{\text {null: }}$ Stock return performance is weakly positively related to company-level tax internal control weaknesses.

H5 $5_{\text {null: }}$ The negative relation between stock return performance and company-level tax internal control weaknesses is less negative among tax aggressive firms.

\subsection{Conclusions}

In this chapter I posit five hypotheses to be tested in subsequent empirical analyses. I present my first three hypotheses in support of a relation between tax avoidance and tax internal control weaknesses. In the null, I predict that tax avoidance is unrelated to general, account-level and company-level tax internal control weaknesses. I present my second two hypotheses in support of an interaction between tax aggressiveness and tax internal control weaknesses that affects shareholder returns. In the null, I predict a positive relation between abnormal returns and tax internal control weaknesses and that the relation is more positive for tax aggressive firms. 


\section{CHAPTER 4 \\ SAMPLE SELECTION AND RESEARCH DESIGN}

\subsection{Introduction}

In this chapter I describe all aspects related to the empirical design of my sample and primary analysis. The chapter begins by describing the method for selecting my sample firms and follows with separate discussions of my selection and construction of proxies for internal control weaknesses and long-run tax avoidance. This chapter also presents the empirical models used to test Hypotheses 1 through 5. Overall, this chapter includes seven sections, including this introduction and a conclusion.

Section 4.2 outlines my sample selection criteria and primary sample period. SOX 404 disclosures are obtained for firms that report weaknesses in their internal controls during the period 2004 to 2006. These firms must also be included in the S\&P 1500 at one point in time during this sample period.

Section 4.3 describes the manual coding procedure I use to quantify the information contained in the internal control weakness disclosures. I rely on a modified version of the Hammersley et al. (2008) classification method. This method permits me to separate individual internal control weaknesses into account-level and company-level components. Section 4.4 provides rationale for my decision to use Cash ETR as a proxy for long-run tax avoidance and to justify why it is the most appropriate measure for my specific context.

Section 4.5 presents two similar models to test Hypotheses 1 through 3. Equation (2) is a model that includes general tax and non-tax internal control weakness variables while Equation (3) is a model that includes account-level and company-level tax and non-tax internal control weakness variables. Both models are tested empirically using OLS methods. 
Section 4.6 presents a model to test Hypotheses 4 and 5. Equation (4) is a model that is based on Wilson (2009) and includes separate variables for the four comparison groups that result from the interaction of dichotomous aggressive tax avoidance and internal control quality variables. Like Equations (2) and (3), Equation (4) is also tested empirically using OLS methods. Section 4.7 concludes the chapter.

\subsection{Sample}

Annual SOX 404 internal control data are obtained from Audit Analytics. After determining the firm-year observations with disclosed weaknesses, I collect 10-K filings in order to appropriately categorize account and company-level weaknesses. I do not rely on Audit Analytics internal control weakness coding because many of their categories blend together individual internal control weaknesses that would otherwise be account-level or company-level only. I restrict my sample of firms in Audit Analytics to those that trade on any of the S\&P 500, 400 or 600 indices (i.e. S\&P 1500) to reduce the extent of required manual coding. S\&P index composition is provided in Table $1 .^{8}$ The data are merged with additional information from Compustat and CRSP to allow for analysis of other company variables included as covariates in the empirical regressions, described below.

The data collection begins in 2004 when accelerated filers were first obligated to produce internal control reports under SOX 404 and ends in 2009. Additional data is collected prior to 2004 in order to construct relevant five-year averages as described subsequently in this chapter. I have also restricted my primary sample to the firms that filed SOX 404 reports between 2004 and 2006 to avoid overlap associated with two changes in financial reporting. First, Financial

\footnotetext{
${ }^{8}$ Although the primary analysis in my thesis is based on the years 2004 to 2006, supplemental tests include years 2007 to 2009 and as a result my initial data collection includes all years from 2004 to 2009. Consequently, a firm that trades in the S\&P 1500 during any one of the years from 2004 to 2009 can be included in my sample and thus the number of unique S\&P 1500 firms in my final sample is greater than 1,500 observations.
} 
Interpretation No. 48's Accounting for Uncertainty in Income Taxes (FIN 48) became effective January 1, 2007. FIN 48 standardizes the reporting of uncertain tax positions (i.e. positions that often result from strategic tax planning) and requires disclosure of the aggregate amount of these uncertain reserves. Blouin, Gleason, Mills and Sikes (2007) acknowledge that firms had an incentive to release their reserves prior to January 1, 2007 and furthermore, the Internal Revenue Service offered to accelerate resolutions and settlements of reserves with corporate taxpayers. Any resolutions or settlements are likely to affect taxes paid, my dependent measure of tax avoidance, and thus FIN 48 represents a potentially endogenous shock that could confound my subsequent results. Second, Boritz et al. (2010) document that the wording of the risk of material misstatement in the definition of "material weakness" changed slightly as Auditing Standard No. 2 (PCAOB 2004) was replaced by Auditing Standard No. 5 (PCAOB 2007) in 2007. To the extent that this change in wording has an effect on management or auditor judgment of reported material weaknesses, another potential confounding event exists.

Table 1 includes the sample and industry composition for my tests. Panels A and B report the composition that pertains to my primary firm-level sample and Panels C and D report the composition that pertains to my secondary overlapping, annual firm-year sample. My main tests use average values for each firm and not annual firm-year observations. For internal control weakness variables, the averages include data from 2004 to 2006 and for all other variables the averages include data from 2002 to 2006. Table 1, Panel A shows that there are 1,286 unique firms in the sample with available data to estimate Equations (2) and (3). ${ }^{9} 208$ of these firms (16.2\%) have at least one material internal control weakness during the period 2004-2006 and

\footnotetext{
${ }^{9}$ Initially, 1,827 firms exist in my dataset with some combination of the necessary variables to estimate Equations (2) and (3). Thus 541 firms are excluded because of data restrictions, where 267 of these excluded firms lack five consecutive years of data to estimate $\mathrm{CASH}_{-}$ETR5. For the overlapping, annual panel sample, 4,826 firms exist initially. 1,475 observations are excluded due to data restrictions, 720 of which relate specifically to a lack of consecutive years to estimate $C A S H \_E T R 5$.
} 
1,078 of these firms (83.8\%) do not have any disclosed material weaknesses during the period. As shown subsequently in Table 3, 83 of the 208 ICW firms (39.9\%) identify tax-related ICWs. ICWs are most frequent in the smallest firms (i.e. S\&P 600) consistent with evidence in the prior literature.

Table 1, Panel C shows that there are 3,351 total firm-year observations in the overlapping sample with available information to estimate Equations (2) and (3). 271 firm-year observations (8.1\%) report at least one instance of any type of ICW. Of these observations, 118 firm-year observations (3.5\% of total sample; $43.5 \%$ of ICW sample) have at least one tax ICW. Table 1, Panels B and D present the industry composition of the firm-level and firm-year samples respectively. Industry membership is based on two-digit NAICS classifications and an NAICS industry is excluded from my sample if it does not contain any internal control weakness firms. I control for cross-industry variation in tax avoidance in my subsequent regression analysis, consistent with prior literature.

\subsection{Internal Control Weakness Classification}

Within Audit Analytics, there are four categories by which a firm's internal controls may be considered ineffective: accounting rule (i.e. financial statement account), financial fraud, errors, and other reasons. Each observation with ineffective controls (i.e. a weakness) must have at least one accounting rule identified; frauds and errors are rarely identified. Thus I first identify tax-related ICWs by searching the Audit Analytics accounting rule category for the tax-specific number code, 41. Firms with non-tax related ICWs are also identified.

Hypotheses 2 and 3 differentiate between account-level and company-level ICWs. Appendix A provides a simple classification method used by Doyle et al. (2007a) however I rely on the more comprehensive classification method of Hammersley et al. (2008), included in 
Appendix B. Their method categorizes the many possible company-disclosed reasons for material weaknesses into less-auditable (“Category A”) and more auditable (“Category B”) categories and sub-categories. The less-auditable and more-auditable categories map to the concepts of company-level and account-level, respectively. ${ }^{10}$

Firm-years disclosing a tax weakness and at least one "Category A" weakness are coded as having a tax-related company-level ICW. Similar to Doyle et al. (2007a and 2007b), I code firms as having a company-level weakness if they describe three or more "Category B" weaknesses in their disclosure as a greater number of weaknesses suggest entity-wide issues. I evaluate the sensitivity of my results to this "three or more" classification in subsection 5.3.2.2 of Chapter 5.

Firm-years disclosing a tax weakness and no more than two "Category B" weaknesses and no "Category A" weaknesses are coded as having a tax-related account-level ICW. Firms that disclose other types of weaknesses, but not tax weaknesses, are coded similarly as "non-tax" or “other” company-level and account-level ICWs. Appendix C contains excerpts of material weakness disclosures from sample 10-K reports.

Table 1, Panel E shows coding as per Appendix B. Of the individual ICWs, $23.6 \%$ are company-level issues. Of these company-level issues, $8.4 \%$ relate to insufficient documentation and policies, and that figure translates to $34.7 \%$ of all firm-year observations having an instance of this specific issue. With respect to tax planning, insufficient documentation and policies could represent, among other issues, a lack of contemporaneous documentation necessary to support

\footnotetext{
${ }^{10}$ The Hammersley et al. (2008) sub-categories generally are the same sub-categories as those identified by Moody's (Doss and Jonas, 2004) but the classification as company-level or account-level differs slightly at the individual level. In addition, the "weak risk assessment” company-level weakness identified by Moody's is not identified by Hammersley et al. (2008). For purposes of my primary analysis, I follow the Hammersley et al. (2008) method, modified to include disclosures related to risk assessments as company-level weaknesses. I evaluate the Moody's classification as a robustness test in subsection 5.3.2.2 of Chapter 5.
} 
transfer pricing or simply a general lack of controls to ensure that tax planning procedures are carried out consistently and effectively by personnel across all of a firm's sub-units. The next three largest percentages of company-level ICWs are for issues in the financial statement close process (8.4\%), poor communication (3.4\%) and lack of key personnel (2.2\%). Although issues with the financial statement close process do not have a direct tie-in to tax planning, they suggest a lack of reporting discipline within the organization that could extend subsequently to tax elections and filings. Inadequate communication with respect to the tax function can suggest the potential for a discretionary environment in which managers act opportunistically, while a lack of key personnel implies a lack of knowledge, resources and leadership for conducting strategic tax planning.

Table 1, Panel E also shows that $76.4 \%$ of the individual ICWs are account-level issues. Lack of timely review (14.6\%) and lack of training/staff $(14.2 \%)$ are the two largest accountlevel categories. Many of the “B2” weaknesses appear to relate to financial statement-related problems, such as a lack of timely reviews or account reconciliations. These types of issues are not likely to be associated with active tax planning. Some of the "B1" issues have a potentially pervasive undertone, such as lack of quality corporate governance and internal monitoring. Although these issues could contribute to a discretionary planning environment, consistent with Hammersley et al. (2008) they are categorized as account-level issues. Note again however that the presence of three or more of these account-level issues can signal a greater lack of control within the firm that ultimately results in a company-level categorization for that firm-year.

\subsection{Tax Avoidance Proxy}

As discussed in Chapter 2, common tax avoidance proxies include effective tax rates $(E T R)$, various measures of BTD and Cash ETR. As explained below, in this thesis I use Cash 
ETR following Dyreng et al. (2008). This continuous variable is a proxy for long-run tax planning that I measure as follows:

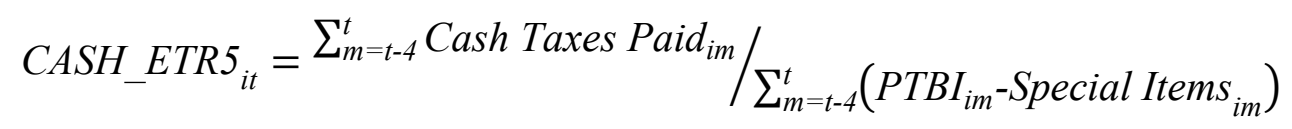

(1).

The numerator is Cash Taxes Paid, a cash flow statement item. The denominator is the difference between PTBI, pre-tax book income, and Special Items, both income statement items. Observations in my sample are set to missing if the denominator is negative. Both the numerator and denominator can be accumulated over time, and for purposes of this dissertation are accumulated for firm $i$ over the five year period from years $t$-4 through $t$. Dyreng et al. (2008) evaluate Cash ETR using one, five and ten year averages and document that the annual measure is a noisy predictor of long-run tax planning. The distribution of the five and ten year measures, however are relatively consistent. Requiring ten consecutive years of data results in half as many firms in their sample than requiring five consecutive years of data does. Thus I choose to measure Cash ETR as a five-year average to avoid any significant reduction of my sample size and survivorship bias. Ayers et al. (2009), Ayers, Laplante and McGuire (2009), and Rego and Wilson (2010) also measure Cash ETR over a five-year period.

In this dissertation, Cash ETR refers to the theoretical concept of taxes paid and the measure as used in prior literature, whereas $C A S H_{-} E T R$ refers to my annual empirical measure and CASH_ETR5 refers to my five-year average empirical measure. A lower value of CASH_ETR5 (or $C A S H \_E T R$ or Cash ETR) represents a firm that avoids more tax - lower values equate to lower tax rates.

The shareholder returns tests described in Section 4.5 require firms to be classified as tax aggressive and, conversely, not tax aggressive. I consider firms to be tax aggressive if they are 
ranked in the lowest quintile based on $C A S H_{-} E T R 5 .{ }^{11}$ The variable $T A G$ is a dichotomous variable equal to 1 if a firm's $C A S H \_E T R 5$ is in the bottom quintile, 0 otherwise. NON_TAG represents "control firms" that are not highly tax aggressive and is coded as 1 if a firm's CASH_ETR5 is not in the bottom quintile, 0 otherwise. The use of quintiles and rankings of CASH_ETR5 allows me to identify tax aggressive firms with a proxy that, in continuous form, is a broad measure that captures varying degrees of tax avoidance.

I use Cash ETR as a proxy for tax avoidance for several reasons. First, Cash ETR includes both permanent and temporary book-tax differences and thus is a broad measure of tax planning that reflects how firms may avoid paying taxes by various means (Dyreng et al., 2008; Chen et al., 2010). Cash ETR recognizes the tax benefits associated with stock options (Ayers et al., 2009) and persistent timing differences that do not reverse during the estimation period (Dyreng et al., 2008; Rego and Wilson, 2010). Conversely, measures that include permanent differences only are more appropriate for studies that reflect tax shelter activity (Frank et al., 2009a), an extreme form of tax planning. Second, this study focuses on sustainable tax planning and not merely "one-off" transactions; Cash ETR is better suited as a long-run measure than as a short-term measure (Dyreng et al., 2008). For these reasons I believe Cash ETR is the appropriate measure to address my specific research question.

Cash ETR does have limitations, however. The measure may be biased downward, in favour of more tax avoidance, for firms that engage in upwards earnings management (Frank et al., 2009a; Rego and Wilson, 2010). Although it captures non-conforming tax avoidance, that is, where tax and accounting treatments differ, like most measures it does not capture conforming

\footnotetext{
${ }^{11}$ To alleviate concerns of in-sample data evaluation, subsequent tables typically report results from in-sample and out-of-sample tests. For in-sample tests, firms are ranked on $C A S H \_E T R 5$ based on firm-level values obtained for my primary 2004-2006 sample firms (i.e. observations span the years 2002-2006). For out-of sample tests, firms are ranked on $C A S H \_E T R 5$ for the period immediately preceding my sample period and so in this analysis each firm is ranked based on $\bar{C} A S H \_E T R 5$ spanning the years 1999-2003.
} 
tax avoidance because the numerator and denominator are similarly affected by activities that reduce both taxable income and accounting income (Hanlon and Heitzman, 2010). In addition, the denominator reflects an estimate of income from the financial statements and thus has inherent measurement error as a crude proxy for taxable income. In sensitivity analysis, I identify two related BTD proxies which capture some of the same inferences as Cash ETR and test them as dependent variables in my empirical models. Finally, like most measures, Cash ETR cannot distinguish between firms that avoid less tax because they conduct little tax planning and firms that avoid less tax because they conduct unsuccessful tax planning.

\subsection{Empirical Models - Tax Avoidance and Internal Control Quality}

I test Hypothesis 1, that tax avoidance is unrelated to tax-specific internal control weaknesses, by estimating the following OLS regression model:

$$
\begin{aligned}
& \text { CASH_ETR } 5_{i t}=\beta_{0}+\beta_{1} \text { TICW }_{i t}+\beta_{2} \text { OICW }_{i t}+\beta_{3} \text { ROA5 }_{i t}+\beta_{4} \mathrm{LEVS}_{i t}+\beta_{5} \text { FORINC5 }_{i t}+ \\
& \beta_{6} \text { FOROPS5 }_{i t}+\beta_{7} \text { BMS }_{i t}+\beta_{8} A G G R_{-} \text {LOSS5 }_{i t}+\beta_{9} C O C F 5_{i t}+\Sigma_{t} D Y E A R_{t}+\Sigma_{j} D I N D_{j}+\varepsilon_{i t}
\end{aligned}
$$

I test Hypotheses 2 and 3 by modifying Equation (2) to separate the influence of accountlevel and company-level tax ICWs. The modifications result in the following OLS regression model:

$$
\begin{aligned}
& C A S H \_E T R 5_{i t}=\beta_{0}+\beta_{1} T I C W 3 \_A C C T 3_{i t}+\beta_{2} T I C W 3_{-} C O M P 3_{i t}+\beta_{3} O I C W 3_{-} A C C T 3_{i t}+ \\
& \beta_{4} O I C W 3 \_C O M P 3_{i t}+\beta_{5} R_{2} O A 5_{i t}+\beta_{6} L_{E V 5} 5_{i t}+\beta_{7} \text { FORINC5 }_{i t}+\beta_{8} F O R O P S 5_{i t}+\beta_{9} B M 5_{i t}+ \\
& \beta_{10} A G G R_{-} L O S S 5_{i t}+\beta_{11} C O C F 5_{i t}+\Sigma_{t} D Y E A R_{t}+\Sigma_{j} D I N D_{j}+\varepsilon_{i t}
\end{aligned}
$$

The variables across these models are defined as follows:

CASH_ETR $5_{i t}=$ a proxy for long-run tax avoidance defined in Equation (1);

$T I C W 3_{i t}=$ an indicator variable equal to one if firm $i$ has a tax-related internal control weakness between $t-2$ and $t$, and zero otherwise; 
$O I C W 3_{i t}=$ an indicator variable equal to one if firm $i$ has a non-tax-related internal control weakness between $t$-2 and $t$, and zero otherwise;

TICW3_ACCT3 ${ }_{i t}=$ an indicator variable equal to one if firm $i$ has a tax-related account-level internal control weakness between $t$ - 2 and $t$, and zero otherwise;

TICW3_COMP $3_{i t}=$ an indicator variable equal to one if firm $i$ has a tax-related company-level internal control weakness between $t$ - 2 and $t$, and zero otherwise;

OICW3_ACCT3 ${ }_{i t}=$ an indicator variable equal to one if firm $i$ has a non-tax-related account-level internal control weakness between $t$ - 2 and $t$, and zero otherwise;

$O I C W 3 \_C O M P 3_{i t}=$ an indicator variable equal to one if firm $i$ has a non-tax-related companylevel internal control weakness between $t-2$ and $t$, and zero otherwise.

$R O A 5_{i t}=$ the average Return on Assets for firm $i$ for years $t-4$ through $t$, measured as five-year average operating income scaled by average lagged assets measured at $t-5$ and $t-1$;

$L E V 5_{i t}=$ the average leverage for firm $i$ for years $t$ - 4 through $t$, measured as long-term debt at $t-4$ scaled by lagged assets plus long-term debt at $t$ scaled by lagged assets, divided by two;

FORINC $5_{i t}=$ the average foreign income for firm $i$ for years $t-4$ through $t$, scaled by average lagged assets measured at $t-5$ and $t-1$;

$F O R O P S 5_{i t}=$ an indicator variable equal to one if $F O R I N C 5_{i t}$ is non-zero or non-missing, zero otherwise;

$B M 5_{i t}=$ the average book-to-market ratio for firm $i$ at the beginning of year $t$, measured as the book value of common equity scaled by the market value of common equity at $t-5$ plus the book value of common equity scaled by the market value of common equity at $t$ - 1 , divided by two;

$A G G R \_L O S S 5_{i t}=$ an indicator variable equal to one if earnings before extraordinary items for years $t-4$ through $t$ sum to less than zero, and zero otherwise;

$C O C F 5_{i t}=$ one minus the average operating cash flows $(O C F 5)$ of firm $i$, with $O C F 5$ measured as five-year average operating cash flows scaled by average lagged assets measured at $t-5$ and $t$ 1

$\Sigma_{t} D Y E A R_{t}=$ a vector of year-specific indicator variables (2006 is the omitted year);

$\Sigma_{j} D I N D_{j}=$ a vector of industry-specific indicator variables ("Other” is the omitted industry). 
CASH_ETR5 is measured as defined in Equation (1), and again observation values are set to missing if the denominator of $C A S H_{-}$ETR5 is negative. ${ }^{12}$ All control variables are based on a five-year average so as to be consistent with the measurement of $C A S H \_E T R 5$, and only one observation per firm is used in the regression to avoid a lack of independent observations. ${ }^{13}$ CASH_ETR5, ROA5, LEV5 and BM5 are winsorized at the $1 \%$ and $99 \%$ levels to reduce the influence of outliers. ${ }^{14}$ Year and industry dummies are included in the regression equations to control for any unobserved, linear effects that result from time or industry differences.

In addition, the standard errors in the empirical specification of Equations (2) and (3) are clustered by two-digit NAICS industry classification. I made this design choice to mitigate the influence of heteroskedasticity and further correlation of the residuals within industry. With the short duration of my sample period, it is difficult to determine whether the influence of industry is permanent or temporary and thus whether a linear specification of industry effects (i.e. including binary industry variables in my models) is sufficient (Petersen, 2009). Plots of residual values from the subsequent regressions in Section 5.2 of Chapter 5 suggest a lack of independence, which is corroborated by post-estimation tests (individual and joint) of skewness and kurtosis that reject the null of normality. Such evidence supports the decision to cluster standard errors by industry, in addition to specifying industry fixed effects.

TICW3, TICW3_ACCT3 and TICW3_COMP3 are indicator variables for overall, accountlevel and company-level internal control weaknesses related to tax, respectively. These variables

\footnotetext{
${ }^{12}$ Negative values of $\mathrm{CASH}_{-}$ETR5 5 are infrequent in my data. Despite the relative truncation of values between zero and one, zero values are also infrequent and thus most observations are strictly greater than zero. OLS is a suitable estimation method under these conditions.

${ }^{13}$ As shown in Table 2, Panel B, over 90\% of the observations are from 2006. Some observations are observed in 2004 or 2005 because of attrition. The term $t$ refers to the current year in which the five-year average is observed.

${ }^{14}$ The winsorizing procedure adjusts all observations outside of the specified intervals (i.e. all observations in the $1^{\text {st }}$ and $99^{\text {th }}$ percentile of the distribution of $\left.C A S H_{-} E T R 5\right)$ so that they equal the next closest value within the interval. Winsorized variables are used as a conservative approach to avoid Type I errors related to extreme outliers. Results are quantitatively similar when $C A S H \_E T R 5$ is truncated at $[0,1]$ and/or ROA5, LEV5 and BM5 are not winsorized.
} 
identify whether a firm has any of these levels of tax ICWs in the three-year period between 2004 and 2006. OICW3, OICW3_ACCT3 and OICW3_COMP3 similarly reflect these three levels of non-tax ICWs. The non-tax ICWs are included because some firms with weaknesses in their tax functions may also have weaknesses in other areas of accounting, and arguments suggest that the disclosure of weaknesses is a negotiated process whereby only the most severe weaknesses are disclosed (Wolfe, Mauldin and Chandler, 2009). Thus the presence of non-tax ICWs, particularly those at the company-level, may influence tax avoidance. The intercepts in Equations (2) and (3) capture the average values of firms with no internal control weaknesses.

TICW3_ACCT3 and TICW3_COMP3 are mutually exclusive indicator variables, as are OICW3_ACCT3 and OICW3_COMP3. If a firm has both an account-level weakness and a company-level weakness, the observation is coded as a company-level weakness, consistent with the method of Doyle et al. 2007a and 2007b. ${ }^{15}$

Hypotheses 1 and 3 suggest two possible scenarios. If overall tax ICWs and companylevel tax ICWs signal an inability to manage the tax function, then TICW3 and TICW3_COMP3 are consistent with a higher value of $C A S H \_E T R 5$ and positive coefficients should result. If overall tax ICWs and company-level tax ICWs signal opportunities for managerial discretion, then TICW3 and TICW3_COMP3 are consistent with a lower value of $C A S H \_E T R 5$ and negative coefficients should result. With respect to Hypothesis 2, I expect that the coefficient on

\footnotetext{
${ }^{15}$ As a result of this construction, there is no need to estimate an interaction between company and account ICWs in my empirical analysis. However, the Pearson correlation between the raw annual overall tax ICWs and non-tax ICWs is 0.439 and significant. This correlation raises concerns about multicollinearity if both tax and non-tax ICWs are included as independent variables. Therefore I modify the ICW construction at the annual level such that tax and non-tax are mutually exclusive, consistent with Doyle et al. (2007a). When constructing TICW3 and OICW3 from these adjusted annual variables, I do not impose further mutual exclusivity. The Pearson coefficient for TICW3 and $O I C W 3$ is 0.104 and significant, but multicollinearity is not a concern.
} 
TICW3_ACCT3 will be indistinguishable from zero. Such a result is consistent with accountlevel tax ICWs having no influence on tax avoidance. ${ }^{16}$

Consistent with prior studies in the tax avoidance literature (e.g. Gupta and Newberry, 1997; Mills et al., 1998; Rego 2003; Dyreng et al,. 2008; Frank et al., 2009a; Wilson, 2009; Chen et al., 2010), I control for firm characteristics that are associated with tax avoidance and tax aggressiveness. The annual variables FORINC, FOROPS and BM are also associated with the internal control literature. The annual variable $A G G R_{-} L O S S$ is common to the internal control literature but not the tax avoidance literature.

ROA5 reflects profitability and is measured as the five-year average of a firm's pre-tax return on assets, scaled by average lagged assets measured at year $t-5$ and year $t-1$. LEV 5 represents leverage and is measured as the average of a firm's long-term debt at year $t-4$ and at year $t$, with each year's observation scaled by lagged assets. More profitable firms and firms with greater leverage or complex financing arrangements have greater incentives or opportunities to avoid taxes, so ROA5 and LEV5 should be negatively related to CASH_ETR5. Although I set CASH_ETR5 to missing if its denominator is negative, I do not impose a similar restriction if the numerator of $R O A 5$ is negative. Thus some firms in my sample may have a negative $R O A 5$ value if its five-year sum of pre-tax income is negative.

FORINC5 and FOROPS5 are measures that capture the presence of firms in foreign jurisdiction. FORINC5 is calculated as foreign pre-tax income scaled by lagged assets and averaged over the years $t-4$ to $t-1$ and FOROPS5 is an indicator variable equal to one if FORINC5 is non-zero or non-missing. Firms that have missing foreign income in Compustat are coded as having zero, rather than missing, foreign income if domestic income is equal to total

\footnotetext{
${ }^{16}$ The coefficients on the non-tax ICW variables would be interpreted in the same way as the tax ICW variables; however I generally do not posit a relation between non-tax ICWs and tax avoidance.
} 
income. Foreign operations allow firms the opportunity to tax plan and avoid taxes, thus both variables should also be negatively associated with $C A S H \_E T R 5$.

$B M 5$ represents growth and is measured as the average opening book value of equity to market value of equity ratio at year $t-4$ and year $t$. Firms with greater growth opportunities (i.e. lower BM5) make less timely modifications of their internal controls for changes in their environment (Doyle et al., 2007a) and presumably make less timely modifications of their tax plans too. Thus BM5 should also be negatively associated with $C A S H \_E T R 5$.

Finally, firms that perform poorly have fewer financial resources to allocate to their internal control systems because they are concerned with remaining in business (Doyle et al., 2007a; Ashbaugh-Skaife et al., 2007). The same logic can be applied to poorly performing firms and allocation of time and effort to tax planning. Although these firms may pay less total tax relative to financially healthy firms, a lack of tax planning suggests that the rate at which they pay taxes should be close to the statutory rate. I include two proxies for resource constraints: AGGR_LOSS5 (Doyle et al., 2007a) equals one for firms with consecutive accounting losses, zero otherwise; COCF5 represents constrained firm resources, operationalized as one minus average operating cash flows.

As reported in Table D.1 of Appendix D, to ensure a parsimonious set of control variables, I exclude from my analysis certain variables common in the tax avoidance literature that do not load consistently in my firm-level sample of data. The excluded variables are proxies for tax loss carry-forwards (NOL5), size (SIZE5), capital intensity (PPE5) and intangible assets (INTANG5). To test for their exclusion from Equation (2), and similarly Equation (3), I drop each variable from the model in the following sequence: INTANG5, PPE5, SIZE5 and NOL5. 
Panel A of Table D.1 reports my examination of the firm-level sample of data with these four variables included. For additional analysis, I also report my examination of the firm-year sample with annual values (Panel B) and a firm-level sample of the Compustat universe with average values (Panel C). The above exclusion sequence is determined by each variable's relative statistical insignificance at each stage of the process reported for the firm-level sample in Panel A. In Panels B and C however, NOL5 is typically statistically significant, and at times so is PPE5. Nevertheless, the magnitudes of the majority of the coefficients of the Equation (2) variables are not significantly affected by the exclusion of these four variables. In particular, the coefficients of $T I C W$ and $O I C W$ are consistent across the columns in Panels A and B.

This discussion of control variables and excluded variables also raises two inter-related issues: simultaneity of tax avoidance and internal control weaknesses, and correlated omitted variables. With respect to the potential for simultaneity (and endogeneity), it is highly unlikely that tax avoidance influences internal controls. Recall that the primary goal of SOX regulation is to improve internal controls and thereby subsequently improve financial reporting quality. Therefore, conceptually, the internal control decision cannot lag the financial reporting outcome. In the same manner, internal controls in the tax function cannot follow tax avoidance. On the other hand, it is plausible that managers jointly decide to avoid or not avoid taxes while they decide to address or not address internal control considerations. To that end, some factors that influence tax avoidance could also influence the presence of ICWs. The unexplained portion of CASH_ETR5 captured by the error terms of Equations (2) and (3) could be correlated with TICW3, OICW3, etc. and thus the resulting regression coefficients would be biased.

However, Equations (2) and (3) include variables that relate to both tax avoidance and internal control weaknesses, as discussed previously in Chapter 2 and this subsection. In 
particular, profitability, leverage and resources are three key variables in Equations (2) and (3) that appear prominently in the internal control literature. Given that these variables are controlled for, any bias in the internal control coefficients should relate to multicollinearity and not to omission. Subsequent analysis in this thesis will help to further alleviate the above concerns. First, univariate correlation analysis is reported in Section 5.2, including the associations between internal control variables and the other control variables. Second, I examine the inclusion of a corporate governance variable in Subsection 5.4.2, a previously omitted variable that is common in both the tax avoidance and internal control literatures. Third I examine the interaction between internal control quality and resources in Subsection 5.4.3. The availability of resources is arguably the key factor when tax avoidance and internal control decisions are considered to be simultaneous.

\subsection{Empirical Models - Stock Returns, Tax Avoidance and Internal Control Quality}

To test Hypotheses 4 and 5, I employ a technique based on Wilson (2009) and regress monthly returns on the four-factor Fama-French (1993) model and dichotomous tax aggressiveness and internal control quality variables. This technique allows me to compare the performance of tax aggressive firms and non-tax aggressive firms by their level of internal control quality and to rule out that any differences between the two are driven solely by the difference in internal control quality. The model is as follows:

$$
\begin{aligned}
& R_{i t}=\beta_{0}+\beta_{I} T I C W C^{*} T A G_{i}+\beta_{2} T I C W C^{*} N O N_{-} T A G_{i}+\beta_{3} T I C S C^{*} N O N_{-} T A G_{i}+b M R F_{t}+ \\
& S S M B_{t}+h H M L_{t}+w U M D_{t}+\varepsilon_{i t}
\end{aligned}
$$

Where:

$R_{i t}=$ firm $i$ 's excess stock return during month $t$, the stock return minus risk-free rate $\left[\mathrm{r}_{\mathrm{it}}-\mathrm{r}_{\mathrm{ff}}\right]$; 
$T I C W C^{*} T A G_{i}=$ an indicator variable equal to one if firm $i$ is tax aggressive based on the definition of $T A G$ in Section 4.3 and has a company-level tax-related internal control weakness during period $y$, and zero otherwise;

$T I C W C^{*} N O N \_T A G_{i}=$ an indicator variable equal to one if firm $i$ is not tax aggressive based on the definition of NON_TAG in Section 4.3 and has a company-level tax-related internal control weakness during period $y$, and zero otherwise;

$T I C S C * N O N \_T A G_{i}=$ an indicator variable equal to one if firm $i$ is not tax aggressive and has no company-level tax-related internal control weakness during period $y$, and zero otherwise;

$M R F_{t}=$ the excess market return in month $t$, the value-weighted market return minus risk-free rate $\left[\mathrm{r}_{\mathrm{mt}}-\mathrm{r}_{\mathrm{ft}}\right]$

$S M B_{t}=$ the size premium for month $t$, the difference in returns between the portfolios of small and big cap firms;

$H M L_{t}=$ the book-to-market premium for month $t$, the difference in returns between the portfolios of high and low book-to-market firms;

$U M D_{t}=$ the momentum premium for month $t$, the difference in returns between the portfolios of previously well performing (winners) and poorly performing firms (losers);

Monthly returns will be regressed on the set of indicator variables and Fama-French (1993) factors for my sample period. In sensitivity analysis, I estimate the model for the twelvemonth periods preceding and following my sample period. Time-series data for each of the Fama-French factors are retrieved from Ken French’s website. ${ }^{17}$

Firms are tax aggressive if they are ranked in the lowest quintile of $C A S H \_E T R 5$ and not tax aggressive otherwise, resulting in the indicator variables $T A G$ and $N O N_{-} T A G$ as described in subsection 4.3. TICW3_COMP3 (as TICWC) is interacted with TAG and NON_TAG to identify tax aggressive and non-tax aggressive firms with weak company-level tax-related internal controls. TICSC, a variable coded 1 if a firm does not have a company-level tax-related weakness and 0 otherwise, is also interacted with $N O N \_T A G$ to identify non-tax aggressive firms

\footnotetext{
${ }^{17}$ http://mba.tuck.dartmouth.edu/pages/faculty/ken.french/data_library.html.
} 
with strong internal controls; thus the intercept in this returns regression represents the effect for tax aggressive firms with strong company-level internal controls.

Consistent with rejecting the null form of Hypothesis 4, I expect that the coefficients on the interaction terms $T I C W C^{*} N O N \_T A G$ and $T I C W C^{*} T A G$ will be negative. A larger negative coefficient on $T I C W C^{*} T A G$ is consistent with rejecting the null form of Hypothesis 5. The coefficient on the intercept from the returns regression should be positive. Thus the coefficients on each indicator variable can be interpreted as that group's incremental abnormal monthly return relative to the tax aggressive firms with strong internal controls. These predictions represent lower shareholder wealth in firms with weak tax-related internal controls, particularly tax aggressive firms with weak tax-related internal controls. Tax aggressive firms with strong tax-related internal controls on the other hand are predicted to create the most wealth for their shareholders.

Although I adapt Wilson’s (2009) model of returns analysis, I distinguish my research from Wilson (2009) on several grounds. First, Wilson (2009) classifies firms as highly tax aggressive based on tax shelter participation, a specific and extreme type of tax planning. I use a more broad and long-run measure of tax avoidance, Cash ETR, to classify firms as highly tax aggressive in my analysis. In supplementary tests Wilson (2009) observes no significant relation between Cash ETR and his sample of tax shelter firms, further validating that our proxies do not capture the same type of tax planning.

Second, I investigate a measure of internal governance that practitioners typically associate with corporate governance (Bedard, Hoitash and Hoitash, 2009). Management designs the internal controls to govern internal processes of a firm and the Board of Directors monitors these controls. The Gompers et al. (2003) index of corporate governance (G-Index) used by 
Wilson (2009) is a composite measure of shareholder protection rights and so it proxies for external monitoring. ${ }^{18}$ Internal and external monitoring represent different concepts and the scope of this dissertation is to evaluate the influence of internal monitoring through examination of internal control systems. In this regard, I focus on a less frequently studied construct and provide new insight about the individual influence of internal control quality (interacted with tax aggressiveness) on returns. Sensitivity analysis in Chapter 5 of this thesis, however, considers the potential influence of corporate governance in my empirical models.

\subsection{Conclusions}

This chapter reviews my sample selection and data collection methods, the construction of my long-run internal control weakness and tax avoidance measures, and the design of my empirical models. The majority of the subsequent empirical analysis will be conducted using long-run, average values of my variables, however certain tests are also conducted using annual values of the variables. Equations (2) and (3) in this chapter form the base of my tests for Hypotheses 1 through 3 and the results of these tests will be reported in Chapter 5 . Equation 4 in this chapter forms the base of my tests for Hypotheses 4 and 5 and the results of these tests will be reported in Chapter 6.

\footnotetext{
${ }^{18}$ In addition to being a measure of external monitoring outside of the primary scope of this thesis, the G-INDEX index has other limitations. Potential measurement error results because of the equal-weighting of individual factors; the relative importance of each individual factor or correlations between factors is not considered (Larcker, Richardson and Tuna, 2007). The results of the Gompers et al. (2003) study also appear to be sensitive to the authors' construction of certain portfolios, raising questions about the inferences that can be made (Cremers and Nair, 2005). Finally, G-INDEX only includes shareholder protection/anti-takeover provisions; greater likelihood of takeover represents good governance but in general firms that are targets for takeover perform poorly (Cremers and Nair, 2005). Readers should bear these caveats in mind when analyzing the subsequent sensitivity tests in this study.
} 


\section{CHAPTER 5}

\section{EMPIRICAL ANALYSIS - TAX AVOIDANCE AND INTERNAL CONTROL QUALITY}

\subsection{Introduction}

In this chapter, I test my first three hypotheses and thus investigate the empirical relation between long-run tax avoidance and general, account-level and company-level tax internal control weaknesses. I empirically examine Equations (2) and (3) from Section 4.5 using firmlevel samples of data, with average values observed during the 2004-2006 time period. In supplemental tests in this chapter I test the sensitivity of this empirical analysis to alternative methods. These methods include estimation of overlapping, annual regressions of average variables, estimation of annual regressions of data with alternative dependent variables, factor analysis of resource constraint variables, and remediation of internal control weaknesses. This chapter includes five sections, including this introduction and a conclusion.

Section 5.2 of this chapter examines the descriptive statistics relevant to my primary tests of Hypotheses 1 through 3. This examination also includes a review of a correlation table for my primary variables of interest and control variables. Section 5.3 of this chapter provides the main table of analysis for Hypotheses 1 through 3 . Table 5 of this section reports the statistics estimated with firm-level, average values of my sample firms.

Section 5.4 provides a number of different alternative regressions and additional analysis in an effort to support or extend the results documented in Section 5.3. This section includes four subsections, divided as follows: (1) alternative firm-year regressions; (2) alternative tax avoidance proxies and alternative independent variables, including additional classifications of my manually-coded internal control weakness data and the addition of corporate governance; (3) 
further investigation of resource constraints, including factor analysis and interaction variables, and; (4) remediation of internal control weaknesses. Section 5.5 concludes this chapter.

\subsection{Descriptive Statistics and Univariate Analysis}

Table 2 presents descriptive statistics for both annual and average values of the variables. Panel A contains the annual values and Panel B contains average values for the firm-level sample of firms. For completeness, Panel C contains average values for the overlapping, annual sample of firms. Although Panel C contains more observations than Panel B, the summary statistics are similar because of the inherent smoothing in each set of average variables. I thus restrict my subsequent discussion to the results in Panels A and B of Table 2.

For each type of ICW, the proportion of firms with at least one ICW in the firm-level sample of Panel B is higher than the proportion of firm-year observations with ICWs in the annual sample of Panel A. Of the firms reporting ICWs, more firms are categorized as having company-level issues than account-level issues, and more non-tax ICWs exist than tax ICWs. ${ }^{19}$ As one might also expect, the mean, median and variance of continuous variables are generally smaller for firm-level values in Panel B than for annual values in Panel A, with typical rightskewness for all continuous variables. The percentage of firms with FOROPS equal to one increases slightly in the firm-level sample. Finally, the annual observations are least frequent in 2004, the first year of SOX 404 reporting for accelerated filers, and evenly split in 2005 and 2006. In the firm-level sample, most observations occur in 2006, implying that $92 \%$ of firms with available data in 2004 survive to 2006.

Table 3 presents descriptive statistics on five-year average values and makes comparisons for three sub-samples: firms with ICWs vs. firms without ICWs (Panel A), firm with tax ICWs

\footnotetext{
19 Among the 208 firms that have a firm-level ICW, 148 company-level ICWs exist and 75 account-level ICWs exist. Recall that mutual exclusivity occurs at the annual level, but not necessarily at the average or firm level.
} 
vs. firms without ICWs (Panel B), and firms with tax ICWs vs. firms with non-tax ICWs (Panel C). Firms with tax-related ICWs have the highest mean (median) $C_{A S H}$ ETR5 at $30.8 \%$ (26.1\%), and the mean is significantly different from the $22.2 \%$ reported for firms without ICWs. The mean (median) is not significantly different from the $24.9 \%$ (23.3\%) reported for firms with non-tax-related ICWs. The mean and median $C A S H \_E T R 5$ for all firms with ICWs are, however, significantly different from firms without ICWs. Comparing mean values for firms with ICWs to those without, ICW firms appear to be significantly less profitable, use significantly less leverage, engage in significantly more foreign activity (although with less foreign income on average), have significantly less growth opportunities and have significantly greater resource constraints than the control group.

$R O A 5$ is highest for the control group and lowest for the tax ICW group (the difference is statistically significant at the $1 \%$ level). LEV5 is only significantly different, at the $5 \%$ level, when comparing firms with ICWs and firms without ICWs; this difference appears to be driven by the non-tax ICW group. Firms with tax ICWs, on average, have more foreign activity than both firms without ICWs and firms with non-tax ICWs, although only the median differences on FORINC5 and the mean differences on FOROPS5 are significant, where available. Firms with tax ICWs also have the highest percentage of aggregate losses and cash flow constraints, while firms with non-tax ICWs and firms without ICWs have, on average, similar values. BM5 is smallest for the control group although I would expect that firms with ICWs have a lower value, indicative of firms with more growth opportunities. Finally, the number of observations in 2006 is consistent across the sub-samples and not significantly different across groups, suggesting that the rate of attrition for ICW firms is no greater than that of firms without ICWs. 
Table 4 presents Pearson correlation coefficients for the complete set of average variables, other than TICW3 and OICW3. Typically all correlations of more than 5\% in absolute value are statistically significant at a 5\% level or better. $C A S H \_$ETR5 shares positive 0.116 and 0.084 associations with $T I C W 3 \_C O M P 3$ and $O I C W 3 \_C O M P 3$, respectively, both statistically significant at the $1 \%$ level. CASH_ETR5 is not significantly related to the account-level ICW measures. These results suggest that the presence of company-level ICWs lead to less tax avoidance (i.e. a higher Cash ETR value). As expected, greater leverage is associated with more tax avoidance but higher profitability is unexpectedly associated with less tax avoidance (correlation coefficients of -0.138 and 0.055 , respectively); on the other hand, Dyreng et al. (2008) document similar univariate results for these two variables. Although negative as expected, FORINC5 does not have a significant relation with CASH_ETR5, and the presence of foreign operations is positively and significantly related to $C A S H \_E T R 5$. An explanation for this positive relation is that foreign operations allow the opportunity to tax plan but other resource needs in those foreign ventures can reduce the resources to tax plan aggressively. AGGR_LOSS5 and COCF5 are positively associated with CASH_ETR5, but only the association with $A G G R \_L O S S 5$ is significant. BM5 is not significantly correlated with $C A S H \_E T R 5 .^{20}$

\subsection{Hypothesis Tests - H1 through H3}

Table 5 contains the results of the main tests used to evaluate Hypotheses 1-3; the first column presents evidence related to $\mathrm{H} 1$ and the second column presents evidence related to $\mathrm{H} 2$ and H3. The main tests rely on cross-sectional variation to estimate the coefficients. According to the first column of Table 5, and consistent with the univariate results, the presence of tax-

\footnotetext{
${ }^{20}$ As noted earlier, the ICW variables are constructed such that correlations with one another are not at levels that raise concerns about multicollinearity. FORINC5 and FOROPS5, BM5 or AGGR_LOSS5 or COCF5 and ROA5, and $B M 5$ and COCF5 have significant magnitudes of association with one another. It is not critical that the coefficients of these control variables be completely and separately identified from the coefficients of other variables.
} 
related ICWs is positively related to $C A S H_{-} E T R 5$ and statistically significant at the 5\% level. The TICW3 coefficient suggests that $C A S H_{-}$ETR5 is 4.5 percentage points higher for the tax ICW group than the control group. In economic terms, this coefficient suggests that the mean firm in my sample would have a $19.6 \%$ increase in the rate of taxes paid in the presence of a tax ICW. $^{21}$ This evidence rejects the null hypothesis and is consistent with the argument that tax ICWs are indicative of some combination of weak tax risk management, foregone tax planning opportunities and resource constraints that result in less tax avoidance. The $O I C W 3$ coefficient for the presence of non-tax ICWs is not significantly different from zero.

With respect to control variables, ROA5 and FOROPS5 are positively and significantly related to CASH_ETR5. These coefficient estimates are inconsistent with the majority of the prior literature but are consistent with the univariate results. The positive estimate of $R O A 5$ is also consistent with evidence in Dyreng et al. (2008). ${ }^{22}$ LEV5 and FORINC5 are significantly related to $C A S H \_E T R 5$ and in the predicted negative direction. These results suggest that greater leverage or use of debt-tax shields helps to reduce taxes paid. Furthermore, firms appear to invest in foreign jurisdictions to generate income that attracts a lower tax rate. Consistent with the univariate results, $B M 5$ is not significantly associated with $C A S H \_E T R 5$. The coefficients on AGGR_LOSS5 and COCF5 are positive and significant at the $1 \%$ level. The coefficient on this $A G G R \_L O S S 5$ indicator variable reflects an 18 percentage point increase in CASH_ETR5 for firms with consecutive book losses, consistent with such firms being unable to spare scarce resources to invest in tax planning. Finally, the F-statistics and related probabilities suggest that

\footnotetext{
${ }^{21}$ To estimate this economic effect, I divide the coefficient on TICW3 (0.045) from Table 5 by the mean value of CASH_ETR5 (0.230) from Panel B of Table 2.

${ }^{22}$ Dyreng et al. (2008) find that Cash ETR is negatively associated with $\mathrm{R} \& \mathrm{D}$ and conjecture that the higher spending on R\&D for "tax avoiders" likely contributes to the positive relation between Cash ETR and ROA. Expensing R\&D costs reduces the amount of pre-tax profit generated. I do not include an R\&D variable in my study because data availability of R\&D would greatly reduce my sample and the power of my tests. Of the 1,286 firms in my sample, 567 are missing long-run R\&D data, including 82 of the 208 firms that report ICWs.
} 
the time dummies for 2004 and 2005 are not statistically different from zero but the industry dummies are jointly statistically significant.

In the second column of Table 5, the coefficient for TICW3_ACCT3 is not significant. As a result, I am unable to reject the null of H2. However, company-level tax ICWs are consistent with an over 4 percentage point increase in $C A S H \_E T R 5$ or an $18.7 \%$ increase in the rate of taxes paid for the mean firm in my sample; the coefficient on TICW3_COMP3 is significant at the 5\% level (two-tailed). Thus I can reject the null form of Hypothesis 3 and, similar to the results for Hypothesis 1, this evidence implies that company-level tax ICWs indicate a failure to plan taxes rather than an opportunity for discretionary activities, on average. This evidence also could imply that increased attempts at aggressive tax planning in the presence of company-level tax ICWs are more often unsuccessful, also resulting in higher taxes paid. The coefficient on OICW3_ACCT3 is insignificant but the coefficient on OICW3_COMP3 is positive and significant at the $10 \%$ level. Prior research suggests that disclosed ICWs are negotiated (Wolfe et al., 2009) and thus issues with the tax function could be left undisclosed. If undisclosed ICWs are present in my sample, entity-wide ICWs could indeed have an influence on the tax function, on average. Alternatively, the research reviewed in Chapter 2 observes that company-level ICWs in general are associated with firms that are younger and financially constrained. Younger firms could have less sophisticated tax planning ex-ante, and resource constraints are argued to be and shown to be negatively associated with tax avoidance in this thesis. Thus the same characteristics that are associated with weaker tax planning could be as prevalent in firms with non-tax ICWs as they are in firms with tax ICWs. The results for the remaining variables are consistent with the first column in Table 5. 
In summary, the results in the two columns of Table 5 suggest that tax avoidance is constrained by the presence of tax ICWs, in particular company-level tax ICWs. The evidence supports the conjecture that company-level ICWs call into question management's ability to control its operations and that certain ICWs can provide information beyond financial reporting quality. This negative relation between tax ICWs and tax avoidance also provides an alternative perspective to recent evidence from Gleason et al. (2010). In their setting, material tax ICWs allow management to engage in short-term, discretionary reporting of ETR, leading to a positive association between tax ICWs and financial reporting aggressiveness.

Although firms can make trade-offs between financial reporting aggressiveness and tax avoidance, evidence from Frank et al. (2009a) indicates that with non-conforming accounting standards and tax law the two, measured as annual constructs, are positively related rather than negatively related. Cook et al. (2008) and Hanlon and Heitzman (2010) suggest that the ETR management studied in Gleason et al. (2010) can be accomplished through earnings management or tax avoidance behaviour, further supporting a possible positive relation between financial reporting aggressiveness and tax reporting aggressiveness. The differing findings across my study and Gleason et al. (2010) could be the result of a difference in horizons. It could also be the result of different aggressiveness constructs.

\subsection{Robustness Checks and Additional Analysis}

\subsubsection{Firm-year Regressions}

My previous tests rely on average variables to test long-run tax avoidance and thus smooth-out the short-run volatility of tax payments and refunds. Conservatively, I also restrict my sample to one observation per firm; I use this restriction to maintain independence among observations. As an alternative I regress overlapping, annual averages of all variables for the 
sample period 2004-2006 to capture both time-series and cross-sectional variation and report the empirical results in Table 6. I attempt to alleviate concerns regarding independent observations by clustering the standard errors on two dimensions, industry and firm. In the next paragraph, I explain why average values of the ICW variables are used in this alternative regression.

In firm-level analysis with average variables, a firm with an ICW in any year from 20042006 is an ICW firm. However, in firm-year analysis with annual variables, a firm could have an ICW in the current year and none in the subsequent year, or have a tax ICW in the current year and a non-tax ICW in the subsequent year, etc. Implicit in my design to examine long-run tax avoidance is an assumption that it takes considerable time to change or improve strategic tax planning. Thus use of firm-level ICW values in the overlapping, annual regressions is consistent with the view that ICW firms, particularly tax ICW firms, do not necessarily alter their internal control profile in quick succession.

Table 6 shows that the coefficient estimates are generally consistent with the results in Table 5, although the fit of Equations (2) and (3) are not as strong when estimated with this panel of data. $T I C W$ and $T I C W_{-} C O M P$ are positive and statistically significant (at the $5 \%$ level) and among the non-tax ICW variables, again only the coefficient on $O I C W_{-} C O M P$ is statistically significant (at the 10\% level). All of the coefficients for the control variables are consistent in sign with the results in Table 5 although FORINC and FOROPS are not statistically significant in either column of Table 6.

\subsubsection{Alternative Proxies and Additional Variables}

\subsubsection{Alternative Tax Avoidance Proxy}

In Chapter 4 I discussed why CASH_ETR5 is the appropriate measure of tax avoidance

for my setting. Nevertheless, there is a lack of consensus in the literature concerning both the 
definitions and constructs of tax avoidance and tax aggressiveness and so I evaluate the sensitivity of my results with an alternative proxy, total book-tax differences. Hanlon and Heitzman (2010) argue that, conceptually, total BTDs are similar to tax rate measures such as CASH_ETR5 because both constructs capture elements of book and tax as well as nonconforming tax avoidance, and both constructs reflect deferral strategies. The extant literature argues that firms avoid more tax as the gap between book income and taxable income increases.

To determine if my main results are robust to alternative measures of tax avoidance, I rely on two proxies of total BTDs - the measure of Manzon and Plesko (2002), BTD1, and the measure given in Hanlon and Heitzman (2010), BTD2. These proxies are defined as follows:

BTD1 = [US domestic pre-tax income - (current US domestic tax expense / US statutory rate) - state income taxes - other income taxes - equity in earnings] / lagged assets

BTD2 = [pre-tax income - (current US domestic tax expense + current foreign tax expense) / US statutory rate - change in NOL from t-1 to t] / lagged assets (6).

Table 7 provides summary statistics for the new variables of interest that are empirically examined in Section 5.4. In Panels A and B, the average values of the relevant variables are reported. These variables are used in additional analyses of firm-level regressions in this subsection and subsection 5.4.3. In Panels C and D, the annual values of the relevant variables, including $B T D 1$ and $B T D 2$, are reported. The variables in these two panels, other than $B T D 1$ and BTD2, are relevant to the analysis in subsection 5.4.4.

Since my previous results hold for both Equations (2) and (3), I test BTD1 and BTD2 in regressions of Equation (3) only, and consistent with the prior literature I estimate BTDs in 
annual regressions. ${ }^{23}$ Clustering of standard errors is again calculated both within industry and within firm. The results of this analysis are presented in Table 8.

$T I C W_{-} C O M P$ has a negative association with $B T D 1$, consistent with the positive association with $C_{A S H}$ ETR5 in my main tests. The control variables are all statistically significant and generally significant at a $5 \%$ level, as expected given the majority of these control variables are common to the BTD literature. However, $R O A$ and $C O C F$ have opposite signs than predicted. The results for $B T D 2$ are generally weaker. None of the ICW variables, and only four of seven control variables, have statistically significant coefficients in the regression. The number of observations is significantly lower in the regression of BTD2 than in BTD1 because of missing values related to tax loss carryforwards. Combined, the annual BTD measures provide weaker evidence than Cash ETR regarding the influence of tax ICWs on tax avoidance. Several reasons explain why this BTD analysis should be interpreted with caution.

First, it has been argued that BTDs are particularly associated with tax shelter activity (e.g. Wilson, 2009). Prior literature also demonstrates that BTDs are associated with earnings management. Thus, despite some similarities between BTDs and Cash ETR, the former captures elements of tax aggressive and financial reporting aggressive behaviour that is not captured by the latter.

Second, in my particular setting, tax ICWs may proxy for ineffective tax planning and/or resource constraints. Firms with such issues are more likely to pay tax at a rate closer to the

\footnotetext{
${ }^{23}$ Calegari (2000) argues that BTDs are transitory and thus their suitability as a long-run measure may be limited. Although Dyreng et al. (2008) conjecture that Cash ETR and BTDs will be associated with one another in the long run, they do not test this relation. Chen et al. (2010) demonstrate an association between BTDs and Cash ETR using annual proxies, but they also report results of a five-year average BTD measure identical to BTD1 in sensitivity analysis. Although the fit of the model is consistent in the annual and average regressions, the significance of most variables weakens in the average regression, including their variable of interest. Cash ETR is constructed as a longrun measure to reduce misspecification due to the timing and variability of tax payments across taxation years but no such justification exists for measuring BTDs as a long-run measure. In effect, BTDs are relatively well-specified as annual measures and thus annual tests with BTDs are sufficient for comparison.
} 
statutory rate, implying that they are less likely to make effective use of tax credits or foreign activities. A Cash ETR measure can distinguish these firms with higher tax rates from those firms that lower their rate through tax credits and foreign activity. Furthermore, since BTD measures use a domestic rate to estimate taxable income, greater measurement error exists for firms that are able to lower their tax rate through credits and foreign activity. This error narrows the gap between higher tax rate firms and lower tax rate firms in an empirical BTD measure. Since firms with company-level ICWs are less likely to have significant foreign transactions (Doyle et al., 2007a), this BTD issue is more pronounced in my setting. BTD1 is based on domestic taxable income and thus suffers from less measurement error than BTD2. In addition, BTD2 implicitly assumes that all foreign income is repatriated (global income is grossed up at the domestic rate) and such an implicit assumption is subject to challenge from the existing literature.

\subsubsection{Internal Control Weakness Classification}

My categorization of internal control weaknesses into account-level and company-level components uses Hammersley et al.’s (2008) criteria. My calculation incorporates the adjustment of Doyle et al. (2007a and 2007b): three or more individual account-level issues constitute a company-level weakness. In this section, I analyze the sensitivity of my results to these two empirical design choices.

First, I examine the data when only firms disclosing an individual company-level weakness are coded as such. With this adjustment, more account-level ICWs than company-level ICWs result. ${ }^{24}$ The first column of Table 9 shows, after re-estimation of Equation (3), results generally consistent with prior evidence in this dissertation. TICW3_COMP3 is positive and

\footnotetext{
${ }^{24} 174$ account-level ICWs and 142 company-level ICWs exist at the firm level with this adjustment.
} 
significant at the $10 \%$ level, while no other internal control weakness variables are statistically significant. The control variables are consistent in both sign of the coefficient and statistical significance.

Second, I use criteria provided by Moody's (Doss and Jonas 2004) as an alternative classification method. Moody’s considers four general themes to reflect pervasive company-level issues: ineffective control environment; ineffective audit committee; ineffective internal audit or risk assessment function, and; ineffective financial reporting function. Using specific comments within the Moody's commentary as a guide, I cross-reference these issues to the categories of Hammersley et al. (2008) presented in Appendix B. Consequently, Moody’s company-level internal control weaknesses generally include the "Category A" issues, several of the "Category B" issues in Appendix B, and the presence of three or more "Category B" issues. ${ }^{25}$

The second column of Table 9 shows the empirical results for Equation (3) using the Moody's classification method. The evidence is consistent with my main analysis. The magnitude and statistical significance of TICW3_COMP3 and OICW3_COMP3 are comparable to the results in Table 5, as are the magnitude and statistical significance of the control variables. As reported in the third column of Table 9, if I remove the restriction that three or more accountlevel issues constitute a company-level ICW with the Moody's classification scheme, the magnitude of TICW3_COMP3 increases, OICW3_COMP3 becomes statistically insignificant

\footnotetext{
${ }^{25}$ In addition to the "Category A" weaknesses, the Moody's commentary suggests that some "Category B" weaknesses in Appendix B are also pervasive. Lack of quality corporate governance, lack of internal audit function and poor segregation of duties are three "Category B" issues that I consider to be at the company-level under Moody's criteria. The result is 104 account-level ICWs and 208 company-level ICWs at the firm-level. Inadequate training, staffing limitations, incomplete account analysis and inadequate account reconciliations are four "Category B” weaknesses that I do not code as company-level ICWs, despite Moody's comments. These four issues are frequently disclosed by firms and their inclusion as company-level ICWs would cause company-level issues (243 instances) to dominate account-level issues (60 instances) under the Moody’s classification scheme.
} 
and results for all other variables generally remain consistent relative to the second column results.

In summary, changes to the classification method of internal control weaknesses have little influence on the empirical results. The coefficient for non-tax-related company-level ICWs can lose statistical significance depending on the alternative method chosen. Most importantly, the effect on the tax-related ICWs does not change inferences. Tax-related company-level ICWs consistently show a positive and statistically significant association with my dependent measure of CASH_ETR5.

\subsubsection{Corporate Governance}

In section 4.5 of Chapter 4, I discuss how systems of internal controls that reflect the internal monitoring within an organization are distinct from shareholder protection rights and other similar measures that reflect the external monitoring of an organization. These external forms of monitoring reflect typical themes of corporate governance in the literature, and in this section I control for the influence of corporate governance in Equations (2) and (3) when estimating the association between internal control quality and tax avoidance.

As my proxy, I calculate a multi-year average estimate of the Gompers et al. (2003) index (GOVERN) of corporate governance. ${ }^{26}$ A lower value of GOVERN indicates stronger external monitoring because defensive takeover tactics are reduced and thus existing managers are less likely to become entrenched. Evidence in Wilson (2009) argues that strong corporate governance

\footnotetext{
${ }^{26}$ G-INDEX is a composite measure calculated for S\&P 1500 firms. The data are available from Andrew Metrick's website (http://www.som.yale.edu/faculty/am859/data.html). GOVERN represents the mean of a firm's time-series of G-INDEX scores and thus GOVERN varies by firm, but not by time period. Untabulated analysis of the means and standard deviations shows that the individual scores are quite "sticky". The mean standard deviation is 0.709 units, thus less than a one unit change in G-INDEX. In the $25^{\text {th }}$ percentile and below, the standard deviation is 0.0 and at the $75^{\text {th }}$ percentile, the standard deviation is 1.0. Accordingly, use of the mean G-INDEX score appears justified. Although individual G-INDEX scores are not compiled after 2006, subsequent tests that include data from periods after 2006 can also use GOVERN. The "stickiness" of the variable suggests extrapolation is unnecessary.
} 
can be associated with an increase in tax avoidance because tax planning activities in such firms create wealth for shareholders rather than divert rents to managers, implying a positive association between GOVERN and CASH_ETR5.

Table 10 presents the results for Equations (2) and (3) when estimated with GOVERN. ${ }^{27}$ Consistent with earlier results, TICW3, TICW3_COMP3 and OICW3_COMP3 are all positive and statistically significant at the $5 \%$ level. $O I C W 3$ is also positive and statistically significant at the 5\% level. The other ICW variables are not statistically significant. The coefficient on FOROPS5 is not statistically significant in these regressions but all other control variables maintain the same sign and equal or better statistical significance than in previous regressions. As expected, the coefficient of GOVERN is positive and it is statistically significant at the 5\% level. If I replace GOVERN with a dichotomous variable POOR_GOV that equals one for firms with above median GOVERN scores and zero for firms with at or below median GOVERN scores, the results and inferences do not change. These results are reported in columns 3 and 4 of Table 10 .

In summary, strong corporate governance is positively associated with tax avoidance in my analysis. However, the presence of corporate governance does not diminish the influence of internal control quality on tax avoidance, nor does its exclusion significantly affect the estimated coefficients of the internal control variables. Overall, both internal control quality and the common Gompers et al. (2003) measure of corporate governance appear to be important factors in my model of tax avoidance.

\footnotetext{
${ }^{27}$ Although the firms in my sample are S\&P 1500 firms, they do not all have G-INDEX data available. Based on available data for my sample firms, GOVERN is negatively correlated with each of TICW3, OICW3, TICW3_COMP3 and OICW3_COMP3 but, in absolute value, the magnitude of correlation with each of these variables is greater than $0 . \overline{1} 0$. GOVERN does not share a statistical correlation with TICW3_ACCT3 or OICW3_ACCT3.
} 


\subsubsection{The Influence of Resource Constraints}

\subsubsection{Factor Analysis}

The results thus far are consistent with tax ICWs limiting corporate tax avoidance, and so the tax ICW measures TICW3 and TICW3_COMP3 hypothetically capture elements of both risk management and resource issues. Furthermore, with resource constraints explicitly included in the empirical model, the importance of tax ICWs is not diminished. Although in the absence of a reasonable proxy I cannot further directly evaluate tax risk management, I can empirically examine how resource constraints relate to tax internal control weaknesses.

My first step in this section is to consider the effect of the resource constraint proxies, $A G G R_{-} L O S S 5$ and COCF5, in my model. In general, no consistent proxy for resource constraints has emerged in the literature and so as a robustness check I analyze several known proxies using factor analysis. In addition to COCF5 and a continuous form of AGGR_LOSS5, similar to Klassen, Pittman and Reed (2004) I include debt and bond rating measures. DEBT5 equals one minus a firm's five-year average debt to asset ratio and NRATING5 equals one if the firm does not have a public bond rated by S\&P at any time during a five-year period, zero otherwise. ${ }^{28}$ Since leverage is naturally highly positively correlated with the debt to asset ratio, I include CLEV5 (one minus LEV5) in the factor analysis as well. By construction, all five variables are expected to be positively related to $C_{A S H}$ ETR5. NRATING5 should be positively related to $C A S H \_E T R 5$ because the absence of public debt suggests fewer options to obtain financing and thus fewer opportunities or incentives to avoid taxes (i.e. a higher CASH_ETR5).

\footnotetext{
${ }^{28}$ DEBT5 = one minus [the average of long-term debt at $t-4$ scaled by lagged assets plus long-term debt at $t$ scaled by lagged assets]; and NRATING5 = one if a firm lacks an S\&P bond rating during all years from $t-4$ to $t$, and zero otherwise. I use a continuous measure of $A G G R \_L O S S 5$ (i.e. one minus [five-year sum of income before extraordinary items scaled by average lagged assets at $t-4$ and $t]$ ).
} 
The factor analysis, reported in Panel A of Table 11, results in two factors: CC15 represents constrained resource flows (i.e. income and cash) and CC25 represents constrained debt capacity. Thus both factors reflect resource constraints and are expected to be positively related to $C A S H \_E T R 5$, my measure of tax avoidance. Panel B of Table 11 presents results from regressions of Equations (2) and (3) with the factors substituted for LEV5, AGGR_LOSS5 and COCF5.

Across the two columns of results in Panel B of Table 11, CC15 loads significantly (at the 1\% level) and in the predicted direction but $C C 25$ does not load significantly in either model. In the first column, TICW3 is positive and significant (at the $1 \%$ level) and OICW3 is statistically insignificant. In the second column, consistent with prior results, TICW3_COMP3 and OICW3_COMP3 are positive and statistically significant (at the 5\% and $10 \%$ levels, respectively). However, both TICW3_ACCT3 and OICW3_ACCT3 are statistically significant (also at the 5\% and 10\% levels, respectively) and while the coefficient on TICW3_ACCT3 is positive, the coefficient on OICW3_ACCT3 is negative. The results for the remaining control variables are generally consistent with the main results reported in Table 5, but note that the overall fit of the models with factors included is not as strong as the fit of these main regressions. The reduced fit of this adjusted model suggests that the factor analysis constrains some of the important variation within the individual variables. ${ }^{29}$

Overall, evidence from this table suggests rejection of the null form of Hypotheses 1 and 3 , consistent with prior analysis. However, the results also suggest rejection of the null form of Hypothesis 2. Further, although the presence of non-tax company-level ICWs continues to

\footnotetext{
${ }^{29}$ Consistent with Appendix D, regressions on a parsimonious set of variables results in a higher adjusted $\mathrm{R}^{2}$ than models with additional control variables (untabulated). The signs and significance of the factor coefficients are also unchanged.
} 
suggest lower levels of tax avoidance, the presence of non-tax account-level ICWs is associated with a higher level of tax avoidance in this model.

\subsubsection{Interaction of Resource Factors and Internal Control Weakness Variables}

As a second step, I consider an interaction between resources available for tax planning and the ability to manage tax planning risks and opportunities. I use the statistically significant resource constraint proxy $C C 15$ from the factor analysis to construct a parsimonious set of interaction terms that link with my account-level and company-level ICW variables. These interaction variables reduce the concern of multicollinearity that could be raised as a result of the theoretical influence that resource availability has on internal control decisions. I refer to these interaction variables as TACCT3 ${ }^{*} C C 15, \quad T C O M P 3 * C C 15, \quad O A C C T 3 * C C 15$ and $O C O M P 3{ }^{*} C C 15$. I add these variables to Equation (3) and re-run the empirical model, with results presented in Table 12.

With internal control weaknesses and a continuous factor of resource constraints interacted, the first column of results in Table 12 shows that the direct influence of companylevel tax and non-tax ICWs and resource constraints on tax avoidance remains, and in directions that are consistent with prior analysis. TICW3_COMP3 is positive and statistically significant and represents the effect for firms with company-level tax ICWs and a CC15 value equal to zero, which is close to the median value of CC15. Thus on average firms with company-level tax ICWs and intermediate resource constraints have a CASH_ETR5 that is approximately 5 percentage points higher than firms without such ICWs. In addition, the coefficient on the interaction term for $T C O M P 3{ }^{*} C C 15$ is statistically significant and positive, which suggests that CASH_ETR5 increases as firms with company-level tax ICWs become more resourceconstrained. Overall, these combined effects suggest that while resource constraints are an 
important factor in the relation between tax avoidance and material tax ICWs, other components, such as tax risk management, are also factors implicit in tax ICWs.

To provide additional interpretation of the interaction coefficients, I separate CC15 into high, intermediate and low levels of resource constraints using their relative rank across three percentiles and I exclude the intermediate group. The use of three percentiles allows me to identify two relatively "extreme" groups based on resource constraints, and the exclusion of the intermediate group allows me to make a more interpretable, direct comparison between the high and low constraint groups. I include an indicator variable for the high resource constraint condition, and interact the high constraint indicator variable with the ICW variables in a modified regression model. The use of indicator variables aids in the interpretation of the interaction coefficients. The second column of Table 12 shows the results.

This analysis comparing high and low levels of resource constraints provides some interesting insights. First, a significant and negative main effect is estimated for company-level tax ICWs. Second, firms with a high level of resource constraints do not have a statistically different association with $C A S H \_E T R 5$ than firms with a low level of resource constraints, if there are no ICWs. Third, the coefficient on the interaction between company-level tax ICWs and highly constrained resources is positive and significant, with an absolute magnitude larger than the main effect. Results of an F-test demonstrate that the sum of TICW3_COMP3 and TCOMP $3{ }^{*} \mathrm{CC} 15 \_H I G H$ is significantly different from zero (at the $1 \%$ level). These results imply that when firms with company-level tax ICWs have available resources, integrity issues that can manifest in discretionary behaviour may dominate competency issues, such that these firms are able to avoid a higher level of taxes. Furthermore, when firms with company-level tax ICWs 
have significantly constrained resources, they do not appear to have the capacity to plan their taxes strategically, consistent with the primary evidence of this dissertation in Section 5.2.

Reconciling the results in columns one and two, the impact of company-level tax ICWs and higher resource constraints is consistent. In addition, consider the observations in the $5^{\text {th }}$ and $95^{\text {th }}$ percentiles of $C C 15$ from Table 7, which have values of -1 and 1 respectively. Firms in the $5^{\text {th }}$ percentile have low resource constraints and when these firms do not have ICWs, the estimated effect on $C A S H \_E T R 5$ is $-0.076(-1 * 0.076)$. However, when firms in the $5^{\text {th }}$ percentile also have company-level tax ICWs, the estimated effect is -0.150 . Thus firms with low resource constraints and company-level tax ICWs have a CASH_ETR5 value that is 0.074 lower than firms with low resource constraints and no ICWs. ${ }^{30}$ This difference is similar to the -0.083 coefficient on TICW3_COMP3 in column two.

On the other hand, firms in the $95^{\text {th }}$ percentile of $C C 15$ have high resource constraints and when these firms have no ICWs, the estimated effect on $C A S H \_E T R 5$ is 0.076 . When these highly constrained firms also have company-level tax ICWs, the estimated effect is 0.246 , representing a difference of 0.150 between the two groups. ${ }^{31}$ This difference is comparable to the 0.130 difference between the highly constrained group without ICWs and the highly constrained group with company-level tax ICWs in the second column. This estimated difference equals the sum of coefficients TICW3_COMP3, CC15_HIGH and TCOMP $3{ }^{*} C \mathrm{C} 15 \_H I G H$ less the coefficient of $C C 15$ in the second column.

In summary, this analysis of the interaction between internal control weaknesses and resource constraints provides some evidence regarding the individual influence of each set of

\footnotetext{
${ }^{30}$ The estimated effect for firms in the $5^{\text {th }}$ percentile of CC15 that have a company-level tax ICW is equal to [0.048*TICW3_COMP3 $+0.076 *$ CC15 $+0.122 *$ TCOMP3*CC15]. Using summary statistics from Table 7 and coefficients from Table 12, the calculation is $[0.048 * 1-0.076 * 1-0.122 * 1 * 1]=-0.150$.

${ }^{31}$ The estimated effect $0.246=[0.048 * 1+0.076 * 1+0.122 * 1 * 1]$.
} 
variables. Theoretically, the competence of management, i.e. tax risk management and tax planning execution, and the availability of resources have a primary role in the association between tax avoidance and tax ICWs. However, the integrity of management can also have an important theoretical influence on tax avoidance. The empirical evidence in this section directly supports the importance of resource constraints, on average, when all firms from the main sample are included. The combination of significant main effects and interaction effects suggests two contrasting results. One, for firms with the highest constraints, and perhaps firms with intermediate constraints, competency issues can also be an implicit factor in company-level tax ICWs. Two, for firms with low resource constraints, or in other words firms with available resources for tax planning, integrity issues could be an implicit factor in company-level tax ICWs that is associated with lower taxes paid. However, in the absence of suitable proxies it is not possible to comment on the strength of, for example, the risk management component relative to identifiable resource constraints.

\subsubsection{Remediation of Internal Control Weaknesses}

Consistent with the literature review in Sections 2.3 and 2.4 of Chapter 2, the analysis in this section investigates the potentially moderating role of remediation on the association between internal control weaknesses and tax avoidance. My long-run tests to this point in the dissertation have implicitly assumed that the influence of internal control weaknesses extend beyond the current reporting period, hence the use of firm-level measures of ICWs. The resulting evidence so far implies that long-run tax avoidance is typically constrained by these firm-level ICWs.

As a more direct test, I follow the method of Ashbaugh-Skaife et al. (2008) to construct remediation variables for use in firm-year regressions with annual values. I replace the firm-level 
ICW variables in Equations (2) and (3) with a set of within-firm "WEAK" and "FIXED" variables that represent on-going internal control issues and remediated internal control weaknesses, respectively. For example, $W E A K_{-} T A X$ is equal to one if a firm has disclosed an individual tax-related ICW in the current or prior year, and zero otherwise. WEAK_OTHER is measured similarly for firms disclosing on-going other (i.e. non-tax) ICWs. Alternatively, TAX_FIXED is equal to one if a firm has disclosed an individual tax-related ICW in the prior year but has no such ICW present in the current year, and zero otherwise. Again, OTHER_FIXED is measured similarly for non-tax ICWs.

Both sets of these general variables are separated into account-level and company-level components as well. WEAK_TAX_ACCT, WEAK_OTHER_ACCT, TAX_ACCT_FIXED and OTHER_ACCT_FIXED represent the account-level variables for on-going and remediated ICWs, respectively. WEAK_TAX_COMP, WEAK_OTHER_COMP, TAX_COMP_FIXED and OTHER_COMP_FIXED represent the company-level variables for on-going and remediated ICWs, respectively. I expect remediation (i.e. "FIXED”) to have the opposite influence on tax avoidance than the on-going ICWs (i.e. "WEAK”) have.

Table 13 presents the results of this remediation analysis. In Panel A, the regressions use annual, not average, constructs of both the dependent and independent variables. In general, the coefficient estimates for the control variables in both columns are consistent with those reported earlier in the dissertation, both in terms of direction and statistical significance. FOROPS and $B M$ are the only two control variables that are not statistically significant. The first column of results shows that coefficient estimates of WEAK_TAX and WEAK_OTHER are positive and significant and furthermore, TAX_FIXED and OTHER_FIXED are negative and significant. F- 
tests for the sum of the respective coefficients fail to reject the null and thus the "FIXED" variables are equivalent in magnitude to their "WEAK" counterparts.

Turning to the second column in Panel A of Table 13, evidence on remediation is available when the pervasiveness of the ICW is taken into consideration. The company-level variables show a significant association with tax avoidance but the account-level variables do not. The presence of on-going company-level ICWs have a positive association with CASH_ETR, but their remediation has an equal or greater negative association. F-tests for the sum of the coefficients fail to reject the null that the sum is equal to zero. Overall this evidence implies that on-going ICWs, specifically the company-level ICWs, limit tax avoidance, consistent with earlier results, but that remediation appears to completely moderate this relation. Thus firms that remediate their ICWs have a similar level of tax avoidance to those firms that have never reported an ICW.

Although tests that use annual variables are best suited for this remediation analysis, Dyreng et al. (2008) argue that Cash ETR does not provide consistent results as an annual variable, relative to other tax avoidance proxies. With this caveat in mind, I conduct some additional analysis reported in Panels B and C of Table 13. First, I test these regressions using annual BTD1 as the dependent variable and report the results in Panel B. Results for the tax variables are consistent with those reported in Panel A. For the non-tax variables, however, only the coefficient of WEAK_OTHER has a statistically significant association with BTD1 that is different from zero. Second, I examine the overlapping, annual regressions with CASH_ETR5 as the dependent variable and average values of the independent variables, except for the "WEAK" and "FIXED" variables. Results of this test are reported in Panel C. All of the "WEAK" tax variables and WEAK_OTHER_COMP are statistically significant at conventional levels, but only 
the coefficient for TAX_ACCT_FIXED is statistically significant. This result provides some support for the conjecture that remediation can lead to an immediate improvement in planning the current period's taxes paid but that changes to the longer-run, sustainable tax plans require multiple periods to take effect.

In summary, analysis at the annual level provides evidence that remediation of tax and non-tax internal control weaknesses are associated with increases in levels of tax avoidance for firms that previously disclosed such weaknesses. These results suggest that improvements in internal controls, particularly in the tax function, could reflect improvements in tax planning. Additional analysis with overlapping, annual regressions of average variables suggests that it may take a number of periods before this remediation improves long-run tax planning, however.

\subsection{Conclusions}

In summary, evidence presented in this chapter is generally consistent with the view that tax internal control weaknesses, particularly company-level tax internal control weaknesses, constrain long-run tax avoidance. My main analysis shows a positive and statistically significant relation between my Cash ETR proxy of tax avoidance and general and company-level tax internal control weaknesses, implying higher taxes paid for firms with such issues. Companylevel non-tax internal control weaknesses share a similar constraining relation with tax avoidance, potentially suggesting that the same factors that give rise to tax ICWs also contribute to non-tax ICWs.

Sensitivity analysis shows that this main result generally holds across alternative tests. Regressions of overlapping, firm-year observations of average data and annual, firm-year observations of an alternative, book-tax difference proxy of tax avoidance show similar results. Furthermore, consistent results are found when alternative classification methods for aggregating 
internal control weaknesses are used, when measures of corporate governance are included in my empirical regressions, or when resource constraint variables derived from factor analysis are included in my regressions. However, not all of my results are consistent with my primary analysis. A second alternative book-tax difference proxy of tax avoidance does not show a significant relation with company-level tax ICWs. In addition, analysis of the interaction between resource constraints and internal control weaknesses suggest that for firms with low constraints and company-level tax ICWs, higher levels of tax avoidance can occur. This result could relate to the arguments regarding discretionary behaviour in Chapter 3, which also contrasts with the argument that firms with tax ICWs pay higher taxes because management's increased attempts at discretionary tax planning are unsuccessful.

Finally, my analysis of remediation provides some interesting results. On the one hand, in panel regressions with annual variables, including annual Cash ETR, I show that firms that subsequently remediate their tax-related internal control weaknesses have higher levels of tax avoidance in the year following the disclosed internal control weakness. This result is corroborated with tests using a book-tax difference proxy of tax avoidance. On the other hand, in overlapping, annual regressions of average variables and annual internal control weaknesses, I find a positive relation between Cash ETR and the disclosure of tax-related internal control weaknesses, but no relation between Cash ETR and remediated tax-related internal control weaknesses. Such evidence implies that remediation can lead to improvements in short-run tax planning, but, as my main tests suggest, improvements in long-run tax planning require more time and effort. 


\section{CHAPTER 6}

\section{EMPIRICAL ANALYSIS - STOCK RETURNS AND THE INFLUENCE OF TAX AVOIDANCE AND INTERNAL CONTROL QUALITY}

\subsection{Introduction}

In this chapter, I test my fourth and fifth hypotheses and thus investigate the empirical

relation between shareholder returns and the interaction of aggressive tax avoidance and company-level tax internal control weaknesses. I empirically examine Equation (4) of Section 4.6 of this dissertation using cross-sectional analysis of my tax avoidance and internal control weakness proxies and monthly Fama-French (1993) factors during my primary 2004-2006 sample period. My primary analysis includes ranking of in-sample and out-of-sample values of my Cash ETR tax avoidance proxy to determine a set of tax aggressive firms.

In supplemental tests in this chapter I test the sensitivity of this empirical analysis to alternative methods. These methods include estimation of regressions with general internal control weakness variables, regressions of values obtained from the twelve months preceding and following my 2004-2006 sample period, and ranking of alternative annual tax avoidance proxies. This chapter includes four sections, including this introduction and a conclusion.

Section 6.2 of this chapter presents brief descriptive statistics relevant to my primary tests of Hypotheses 4 and 5 and provides the main table of analysis, Table 15. Section 6.3 provides several additional regressions with multiple internal control weakness classifications, alternative sample periods, and ranking of alternative tax avoidance proxies Section 6.4 concludes this chapter. 


\subsection{Hypothesis Tests $-\mathrm{H} 4$ and $\mathrm{H5}$}

Table 14 provides summary statistics for the new variables of interest that are empirically examined in this chapter. In Panel A, similar to the panels in Table 7, I provide the mean, standard deviation, median and fifth and ninety-fifth percentiles of the sample firms' monthly abnormal returns and Fama-French factors. In Panel B, I provide cut-off values for the subsequent construction of tax aggressiveness variable $T A G$ and the respective quintile ranking of its tax avoidance proxies. Recall that for Cash ETR proxies, firms ranked below the smallest cut-off value are considered tax aggressive, and for BTD and tax shelter proxies, firms ranked above the largest cut-off value are considered tax aggressive.

Table 15 contains the primary results of the test used to investigate Hypotheses 4 and 5 . Recall that, in the null, Hypothesis 4 predicts that firms with tax-related ICWs will show a weakly positive association with abnormal returns, and Hypothesis 5 predicts that if Hypothesis 4 is rejected, the association is less negative for firms that are tax aggressive. Both of Panels A and B of Table 15 contain three columns. In the first two columns, the tax aggressiveness and internal control weakness variables are based on firm-level average values of CASH_ETR5 and TICW3_COMP3, respectively. In column one, the ranking of CASH_ETR5 relies on the 20042006 firm-level values that are analyzed in the main tests of Chapter 5 (see Section 5.2). In column two, the quintile ranking of tax aggressiveness $(T A G)$ relies on the firm-level values of CASH_ETR5 that are constructed at the end of the 2003 fiscal period, and thus TAG is based on out-of-sample values of CASH_ETR5. In column three, the tax aggressiveness and internal control weakness variables use annual values of $C A S H \_E T R$ and $T I C W \_C O M P$, respectively, constructed during the sample period 2004-2006. In Panel A, Equation (4) is empirically

estimated as shown in Section 4.6. In Panel B, TICWC (i.e. TICW3_COMP3), TAG and their 
interaction variable are substituted into the model as an alternative presentation of the groupwise comparison implicit in Equation (4).

The results are generally consistent across the three columns in Panel A of Table 15. The coefficient on $T I C W C^{*} T A G$ is negative and statistically significant in the first column, which suggests that, to the detriment of shareholders, tax aggressive firms with a weak set of internal controls underperform their tax aggressive, strong internal control counterparts. The coefficient of TICSC*NON_TAG is negative and statistically significant in all of the columns and the coefficient of $T I C W C^{*} N O N_{-} T A G$ is negative and statistically significant across all columns. These results suggest that firms that are not tax aggressive, regardless of internal control quality, underperform relative to the tax aggressive firms with strong internal control quality.

Related specifically to Hypothesis 4, the negative and statistically significant coefficients on both $T I C W C^{*} T A G$ and $T I C W C^{*} N O N \_T A G$ in column one imply that tax-related companylevel ICWs are negatively associated with shareholder returns, rejecting the null form of Hypothesis 4. As reported in Table 15, an F-test for the joint significance of TICWC*TAG and $T I C W C^{*} N O N_{-} T A G$ is rejected at the $5 \%$ level or better across the three columns. In regards to Hypothesis 5, the magnitude of the coefficients on TICWC*TAG and on TICWC*NON_TAG do not appear much different from one another. An F-test for the equality of $T I C W C^{*} T A G$ and TICWC*NON_TAG is not rejected at conventional levels in any of the three columns of Table 15. Overall, these results do not provide support to reject Hypothesis 5, implying that the negative association between returns and tax-related company-level ICWs is not different in the presence of tax aggressiveness.

The results in Panel B of Table 16 corroborate those of Panel A. The coefficient of TICWC is consistently negative and statistically significant across the three columns of Panel B, 
providing direct evidence to reject the null of Hypothesis 4. The interaction coefficient of $T I C W C^{*} T A G$ is not statistically significant, and thus this test fails to reject Hypothesis 5. TAG is positive and statistically significant in all three columns, implying a positive influence of tax aggressiveness on shareholder returns in this sample of firms.

In summary, the results in Table 15 consistently support a negative association between tax-related ICWs and stock returns. Although these results reject the null form of Hypothesis 4, they do not provide support to reject the null form of Hypothesis 5. Thus the empirically determined negative association between stock returns and company-level tax ICWs does not appear to differ when firms are tax aggressive relative to when they are not tax aggressive.

\subsection{Robustness Checks and Additional Analysis}

\subsubsection{Alternative Internal Control Weakness Variables and Alternative Sample Periods}

In Table 16, the analyses of firm-level values that are reported in columns one and two of Table 15 are replicated with general ICWs (tax and non-tax combined; columns one and two) and general tax-related ICWs (account-level and company-level combined; columns three and four) replacing company-level tax ICWs. The results across the two tables are consistent with one another and thus also lend support to reject Hypothesis 4. F-tests for joint significance of TICWC*TAG and TICWC*NON_TAG continue to reject the null in this table. However, although $T I C W C^{*} T A G$ is typically negative in Table 16 , again, F-tests for equality between $T I C W C^{*} T A G$ and $T I C W C^{*} N O N \_T A G$ do not reject the null.

In addition to rejecting the null form of Hypothesis 4, the negative association between general ICWs and stock returns in Table 16 is consistent with evidence in Hammersley et al. (2008) and Beneish et al. (2008) that is based on the use of daily metrics. However, both of these prior studies show negative market reactions or stock returns that are associated with SOX 302 
disclosures. Furthermore, Beneish et al. (2008) fail to find an association for SOX 404 disclosures, whereas my analysis suggests that there is indeed a downward market valuation that is correlated with ICWs disclosed under SOX 404. Finally, given the consistent results in Table 15 with company-level tax ICWs and Table 16 with general tax and non-tax ICWs, the influence of internal control weaknesses on stock returns appears to be related to the specific impact of those weaknesses that exist at the company-level. Such evidence corroborates the relations I study and report in Chapter 5.

I also attempt to show that my findings are not the result of a correlated omitted variable by investigating the abnormal returns in the twelve months preceding and the twelve months following my sample period. The related tests rely on the out-of-sample construction of CASH_ETR5 and firm-level construction of TICW3_COMP3. The results are presented in Table 17. Overall, this evidence does not support the rejection of Hypotheses 4 or 5 , or my aforementioned results. The coefficient of $T I C W C^{*} T A G$ appears positive, not negative, and statistically significant only in the twelve months preceding my sample period. No other interaction coefficients are statistically significant in either column of the table. A partial explanation for these results is that prior to 2004, internal control disclosures are not mandatory and investors would have little public information with which to determine a firm's internal control quality and thus assess the firm's performance on this dimension.

In summary, the results in Table 16, with general ICWs and general tax ICWs, corroborate the negative association between company-level tax ICWs and stock returns identified in the previous section and further suggest that the company-level ICWs are the issues that influence this association. Although these results also provide support to reject the null form of Hypothesis 4, they do not provide support to reject the null form of Hypothesis 5. In addition, 
the analysis of the twelve month periods preceding and following the ICW disclosure period of 2004-2006 does not reject either of the two hypotheses tested in this Chapter.

\subsubsection{Alternative Tax Avoidance Proxies}

In Equation (4), $T A G$ represents tax aggressiveness and is calculated by ranking CASH_ETR5 into quintiles; firms ranked in the lowest quintile are considered to be tax aggressive. As an alternative to $C A S H \_E T R 5$, in this subsection I rank two other annual tax avoidance proxies. The first is BTD1, as described in subsection 5.3.2.1, and the second is PROB_TS. PROB_TS represents the probability between zero and one that a firm is involved in a tax shelter and is calculated using the tax shelter prediction model created by Wilson (2009). The probability is estimated as follows:

$$
\text { PROB_TS }=e^{(T S)} /\left(1+e^{T S)}\right)
$$

To calculate the predicted tax shelter estimate $T S$, I multiply estimated coefficients (i.e. b ${ }_{\mathrm{k}}$ 's) from Wilson's Table 5 (2009, p.988) by my sample firm characteristics in the following model.

$$
\begin{aligned}
& T S_{i t}=-4.86+5.20 * B T D 1_{i t}+4.08 * D A P_{i t}-1.41 * L E V_{i t}+0.76 * S I Z E_{i t}+3.51 * R O A_{i t}+ \\
& 1.72 * F O R O P S_{i t}+2.43 * R \& D_{i t}
\end{aligned}
$$

Where:

$T S_{i t}=$ the predicted tax shelter estimate for firm $i$ in current year $t$;

$B T D 1_{i t}=$ the Manzon-Plesko (2002) book-tax difference as described in subsection 5.3.2.1;

$D A P_{i t}=$ the performance-adjusted discretionary accruals measure based on the modified-Jones model as described below;

$L E V_{i t}=$ leverage for firm $i$, measured as long-term debt at year $t$ scaled by lagged assets;

$S I Z E_{i t}=$ the natural logarithm of firm $i$ 's assets as measured at $t-1$; 
$R O A_{i t}=$ the Return on Assets for firm $i$ in year $t$, measured as operating income scaled by lagged assets;

$F O R O P S_{i t}=$ an indicator variable equal to one if foreign income for firm $i$ in year $t$ is non-zero or non-missing, zero otherwise;

$R \& D_{i t}=$ the research and development expense for firm $i$ in year $t$ scaled by lagged assets.

I calculate $D A P$ as the performance-matched discretionary accruals measure of financial reporting aggressiveness consistent with Kothari, Leone and Wasley (2005) and Frank et al. (2009a). This measure requires calculation of discretionary accruals, which I base on the modified-Jones model (Dechow, Sloan and Sweeney, 1995). First, I estimate total accruals (TACC) using the following model by two-digit NAICS code and fiscal year, where all variables (including the intercept) are scaled by lagged total assets.

$$
T A C C_{i t}=\beta_{0}+\beta_{1}\left(\Delta R E V_{i t}-\Delta A R_{i t}\right)+\beta_{2} P P E_{i t}+\mu_{i t}
$$

Where:

$T A C C_{i t}=\left[I B C_{i t}+T X T_{i t}-\left(A D J O C F_{i t}-X I D O C_{i t}\right)\right]$

$I B C_{i t}=$ income before extraordinary items for firm $i$ from the statement of cash flows in year $t$;

$T X T_{i t}=$ total tax expense for firm $i$ in year $t$;

$A D J O C F_{i t}=$ operating cash flows less taxes paid from the statement of cash flows for firm $i$ in year $t$;

$X I D O C_{i t}=$ extraordinary items and discontinued operations from the statement of cash flows for firm $i$ in year $t$;

$\triangle R E V_{i t}=$ firm $i$ 's sales in year $t$ less its sales in year $t-1$;

$\Delta A R_{i t}=$ firm $i$ 's total receivables in year $t$ less its total receivables in year $t-1$;

$P P E 5_{i t}=$ the property, plant and equipment of firm $i$ at the end of year $t$;

$\mu_{i t}=$ the unadjusted discretionary accruals measure of firm $i$ in year $t$, a residual value. 
Second, after estimating the discretionary accruals residual $\mu$ from Equation (7) I rank $R O A$ by industry-year into deciles and determine the median discretionary accrual value. ${ }^{32}$ I then subtract the median industry-year-ROA_decile discretionary accrual value from each firm's residual value to get the performance-matched discretionary accrual measure $D A P{ }^{33}$ Thus $D A P$ is an annual value calculated for each firm-year in my sample. ${ }^{34}$

Table 18 presents the results of estimating Equation (4) with each of BTD1 and $P R O B \_T S$. These two additional proxies are firm-year measures and therefore I rely on insample values of each measure. Like prior tables in this Chapter, the intercept is positive and the coefficient on $T I C W C^{*} N O N \_T A G$ is negative (both coefficients are significant at the $1 \%$ level) in column one of Table 18. However, the coefficient for $T I C W C^{*} T A G$ is statistically insignificant. Despite this insignificant coefficient, an F-test for joint significance between $T I C W C^{*} T A G$ and $T I C W C^{*} N O N \_T A G$ is rejected, providing some, albeit weaker, evidence to reject the null form of Hypothesis 4 when BTD1 substitutes as a proxy for tax avoidance. The results in column one do not support a rejection of Hypothesis 5. In addition, the results in column two of Table 18 with PROB_TS are not consistent with either alternative forms of Hypothesis 5. Although the intercept is statistically significant, and positive, none of the interaction coefficients or the F-tests are statistically significant at conventional levels.

\footnotetext{
32 The individual discretionary accrual values are set to missing if there are less than 10 observations in the respective industry-year group.

${ }^{33}$ I adjust the median values of each industry-year-ROA_decile group such that no median value is calculated while including the specific firm-year observation for which I am estimating $D A P$.

${ }^{34}$ Using the estimated coefficients from Wilson's (2009) prediction model I am likely to induce some imprecision in my final $D A P$ estimates, particularly since his model is estimated based on 33 tax shelter firms. Wilson's (2009) tax shelter firms have a mean, median and standard deviation of $D A P$ of $-0.01,-0.01$ and 0.04 , respectively. My sample firms, after rounding, have a mean, median and standard deviation of $D A P$ of $-0.001,0.000$ and 0.059 , respectively.
} 


\subsection{Conclusions}

In summary, evidence presented in this chapter is typically consistent with the view that company-level tax internal control weaknesses are negatively associated with shareholder returns. Contrary to arguments in Chapter 3, however, this negative association does not appear to increase for firms that are also tax aggressive. Thus firms with weak tax-related internal controls create less wealth for shareholders than tax aggressive firms with strong internal controls, regardless of the level of tax aggressiveness in the weak internal control firms.

Sensitivity analysis shows that this main result holds when general internal control weaknesses or general tax internal control weaknesses substitute for company-level tax internal control weaknesses. Tests with alternative, annual measures of tax aggressiveness find weak evidence to support these results. Furthermore, examining the twelve month periods before and after my primary 2004-2006 sample period does not provide evidence consistent with the primary analysis of this chapter. 


\section{CHAPTER 7}

\section{CONCLUSION}

In this dissertation I investigate the association between internal control mechanisms and the capacity for strategic tax planning and how these concepts interact to influence stock performance. The requirements of SOX 404 provide a unique opportunity to examine publiclyavailable firm-level disclosures of internal control quality and its relation with tax avoidance. Tax-related internal control weaknesses are frequently disclosed in SOX 404 reports, indicating that many firms appear to struggle with their tax function and as I argue, their tax planning.

Using a firm-level sample of observations from the 2004-2006 post-SOX period, I first examine the relation between long-run tax avoidance and hand-collected tax and non-tax ICW disclosures. I demonstrate that lower levels of tax avoidance occur in the presence of general taxrelated ICWs. Furthermore, pervasive, company-level ICWs - both tax and non-tax - appear to drive this relation and account-level ICWs, as expected, are not associated with tax avoidance. Supplemental factor analysis indicates that tax ICWs reflect resource constraint issues as well as other problems, such as tax risk management issues, but also that firms with tax ICWs and low resource constraints avoid more tax than firms without ICWs. Further supplemental analysis provides some evidence that subsequent to remediating ICWs, firms report higher levels of tax avoidance, consistent with an improvement in their capacity for tax planning. Overall, these results are consistent with disclosed ICWs in the tax function signaling issues beyond financial reporting. Specifically, the evidence is generally consistent with weaker strategic tax planning for firms with tax ICWs such that in the long-run these firms avoid less tax than firms that do not report any ICWs. 
My analysis of monthly abnormal stock return performance supports these results. Firms that have pervasive tax ICWs underperform tax aggressive firms without ICWs. Thus strong internal governance coupled with tax aggressiveness generates wealth for shareholders. However, I do not find evidence that this underperformance by firms with tax ICWs is greater for firms that are also tax aggressive.

My dissertation is informative to the extant literature of both internal control quality and tax avoidance; I believe it also helps to bridge these two literatures. I corroborate prior research (e.g. Doyle et al., 2007a \& 2007b; Hammersley et al., 2008) and show that the type of disclosed ICW matters. ICWs that are less pervasive are not significant in my tests but the pervasive ICWs that "call into question management's ability to govern its operations" (Doyle et al., 2007a, p.196) lead to important inferences about tax avoidance in my study, as they lead to important inferences in other areas of the prior literature. Furthermore, many studies examine the influence of external corporative governance on tax avoidance (e.g. Desai and Dharmapala, 2006; Wilson, 2009). In this dissertation, I demonstrate how internal governance mechanisms play a key underlying role in the ability of firms to avoid taxes. 


\section{REFERENCES}

American Institute of Certified Public Accountants. 1988. Consideration of the Internal Control Structure in a Financial Statement Audit. Statement on Auditing Standards No. 55. New York, NY: AICPA.

American Institute of Certified Public Accountants. 1995. Consideration of Internal Control in a Financial Statement Audit: An Amendment to Statement on Auditing Standards No. 55. Statement on Auditing Standards No. 78. New York, NY: AICPA.

Arlinghaus, B. P. 1998. "Goal setting and performance measures." Tax Executive 50(6):434.

Ashbaugh-Skaife, H., D. Collins and W. Kinney Jr. 2007. "The discovery and reporting of internal control deficiencies prior to SOX-mandated audits." Journal of Accounting \& Economics 44(1/2):166.

Ashbaugh-Skaife, H., D. Collins, W. Kinney Jr. and R. LaFond. 2008. "The Effect of SOX Internal Control Deficiencies and Their Remediation on Accrual Quality." The Accounting Review 83(1):217.

Ayers, B., J. Jiang and S. Laplante. 2009. "Taxable Income as a Performance Measure: The Effects of Tax Planning and Earnings Quality." Contemporary Accounting Research 26(1):1.

Bedard, J. and L. Graham. 2011. "Deficiencies in Tax-Related Internal Controls Detected Under Sarbanes-Oxley Section 404.” Working paper, Bentley University.

Bedard, J., R. Hoitash and U. Hoitash. 2009. "Evidence from the United States on the Effect of Auditor Involvement in Assessing Internal Control over Financial Reporting.” International Journal of Auditing 13(2):105.

Beneish, M., M. Billings and L. Hodder. 2008. “Internal Control Weaknesses and Information Uncertainty.” The Accounting Review 83(3): 665.

Blouin, J., C. Gleason, L. Mills and S. Sikes. 2007. "What Can We Learn about Uncertain Tax Benefits from FIN 48?” National Tax Journal 60(3): 521.

Blouin, J., and I. Tuna. 2007. “Tax contingencies: Cushioning the blow to earnings?” Working paper, University of Pennsylvania. 
Boritz, E., L. Hayes and J. Lim. 2010. “What do Auditor’s Reports on Internal Control tell us about IT Control Weaknesses in Financial Reporting Systems?” Working paper, University of Waterloo.

Calegari, M. J. 2000. "The effect of tax accounting rules on capital structure and discretionary accruals.” Journal of Accounting \& Economics 30(1): 1.

Chan, K., B. Farrell and P. Lee. 2008. "Earnings Management of Firms Reporting Material Internal Control Weaknesses under Section 404 of the Sarbanes-Oxley Act." Auditing 27(2):161.

Chen, S., X. Chen, Q. Cheng and T. Shevlin. 2010. "Are family firms more tax aggressive than nonfamily firms?" Journal of Financial Economics 95(1):41.

Cook, K., G. Huston and T. Omer. 2008. "Earnings Management through Effective Tax Rates: The Effects of Tax Planning Investment and the Sarbanes-Oxley Act of 2002." Contemporary Accounting Research 25(2):4.

Cremers, K. J. M. and Vinay B. Nair. 2005. "Governance Mechanisms and Equity Prices." The Journal of Finance 60(6):2859.

Dechow, P. M., R. G. Sloan and A. P. Sweeney. 1995. “Detecting earnings management.” The Accounting Review 70(2):193.

Deloitte Development LLC. 2011. "Material weakness and restatements: Is tax still in the hot seat?”

Desai, M. A. and D. Dharmapala. 2006. "Corporate tax avoidance and high-powered incentives." Journal of Financial Economics 79(1):145.

Dhaliwal, D., C. Gleason and L. Mills. 2004. "Last-Chance Earnings Management: Using the Tax Expense to Meet Analysts' Forecasts*." Contemporary Accounting Research 21(2):431.

Doss, M., and G. Jonas. 2004. Section 404 reports on internal control: Impact on ratings will depend on nature of material weaknesses reported. Moody’s Investors Service, Global Credit Research (October). New York, NY: Moody’s.

Doyle, J., W. Ge and S. McVay. 2007. "Determinants of weaknesses in internal control over financial reporting." Journal of Accounting \& Economics 44(1/2):193. 
Doyle, J., W. Ge and S. McVay. 2007. "Accruals Quality and Internal Control over Financial Reporting." The Accounting Review 82(5):1141.

Dyreng, S., M. Hanlon and E. Maydew. 2008. "Long-Run Corporate Tax Avoidance." The Accounting Review 83(1):61.

Dyreng, S., M. Hanlon and E. Maydew. 2010. “The Effects of Executives on Corporate Tax Avoidance.” The Accounting Review 85(4): 1163.

Elder, R. J., D. G. Harris and J. Zhou. 2008. “Tax Consulting and Reported Weaknesses in Internal Control.” Working paper, Syracuse University.

Elgood, T. 2006. “Tax-risk policy.” International Tax Review Special Supplement: Tax Management in Companies 14.

European Audit Committee Leadership Network. 2005. “The future of internal audit in Europe / Tax governance." ViewPoints 5: 1 . Available at http://www.tapestrynetworks.com/networks/net_european.html.

Fama, E. F. 1980. "Agency Problems and the Theory of the Firm." The Journal of Political Economy 88(2):288.

Fama, E. F. and K. R. French. 1993. "Common risk factors in the returns on stocks and bonds." Journal of Financial Economics 33(1):3.

Fama, E. F. and M. C. Jensen. 1983. "Separation of Ownership and Control." Journal of Law and Economics 26(2):301.

Feng, M., C. Li and S. McVay. 2009. “Internal Control and Management Guidance.” Journal of Accounting \& Economics 48 (2/3):190.

Frank, M., L. Lynch and S. Rego. 2009. "Tax Reporting Aggressiveness and Its Relation to Aggressive Financial Reporting." The Accounting Review 84(2):467.

Frank, M., L. Lynch and S. Rego. 2009. “Are Aggressive Reporting Practices Associated with Other Aggressive Corporate Policies?” Working paper, University of Virginia and University of Iowa. 
Ge, W. and S. McVay. 2005. "The Disclosure of Material Weaknesses in Internal Control after the Sarbanes-Oxley Act." Accounting Horizons 19(3):137.

Gleason, C. and L. Mills. 2002. "Materiality and contingent tax liability reporting." The Accounting Review 77(2):317.

Gleason, C. and L. Mills. 2007. “Do Auditor-Provided Tax Services Improve the Estimate of Tax Expense?” Working paper, University of Iowa and The University of Texas at Austin.

Gleason, C., M. Pincus and S. Rego. 2010. “Consequences of Material Weaknesses in Tax-Related Internal Controls for Financial Reporting: Earnings Management and Earnings Predictability.” Working paper, University of Iowa and University of California, Irvine.

Gompers, P., J. Ishii and A. Metrick. 2003. "Corporate governance and equity prices." The Quarterly Journal of Economics 118(1):107.

Graham, J. 2008. Taxes and corporate finance. In Eckbo, E., (Ed.). Handbook of Corporate Finance; Empirical Corporate Finance Amsterdam: Elsevier Science.

Gupta, S. and R. Laux. 2008. “Do Firms Use Tax Cushion Reversals to Meet Earnings Targets?” Working paper, Michigan State University and University of Illinois.

Gupta, S. and K. Newberry. 1997. "Determinants of the variability in corporate effective tax rates: Evidence from longitudinal data." Journal of Accounting and Public Policy 16(1):1.

Hammersley, J. S., L. A. Myers and C. Shakespeare. 2008. " Market reactions to the disclosure of internal control weaknesses and to the characteristics of those weaknesses under section 302 of the Sarbanes Oxley Act of 2002." Review of Accounting Studies 13(1):141.

Hanlon, M. and J. B. Slemrod. 2009. "What Does Tax Aggressiveness Signal? Evidence from Stock Price Reactions to News About Tax Aggressiveness." Journal of Public Economics 93(1-2): 126.

Hanlon, M. and S. Heitzman. 2010. “A Review of Tax Research.” Journal of Accounting \& Economics 50(2/3):127.

Healy, P. 1985. “The effect of bonus schemes on accounting decisions.” Journal of Accounting and Economics 7: 85. 
Kothari, S. P., A. J. Leone and C. E. Wasley. 2005. "Performance matched discretionary accrual measures.” Journal of Accounting \& Economics 39(1):163.

Larcker, D. F., S. A. Richardson and I. Tuna. 2007. "Corporate Governance, Accounting Outcomes, and Organizational Performance." The Accounting Review 82(4):963.

Manzon, G. and G. Plesko. 2002.”The relation between financial and tax reporting measures of income.” Tax Law Review 55: 175.

Maydew, E., and D. Shackelford. 2007. “The changing role of auditors in corporate tax planning.” In Taxing Corporate Income in the 21st Century, edited by Auerbach, A. J., J. R. Hines, Jr., and J. B. Slemrod. Cambridge, U.K.: Cambridge University Press.

McGill, G. A. and E. Outslay. 2004. "Lost in Translation: Detecting Tax Shelter Activity in Financial Statements.” National Tax Journal 57(3): 739.

Mills, L., M. Erickson and E. Maydew. 1998. "Investments in tax planning." The Journal of the American Taxation Association 20(1):1.

Petersen, M. A. 2009. “Estimating Standard Errors in Finance Panel Data Sets: Comparing Approaches.” The Review of Financial Studies 22(1): 435.

PricewaterhouseCoopers. 2004. Tax risk management. London: PWC.

Quimby, L., and J. Pearce. 2006. “Lessons learned from SOX 404.” International Tax Review Special Supplement: Tax Management in Companies 26.

Rego, S. 2003. "Tax-Avoidance Activities of U.S. Multinational Corporations." Contemporary Accounting Research 20(4):805.

Rego, S. and R. Wilson. 2010. “Executive Compensation, Equity Risk Incentives, and Corporate Tax Aggressiveness.” Working paper, University of Iowa.

Robinson, J., S. Sikes and C. Weaver. 2010. "Performance Measurement of Corporate Tax Departments.” The Accounting Review 85(3): 1035. 
Scholes, M. and M. Wolfson. 1992. Taxes and Business Strategy: A Planning Approach, first ed. Pearson Prentice Hall, Upper Saddle River, NJ.

Scholes, M., M. Wolfson, M. Erickson, E. Maydew and T. Shevlin. 2009. Taxes and Business Strategy: A Planning Approach, fourth ed. Pearson Prentice Hall, Upper Saddle River, NJ.

Shackelford, D. and T. Shevlin. 2001. "Empirical tax research in accounting." Journal of Accounting \& Economics 31(1-3):321.

U.S. Congress, Joint Committee on Taxation. 2003. Report of Investigation of Enron Corporation and Related Entities Regarding Federal Tax and Compensation Issues, and Policy Recommendations, Volumes I-III. JCS-3-03. GAO-03-138. Washington, D.C.: U.S. Government Printing Office.

Wilson, R. 2009. "An Examination of Corporate Tax Shelter Participants." The Accounting Review 84(3): 969.

Wolfe, C. J., E. G. Mauldin, and M. C. Diaz. 2009. “Concede or deny: Do management persuasion tactics affect auditor evaluation of internal control deviations?” The Accounting Review 84(6): 2013.

Wunder, H. 2009. "Tax risk management and the multinational enterprise." Journal of International Accounting Auditing \& Taxation 18(1):14.

Zimmerman, J. L. 1983. "Taxes and Firm Size." Journal of Accounting \& Economics 5(2):119. 


\section{APPENDIX A \\ Doyle eT AL. (2007A) MATERIAL WeAKNess Classification SchEME}

\section{Account-Specific Material Weaknesses}

1. Inadequate internal controls for accounting for loss contingencies, including bad debts

2. Deficiencies in the documentation of a receivables securitization program

3. No adequate internal controls over the application of new accounting principles or the application of existing accounting principles to new transactions

\section{Company-Level Material Weaknesses}

1. Override by senior management

2. Ineffective control environment 


\section{APPENDIX B}

\section{MATERIAL WEAKNESS ClASSIFICATION SCHEME (BASED ON HAMMERSLEY ET}

AL., 2008)

\begin{tabular}{|c|c|c|}
\hline Disclosure auditability categories & & \\
\hline & $\begin{array}{l}\text { Number of } \\
\text { weaknesses }\end{array}$ & $\begin{array}{l}\% \text { of } \\
\text { weaknesses }\end{array}$ \\
\hline \multicolumn{3}{|l|}{ A. Less auditable disclosure categories } \\
\hline \multicolumn{3}{|l|}{ 1. Weaknesses in key personnel } \\
\hline a. Lack of key personnel—CFO, controller, etc. & 9 & 1.1 \\
\hline b. Evidence of management override of controls or integrity issues & 5 & 0.6 \\
\hline \multicolumn{3}{|l|}{ 2. Financial reporting weaknesses } \\
\hline a. Problems with financial statement closing procedures & 16 & 2.0 \\
\hline \multicolumn{3}{|l|}{ 3. Control environment weaknesses } \\
\hline $\begin{array}{l}\text { a. Internal control weaknesses that are red flags for fraud or that } \\
\text { allowed fraud to occur }\end{array}$ & 15 & 1.8 \\
\hline $\begin{array}{l}\text { b. Insufficient documentation or policies to support transactions or } \\
\text { adjusting entries }\end{array}$ & 47 & 5.8 \\
\hline $\begin{array}{l}\text { c. Inadequate lines of communication between management and } \\
\text { accounting staff and/or auditors that prevent transactions from } \\
\text { being recorded correctly. }\end{array}$ & 15 & 1.8 \\
\hline d. Insufficient risk assessment policies* & N/A & N/A \\
\hline Total less auditable weaknesses & 107 & 13.1 \\
\hline \multicolumn{3}{|l|}{ B. More auditable disclosure categories } \\
\hline \multicolumn{3}{|l|}{ 1. Personnel weaknesses } \\
\hline a. Lack of technical knowledge of FAS or SEC filing requirements & 36 & 4.4 \\
\hline $\begin{array}{l}\text { b. Lack of quality corporate governance-Audit committee, BOD, } \\
\text { etc. }\end{array}$ & 5 & 0.6 \\
\hline c. Inadequate training & 14 & 1.7 \\
\hline d. Staffing limitations and lack of resources at lower level & 52 & 6.5 \\
\hline e. Lack of internal audit function or other monitoring & 16 & 2.0 \\
\hline \multicolumn{3}{|l|}{ 2. Control system weaknesses } \\
\hline a. Inadequate or lack of timely review & 60 & 7.3 \\
\hline b. Incomplete account analysis & 17 & 2.1 \\
\hline c. Untimely preparation of account reconciliations & 44 & 5.4 \\
\hline d. Inadequate controls over non-routine transactions & 14 & 1.7 \\
\hline e. Lack of discipline around financial reporting & 6 & 0.7 \\
\hline f. Approval procedures not followed & 2 & 0.2 \\
\hline g. Other procedures not followed & 1 & 0.1 \\
\hline h. Inadequate general computer controls & 5 & 0.6 \\
\hline i. Poor segregation of duties & 44 & 5.1 \\
\hline j. Inadequate access security & 21 & 2.6 \\
\hline k. Other IT weaknesses & 23 & 2.8 \\
\hline 1. Lack of documentation of control procedures & 29 & 3.7 \\
\hline m. Lack of documentation of IT systems & 8 & 1.0 \\
\hline n. Multiple systems or platforms are in use increasing complexity & 9 & 1.1 \\
\hline o. Use of and lack of control over spreadsheets & 8 & 1.0 \\
\hline p. Use of and lack of control over manual systems & 9 & 1.1 \\
\hline
\end{tabular}




\begin{tabular}{|c|c|c|}
\hline & $\begin{array}{l}\text { Number of } \\
\text { weaknesses }\end{array}$ & $\begin{array}{l}\text { \% of } \\
\text { weaknesses }\end{array}$ \\
\hline \multicolumn{3}{|l|}{ 3. Transaction accounting weaknesses } \\
\hline a. Revenue recognition & 51 & 6.4 \\
\hline b. Expense recognition & 14 & 1.7 \\
\hline c. Accounts receivable & 7 & 0.9 \\
\hline d. Tax accounting & 21 & 2.6 \\
\hline e. Inventory accounting & 25 & 3.1 \\
\hline f. Debt covenants & 2 & 0.2 \\
\hline g. Consolidation & 15 & 1.8 \\
\hline h. Fixed assets & 13 & 1.6 \\
\hline i. Stock-based compensation & 9 & 1.1 \\
\hline j. Fair value accounting & 3 & 0.4 \\
\hline k. Foreign currency & 3 & 0.4 \\
\hline 1. Goodwill & 2 & 0.2 \\
\hline m. Patents and other intangibles & 4 & 0.5 \\
\hline n. Software development & 4 & 0.5 \\
\hline o. Accruals & 16 & 2.0 \\
\hline p. Minority interest & 2 & 0.2 \\
\hline q. Deferred revenue & 1 & 0.1 \\
\hline r. Other assets & 5 & 0.6 \\
\hline s. Earnings per share & 1 & 0.1 \\
\hline t. Accounts payable & 3 & 0.4 \\
\hline u. Payroll & 2 & 0.2 \\
\hline v. Subsidiaries and related parties & 7 & 0.9 \\
\hline w. Oil and gas reserves & 4 & 0.5 \\
\hline x. Loans & 6 & 0.7 \\
\hline y. Leases & 3 & 0.4 \\
\hline z. Cash & 3 & 0.4 \\
\hline aa. Stock issuance & 4 & 0.5 \\
\hline bb. Pension & 2 & 0.2 \\
\hline 4. Lack of control over routine transactions & 7 & 0.9 \\
\hline Total more auditable weaknesses & 662 & 81.2 \\
\hline C. Not enough information disclosed to categorize & 46 & 5.7 \\
\hline
\end{tabular}

* Category per Moody's Investors Service (Doss and Jonas 2004); added by author. 


\section{APPENDIX C \\ EXAMPLES OF TAX-RELATED MATERIAL WEAKNESS DisClOSURES}

\section{Account-Specific Examples}

\section{Intermet Corp}

[W] conducted an assessment of the effectiveness of internal control over financial reporting as of December 31, 2004...adjustments were detected during the year-end audit process that resulted in a revision of income tax expense and accrued income tax liabilities related to the conversion of foreign entity financial statements from local GAAP to United States GAAP during the consolidation process and entries related to the write-off of capitalized debt issuance costs associated with our outstanding senior notes as required by applicable accounting guidance for companies in Chapter 11 bankruptcy proceedings.

\section{The Pep Boys - Manny, Moe \& Jack}

This material weakness, originally determined in the second quarter of fiscal 2007, resulted in errors in our supplemental guarantor information note and statements of cash flows presentation, for which previously issued annual and interim financial statements were restated, an error in the recording of our third quarter fiscal 2007 impairment charge for our store closures and an error in its analyses and documentation supporting the realizability of the Company's net deferred tax asset included in the annual financial statements.

\section{Company-Level Examples}

\section{Parametric Technology Corp}

As of September 30, 2007, we identified a material weakness in our internal control over financial reporting because we did not maintain effective controls over the accounting for income taxes, including the determination and reporting of accrued income taxes, deferred taxes and the related income tax provision. Specifically, we did not have adequate personnel to enable us to properly consider and apply generally accepted accounting principles for taxes, review and monitor the accuracy and completeness of the components of the income tax provision calculations and the related deferred taxes and accrued income taxes, ensure that the rationale for certain tax positions was appropriate, and ensure that effective oversight of the work performed by our outside tax advisors was exercised.

\section{j2 Global Communications, Inc.}

An adjustment to the Company's income tax provision was identified based on the results of the annual financial statement audit for the fiscal year 2005. This adjustment resulted from a deficiency in the operation of controls requiring the assessment of the income tax impact of the pricing for services purchased by j2 Global Communications, Inc. from a subsidiary. This deficiency represents a material weakness in internal control over financial reporting. 


\section{APPENDIX D}

\section{Table D.1 - Determination of a Parsimonious Model of Tax Avoidance}

Equations (2) and (3) in this dissertation are parsimonious models of tax avoidance. Four additional variables common to the tax avoidance literature are excluded from the models based on tests reported in this Appendix. For simplicity, the following equation with the additional variables included is based on Equation (2):

CASH_ETR $5_{i t}=\beta_{0}+\beta_{1}$ TICW $_{i t}+\beta_{2}$ OICW $_{i t}+\beta_{3}$ ROA $_{i t}+\beta_{4}$ LEV $_{i t}+\beta_{5}$ FORINC5 $_{i t}+\beta_{6}$ FOROPS5 $_{i t}$ $+\beta_{7} B \bar{M} 5_{i t}+\beta_{8} A G G R \_L O S S 5_{i t}+\beta_{9}$ COCF5 $_{i t}+\beta_{10} N O L 5_{i t}+\beta_{11}$ SIZE5 $_{i t}+\beta_{12} P P E 5_{i t}+\beta_{13}$ INTANG $_{i t}+$ $\Sigma_{t}$ DYEAR $_{t}+\Sigma_{j} \operatorname{DIND}_{j}+\varepsilon_{i t}$

The additional variables are defined as follows:

$N O L 5_{i t}=$ an indicator variable equal to one if firm $i$ 's opening loss carry forward balance is positive during any year between year $t-4$ and $t$, and 0 otherwise;

$S I Z E 5_{i t}=$ the natural logarithm of firm $i$ 's average assets as measured at $t-5$ and $t-1$;

$P P E 5_{i t}=$ the average property, plant and equipment (PPE) of firm $i$ for years $t-4$ through $t$, measured as PPE scaled by lagged assets at $t-4$ plus the same ratio at $t$, divided by two;

$I N T A N G 5_{i t}=$ the average intangible assets of firm $i$ for years $t-4$ through $t$, measured as intangible assets scaled by lagged assets at $t-4$ plus the same ratio at $t$, divided by two.

As reported below in this Appendix, three sets of tests are conducted to validate the exclusion of these variables. Panel A reports the primary test, with an analysis of the firm-level sample of this dissertation. Panels B and C are secondary tests, with analysis of annual values of the firm-year sample and with analysis of a firm-level, complete Compustat sample (subject to data availability), respectively. In Panel C, ICW variables are not present in the model because Compustat does not provide such data.

In each panel, the first column reports the statistics related to the above regression. The subsequent columns report the results as the variables are excluded in sequence, beginning with the exclusion of INTANG5 and ending with the inclusion of NOL5 only. With NOL5 excluded, the equation matches that of Equation (2) in Section 4.5. Standard errors have been adjusted for clustering within two-digit industry and are reported in parentheses. ****** refer to significance at the $10 \%, 5 \%$ and $1 \%$ levels, respectively. Significance for all variables with a predicted sign is calculated using a one-tailed test; for all other variables, including unreported year and industry effects, two-tailed tests are calculated. 
Panel A - Firm-Level Sample with CASH_ETR5 as DV

\begin{tabular}{|c|c|c|c|c|c|c|c|c|c|}
\hline VARIABLE & $\begin{array}{l}\text { PRED. } \\
\text { SIGN }\end{array}$ & $\begin{array}{l}\text { ALL } \\
\text { VARIA }\end{array}$ & LES & $\begin{array}{l}\text { EXCLL } \\
\text { INTAN }\end{array}$ & & $\begin{array}{l}\text { EXCLU } \\
\text { PPE5 }\end{array}$ & & $\begin{array}{l}\text { EXCLL } \\
\text { SIZE5 }\end{array}$ & \\
\hline INTERCEPT & $?$ & $\begin{array}{l}-0.431 \\
(0.226)\end{array}$ & $* *$ & $\begin{array}{l}-0.432 \\
(0.222)\end{array}$ & $* *$ & $\begin{array}{l}-0.460 \\
(0.193)\end{array}$ & $* *$ & $\begin{array}{l}-0.445 \\
(0.191)\end{array}$ & $* *$ \\
\hline TICW3 & ? & $\begin{array}{l}0.048 \\
(0.018)\end{array}$ & $* *$ & $\begin{array}{l}0.043 \\
(0.017)\end{array}$ & $* *$ & $\begin{array}{l}0.046 \\
(0.017)\end{array}$ & $* *$ & $\begin{array}{l}0.045 \\
(0.017)\end{array}$ & $* *$ \\
\hline OICW3 & & $\begin{array}{l}0.024 \\
(0.015)\end{array}$ & & $\begin{array}{l}0.025 \\
(0.016)\end{array}$ & & $\begin{array}{l}0.026 \\
(0.015)\end{array}$ & & $\begin{array}{l}0.025 \\
(0.016)\end{array}$ & \\
\hline ROA5 & - & $\begin{array}{l}0.686 \\
(0.209)\end{array}$ & $* * *$ & $\begin{array}{l}0.689 \\
(0.209)\end{array}$ & $* * *$ & $\begin{array}{l}0.721 \\
(0.194)\end{array}$ & $* * *$ & $\begin{array}{l}0.715 \\
(0.193)\end{array}$ & $* * *$ \\
\hline LEV5 & - & $\begin{array}{l}-0.037 \\
(0.043)\end{array}$ & & $\begin{array}{l}-0.046 \\
(0.033)\end{array}$ & $*$ & $\begin{array}{l}-0.108 \\
(0.066)\end{array}$ & $*$ & $\begin{array}{l}-0.105 \\
(0.067)\end{array}$ & $*$ \\
\hline FORINC5 & - & $\begin{array}{l}-0.042 \\
(0.105)\end{array}$ & & $\begin{array}{l}-0.111 \\
(0.117)\end{array}$ & & $\begin{array}{l}-0.192 \\
(0.140)\end{array}$ & $*$ & $\begin{array}{l}-0.171 \\
(0.120)\end{array}$ & $*$ \\
\hline FOROPS5 & - & $\begin{array}{l}0.012 \\
(0.009)\end{array}$ & $*$ & $\begin{array}{l}0.015 \\
(0.010)\end{array}$ & $*$ & $\begin{array}{l}0.017 \\
(0.010)\end{array}$ & $*$ & $\begin{array}{l}0.019 \\
(0.011)\end{array}$ & $*$ \\
\hline BM5 & - & $\begin{array}{l}0.033 \\
(0.026)\end{array}$ & & $\begin{array}{l}0.028 \\
(0.025)\end{array}$ & & $\begin{array}{l}0.027 \\
(0.026)\end{array}$ & & $\begin{array}{l}0.025 \\
(0.026)\end{array}$ & \\
\hline AGGR_LOSS5 & + & $\begin{array}{l}0.170 \\
(0.056)\end{array}$ & $* * *$ & $\begin{array}{l}0.175 \\
(0.056)\end{array}$ & $* * *$ & $\begin{array}{l}0.180 \\
(0.055)\end{array}$ & $* * *$ & $\begin{array}{l}0.180 \\
(0.055)\end{array}$ & $* * *$ \\
\hline COCF5 & + & $\begin{array}{l}0.539 \\
(0.201)\end{array}$ & $* * *$ & $\begin{array}{l}0.541 \\
(0.198)\end{array}$ & $* * *$ & $\begin{array}{l}0.546 \\
(0.181)\end{array}$ & $* * *$ & $\begin{array}{l}0.555 \\
(0.174)\end{array}$ & $* * *$ \\
\hline NOL5 & - & $\begin{array}{l}-0.022 \\
(0.010)\end{array}$ & $* *$ & $\begin{array}{l}-0.017 \\
(0.011)\end{array}$ & $*$ & $\begin{array}{l}-0.014 \\
(0.011)\end{array}$ & & $\begin{array}{l}-0.015 \\
(0.012)\end{array}$ & \\
\hline SIZE5 & ? & $\begin{array}{l}-0.001 \\
(0.003)\end{array}$ & & $\begin{array}{l}-0.001 \\
(0.003)\end{array}$ & & $\begin{array}{l}0.002 \\
(0.003)\end{array}$ & & & \\
\hline PPE5 & - & $\begin{array}{l}0.017 \\
(0.037)\end{array}$ & & $\begin{array}{l}0.009 \\
(0.032)\end{array}$ & & & & & \\
\hline INTANG5 & - & $\begin{array}{l}-0.003 \\
(0.025)\end{array}$ & & & & & & & \\
\hline \multirow{3}{*}{\multicolumn{2}{|c|}{$\begin{array}{l}\text { Adjusted } \mathrm{R}^{2} \\
\text { Number of firms with } \\
\text { material weaknesses } \\
\text { Number of total } \\
\text { observations }\end{array}$}} & \multicolumn{2}{|l|}{$11.49 \%$} & \multicolumn{2}{|l|}{$10.85 \%$} & \multicolumn{2}{|l|}{$13.02 \%$} & \multicolumn{2}{|l|}{$13.05 \%$} \\
\hline & & 192 & & 206 & & 208 & & 208 & \\
\hline & & 1154 & & 1231 & & 1286 & & 1286 & \\
\hline
\end{tabular}


Panel B - Annual Sample with CASH_ETR as DV

\begin{tabular}{|c|c|c|c|c|c|c|c|c|c|}
\hline VARIABLE & $\begin{array}{l}\text { PRED. } \\
\text { SIGN }\end{array}$ & $\begin{array}{l}\text { ALL } \\
\text { VARIA }\end{array}$ & LES & $\begin{array}{l}\text { EXCLL } \\
\text { INTAN }\end{array}$ & & $\begin{array}{l}\text { EXCLU } \\
\text { PPE5 }\end{array}$ & & $\begin{array}{l}\text { EXCLL } \\
\text { SIZE5 }\end{array}$ & \\
\hline INTERCEPT & $?$ & $\begin{array}{l}-0.178 \\
(0.127)\end{array}$ & & $\begin{array}{l}-0.177 \\
(0.130)\end{array}$ & & $\begin{array}{l}-0.211 \\
(0.098)\end{array}$ & $* *$ & $\begin{array}{l}-0.194 \\
(0.084)\end{array}$ & $* *$ \\
\hline TICW & ? & $\begin{array}{l}0.086 \\
(0.029)\end{array}$ & $* * *$ & $\begin{array}{l}0.086 \\
(0.030)\end{array}$ & $* *$ & $\begin{array}{l}0.089 \\
(0.028)\end{array}$ & $* * *$ & $\begin{array}{l}0.089 \\
(0.028)\end{array}$ & $* * *$ \\
\hline OICW & & $\begin{array}{l}0.037 \\
(0.016)\end{array}$ & $* *$ & $\begin{array}{l}0.039 \\
(0.015)\end{array}$ & $* *$ & $\begin{array}{l}0.039 \\
(0.015)\end{array}$ & $* *$ & $\begin{array}{l}0.037 \\
(0.016)\end{array}$ & $* *$ \\
\hline ROA & - & $\begin{array}{l}0.075 \\
(0.067)\end{array}$ & & $\begin{array}{l}0.077 \\
(0.071)\end{array}$ & & $\begin{array}{l}0.094 \\
(0.060)\end{array}$ & $*$ & $\begin{array}{l}0.089 \\
(0.057)\end{array}$ & $*$ \\
\hline LEV & - & $\begin{array}{l}-0.080 \\
(0.032)\end{array}$ & $* *$ & $\begin{array}{l}-0.074 \\
(0.027)\end{array}$ & $* * *$ & $\begin{array}{l}-0.147 \\
(0.071)\end{array}$ & $* *$ & $\begin{array}{l}-0.145 \\
(0.073)\end{array}$ & $* *$ \\
\hline FORINC & - & $\begin{array}{l}-0.177 \\
(0.092)\end{array}$ & $* *$ & $\begin{array}{l}-0.187 \\
(0.091)\end{array}$ & $* *$ & $\begin{array}{l}-0.249 \\
(0.097)\end{array}$ & $* * *$ & $\begin{array}{l}-0.233 \\
(0.097)\end{array}$ & $* *$ \\
\hline FOROPS & - & $\begin{array}{l}0.012 \\
(0.012)\end{array}$ & & $\begin{array}{l}0.013 \\
(0.012)\end{array}$ & & $\begin{array}{l}0.011 \\
(0.012)\end{array}$ & & $\begin{array}{l}0.012 \\
(0.012)\end{array}$ & \\
\hline BM & - & $\begin{array}{l}-0.019 \\
(0.016)\end{array}$ & & $\begin{array}{l}-0.016 \\
(0.015)\end{array}$ & & $\begin{array}{l}-0.018 \\
(0.018)\end{array}$ & & $\begin{array}{l}-0.019 \\
(0.018)\end{array}$ & \\
\hline AGGR_LOSS & + & $\begin{array}{l}-0.041 \\
(0.020)\end{array}$ & $* *$ & $\begin{array}{l}-0.044 \\
(0.020)\end{array}$ & $* *$ & $\begin{array}{l}-0.041 \\
(0.017)\end{array}$ & $* *$ & $\begin{array}{l}-0.042 \\
(0.017)\end{array}$ & $* *$ \\
\hline $\mathrm{COCF}$ & + & $\begin{array}{l}0.388 \\
(0.090)\end{array}$ & $* * *$ & $\begin{array}{l}0.385 \\
(0.092)\end{array}$ & $* * *$ & $\begin{array}{l}0.396 \\
(0.070)\end{array}$ & $* * *$ & $\begin{array}{l}0.401 \\
(0.071)\end{array}$ & $* * *$ \\
\hline NOL & - & $\begin{array}{l}-0.021 \\
(0.007)\end{array}$ & $* * *$ & $\begin{array}{l}-0.019 \\
(0.007)\end{array}$ & $* * *$ & $\begin{array}{l}-0.014 \\
(0.010)\end{array}$ & $*$ & $\begin{array}{l}-0.014 \\
(0.010)\end{array}$ & $*$ \\
\hline SIZE & ? & $\begin{array}{l}-0.002 \\
(0.004)\end{array}$ & & $\begin{array}{l}-0.002 \\
(0.004)\end{array}$ & & $\begin{array}{l}0.002 \\
(0.003)\end{array}$ & & & \\
\hline PPE & - & $\begin{array}{l}0.036 \\
(0.033)\end{array}$ & & $\begin{array}{l}0.030 \\
(0.029)\end{array}$ & $* * *$ & & & & \\
\hline INTANG & - & $\begin{array}{l}0.011 \\
(0.020)\end{array}$ & & & & & & & \\
\hline \multirow{2}{*}{\multicolumn{2}{|c|}{$\begin{array}{l}\text { Adjusted } \mathrm{R}^{2} \\
\text { Number of firms with } \\
\text { material weaknesses } \\
\text { Number of total } \\
\text { observations }\end{array}$}} & \multicolumn{2}{|l|}{ 7.77\% } & \multicolumn{2}{|l|}{$7.87 \%$} & \multicolumn{2}{|l|}{$8.62 \%$} & \multicolumn{2}{|l|}{$8.62 \%$} \\
\hline & & $\begin{array}{l}289 \\
3969 \\
\end{array}$ & & $\begin{array}{l}294 \\
4060\end{array}$ & & $\begin{array}{l}299 \\
4242 \\
\end{array}$ & & $\begin{array}{l}299 \\
4242 \\
\end{array}$ & \\
\hline
\end{tabular}


Panel C - Firm-Level Sample of Compustat Firms with CASH_ETR5 as DV

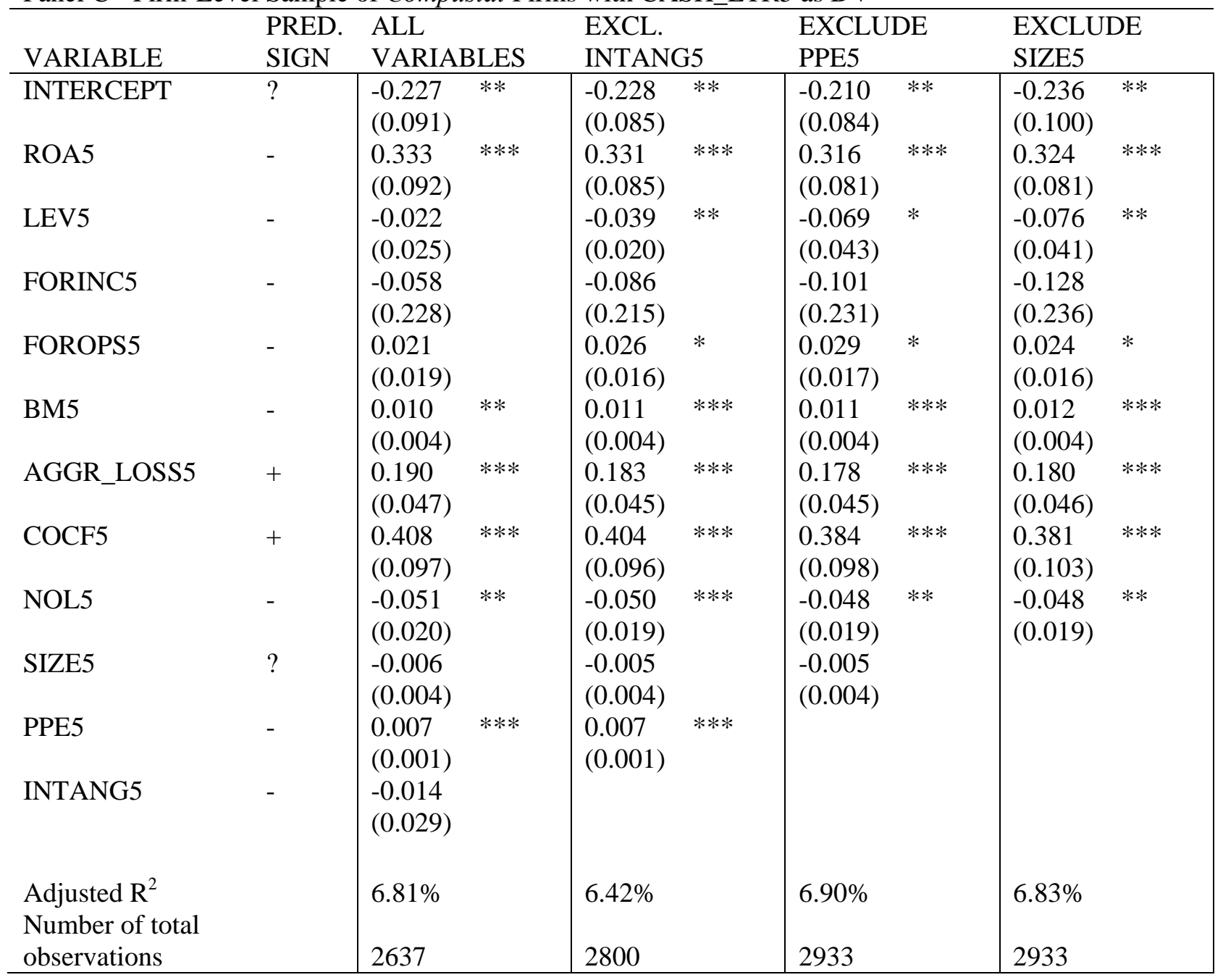




\section{TABLE 1}

\section{SAMPLE, INDUSTRY AND WEAKNESS COMPOSITION}

The composition of firms in Panels A and B is based on a firm-level sample of observations from 2004-2006, with one unique observation per firm. The composition of firms in Panels C, D and E is based on a firm-year sample of observations from 2004-2006, with multiple observations per firm. ICW refers to internal control weakness. For purposes of Panels A and C, sample firms trade on one of the S\&P 500, S\&P 400 or S\&P 600 indices during the sample period. In Panels B and D, industry composition is based on a two-digit NAICS classification. In Panel E, the number of firm-year ICWs is totaled by weakness category. The weakness categories map to individual or aggregated categories based on Hammersley et al. (2008), as shown in greater detail in Appendix B.

Panel A: Sample Composition - Firm-Level Observations

\begin{tabular}{|c|c|c|c|c|c|c|c|c|}
\hline & \multicolumn{2}{|c|}{$\begin{array}{l}\text { S\&P } 500 \\
\text { LARGE CAP }\end{array}$} & \multicolumn{2}{|c|}{$\begin{array}{l}\text { S\&P } 400 \text { MID } \\
\text { CAP }\end{array}$} & \multicolumn{2}{|c|}{$\begin{array}{l}\text { S\&P } 600 \\
\text { SMALL CAP }\end{array}$} & \multicolumn{2}{|c|}{$\begin{array}{l}\text { TOTAL BY } \\
\text { YEAR }\end{array}$} \\
\hline & \# & $\%$ & $\#$ & $\%$ & \# & $\%$ & \# & $\%$ \\
\hline \multicolumn{9}{|c|}{ ICW FIRMS } \\
\hline 2004 & 1 & $(0.5 \%)$ & 0 & $(0.0 \%)$ & 3 & $(1.4 \%)$ & 4 & $(1.9 \%)$ \\
\hline 2005 & 3 & $(1.4 \%)$ & 2 & $(1.0 \%)$ & 6 & $(2.9 \%)$ & 11 & $(5.3 \%)$ \\
\hline 2006 & 40 & $(19.2 \%)$ & 46 & (22.1\%) & 107 & $(51.4 \%)$ & 193 & $(92.8 \%)$ \\
\hline Total & 44 & $(21.2 \%)$ & 48 & (23.1\%) & 116 & $(55.8 \%)$ & 208 & $(100.0 \%)$ \\
\hline \multicolumn{9}{|c|}{ NON-ICW FIRMS } \\
\hline 2004 & 9 & $(0.8 \%)$ & 7 & $(0.6 \%)$ & 18 & $(1.7 \%)$ & 34 & $(3.2 \%)$ \\
\hline 2005 & 12 & $(1.1 \%)$ & 13 & $(1.2 \%)$ & 29 & $(2.7 \%)$ & 54 & (5.0\%) \\
\hline 2006 & 372 & (34.5\%) & 286 & $(26.5 \%)$ & 332 & $(30.8 \%)$ & 990 & $(91.8 \%)$ \\
\hline Total & 393 & (36.5\%) & 306 & $(28.4 \%)$ & 379 & $(35.2 \%)$ & 1078 & $(100.0 \%)$ \\
\hline \multicolumn{9}{|c|}{ TOTAL BY S\&P } \\
\hline INDEX & 437 & (34.0\%) & 354 & $(27.5 \%)$ & 495 & (38.5\%) & 1286 & $(100.0 \%)$ \\
\hline
\end{tabular}


Panel B: Industry Composition - Firm-Level Observations

\begin{tabular}{llll}
\hline INDUSTRY NAME (based on 2-digit & ICW FIRM & NON-ICW FIRM & PERCENT OF \\
NAICS) & FREQUENCY & FREQUENCY & FIRMS W/ICW \\
\hline Mining & 7 & 45 & $13.5 \%$ \\
Utilities & 7 & 61 & $10.3 \%$ \\
Food, beverage and textiles manufacturing & 10 & 57 & $14.9 \%$ \\
Wood, paper, coal, plastic and other & & & \\
manufacturing & 23 & 128 & $15.2 \%$ \\
Primary metal manufacturing & 58 & 308 & $15.8 \%$ \\
Wholesale trade & 6 & 45 & $11.8 \%$ \\
Retail trade & 13 & 55 & $19.1 \%$ \\
Retail trade: sporting and other & 10 & 22 & $31.3 \%$ \\
Transportation and warehousing & 3 & 29 & $9.4 \%$ \\
Information & 20 & 77 & $20.6 \%$ \\
Finance and insurance & 17 & 128 & $11.7 \%$ \\
Real estate and rental and leasing & 2 & 8 & $20.0 \%$ \\
Professional, scientific and technical services & 14 & 45 & $23.7 \%$ \\
Administrative and support and waste & & & \\
management and remediation services & 6 & 30 & $16.7 \%$ \\
Educational services & 3 & 3 & $50.0 \%$ \\
Accommodation and food services & 6 & 30 & $16.7 \%$ \\
Services other than public administration & 2 & 4 & $33.3 \%$ \\
Other & 1 & 3 & $25.0 \%$ \\
\hline
\end{tabular}


Panel C: Sample Composition - Firm-Year Observations

\begin{tabular}{|c|c|c|c|c|c|c|c|c|}
\hline & \multicolumn{2}{|c|}{$\begin{array}{l}\text { S\&P } 500 \\
\text { LARGE CAP }\end{array}$} & \multicolumn{2}{|c|}{$\begin{array}{l}\text { S\&P } 400 \text { MID } \\
\text { CAP }\end{array}$} & \multicolumn{2}{|c|}{$\begin{array}{l}\text { S\&P } 600 \\
\text { SMALL CAP }\end{array}$} & \multicolumn{2}{|c|}{$\begin{array}{l}\text { TOTAL BY } \\
\text { YEAR }\end{array}$} \\
\hline & $\#$ & $\%$ & $\#$ & $\%$ & \# & $\%$ & $\#$ & $\%$ \\
\hline \multicolumn{9}{|c|}{ ICW FIRMS } \\
\hline 2004 & 31 & (11.4\%) & 27 & $(10.0 \%)$ & 43 & (15.9\%) & 101 & (37.3\%) \\
\hline 2005 & 24 & $(8.9 \%)$ & 22 & $(8.1 \%)$ & 54 & (19.9\%) & 100 & (36.9\%) \\
\hline 2006 & 17 & $(6.3 \%)$ & 16 & (5.9\%) & 37 & (13.7\%) & 70 & (25.8\%) \\
\hline Total & 72 & $(26.6 \%)$ & 65 & $(24.0 \%)$ & 134 & (49.4\%) & 271 & $(100.0 \%)$ \\
\hline \multicolumn{9}{|c|}{ NON-ICW FIRMS } \\
\hline 2004 & 328 & $(10.6 \%)$ & 247 & $(8.0 \%)$ & 294 & $(9.5 \%)$ & 869 & $(28.2 \%)$ \\
\hline 2005 & 388 & (12.6\%) & 321 & $(10.4 \%)$ & 389 & (12.6\%) & 1098 & (35.6\%) \\
\hline 2006 & 395 & (12.8\%) & 316 & $(10.3 \%)$ & 402 & (13.1\%) & 1113 & (36.1\%) \\
\hline Total & 1111 & $(36.1 \%)$ & 884 & $(28.7 \%)$ & 1085 & $(35.2 \%)$ & 3080 & $(100.0 \%)$ \\
\hline \multicolumn{9}{|c|}{ TOTAL BY S\&P } \\
\hline INDEX & 1183 & $(35.3 \%)$ & 949 & $(28.3 \%)$ & 1219 & $(36.4 \%)$ & 3351 & $(100.0 \%)$ \\
\hline
\end{tabular}

Panel D: Industry Composition - Firm-Year Observations

\begin{tabular}{lccc}
\hline INDUSTRY NAME (based on 2-digit & ICW & NON-ICW & PERCENT WITH \\
NAICS) & FREQUENCY & FREQUENCY & ICW \\
\hline Mining & 9 & 123 & $6.8 \%$ \\
Utilities & 10 & 181 & $5.2 \%$ \\
Food, beverage and textiles manufacturing & 14 & 158 & $8.1 \%$ \\
Wood, paper, coal, plastic and other & 31 & 372 & $7.7 \%$ \\
manufacturing & & & \\
Primary metal manufacturing & 73 & 842 & $8.0 \%$ \\
Wholesale trade & 8 & 123 & $6.1 \%$ \\
Retail trade & 13 & 163 & $7.4 \%$ \\
Retail trade: sporting and other & 16 & 75 & $17.6 \%$ \\
Transportation and warehousing & 5 & 89 & $5.3 \%$ \\
Information & 28 & 210 & $11.8 \%$ \\
Finance and insurance & 24 & 375 & $10.0 \%$ \\
Real estate and rental and leasing & 3 & 26 & $12.3 \%$ \\
Professional, scientific and technical & 18 & 129 & \\
services & & & $5.2 \%$ \\
Administrative and support and waste & 5 & 92 & \\
management and remediation services & & & $25.0 \%$ \\
Educational services & 4 & 12 & $7.6 \%$ \\
Accommodation and food services & 7 & $11.8 \%$ \\
Services other than public administration & 2 & 10 & $9.1 \%$ \\
Other & 1 & &
\end{tabular}


Panel E: Internal Control Weakness Categories - Firm-Year Observations

\begin{tabular}{|c|c|c|c|}
\hline & $\begin{array}{l}\# \\
\text { ICWs }\end{array}$ & $\%$ OF ICWs & $\begin{array}{l}\text { \% OF ICWs TO } \\
\text { FIRM-YEARS }\end{array}$ \\
\hline \multicolumn{4}{|l|}{ COMPANY-LEVEL ICWs } \\
\hline$\overline{\text { A1a: Lack of key personnel }}$ & 25 & $2.2 \%$ & $9.2 \%$ \\
\hline $\begin{array}{l}\text { A1b: Management override or integrity } \\
\text { issues }\end{array}$ & 15 & $1.3 \%$ & $5.5 \%$ \\
\hline A2a: Financial statement close process issues & 51 & $4.5 \%$ & $18.8 \%$ \\
\hline A3a: Fraud or red flags for fraud & 24 & $2.1 \%$ & $8.9 \%$ \\
\hline A3b: Insufficient documentation and policies & 94 & $8.4 \%$ & $34.7 \%$ \\
\hline A3c: Inadequate lines of communication & 38 & $3.4 \%$ & $14.0 \%$ \\
\hline A3d: Insufficient risk assessment policies & 19 & $1.7 \%$ & $7.0 \%$ \\
\hline Subtotal & 266 & $23.6 \%$ & \\
\hline \multicolumn{4}{|l|}{ ACCOUNT-LEVEL ICWs } \\
\hline B1a: Lack of timely reporting/filing & 63 & $5.6 \%$ & $23.2 \%$ \\
\hline B1b: Lack of quality corporate governance & 51 & $4.5 \%$ & $18.8 \%$ \\
\hline $\begin{array}{l}\text { B1cd: Lack of training \& staffing/resource } \\
\text { issues }\end{array}$ & 160 & $14.2 \%$ & $59.0 \%$ \\
\hline B1e: Internal audit/monitoring issues & 48 & $4.3 \%$ & $17.7 \%$ \\
\hline B2a: Lack of timely review & 164 & $14.6 \%$ & $60.5 \%$ \\
\hline B2b: Incomplete account analysis & 93 & $8.3 \%$ & $34.3 \%$ \\
\hline B2c: Untimely account reconciliations & 101 & $9.0 \%$ & $37.3 \%$ \\
\hline B2d: Issues with non-routine transactions & 41 & $3.6 \%$ & $15.1 \%$ \\
\hline B2e: Lack of discipline in reporting & 1 & $0.1 \%$ & $0.4 \%$ \\
\hline B2f: Approval procedures not followed & 7 & $0.6 \%$ & $2.6 \%$ \\
\hline B2g: Other procedures not followed & 1 & $0.1 \%$ & $0.4 \%$ \\
\hline B2hjkmno: Issues with IT controls & 77 & $6.8 \%$ & $28.4 \%$ \\
\hline B2i: Segregation of duties issues & 33 & $2.9 \%$ & $12.2 \%$ \\
\hline B2l: Lack of documentation of controls & 10 & $0.9 \%$ & $3.7 \%$ \\
\hline B2p: Issues with manual systems/controls & 6 & $0.5 \%$ & $2.2 \%$ \\
\hline B4: Issues with routine transactions & 3 & $0.3 \%$ & $1.1 \%$ \\
\hline \multirow[t]{2}{*}{ Subtotal } & 859 & $76.4 \%$ & \\
\hline & & & $\underline{\text { FIRM-YEARS }}$ \\
\hline Total & 1125 & $100.0 \%$ & 271 \\
\hline
\end{tabular}




\section{TABLE 2}

\section{Summary Statistics for Primary Tests Of HyPOTHeSes 1 - 3}

The Panel A annual sample and the Panel C overlapping, annual sample consist of 3,351 firm-year observations from the S\&P 400, 500 and 600 (i.e. S\&P 1500) between 2004 and 2006. The Panel B average sample consists of 1,286 firm-level observations. CASH_ETR in Panel A contains only 3,251 observations because some annual values with negative denominators are set to missing; over a 5-year period, these firms report a positive average denominator for $C A S H_{-} E T R 5$. Annual variables are simply the one-year value of the average variables. $A G G R \_L O S S$ is a sum of values at time $t-1$ and $t, B M$ is measured at $t-1$, and all other annual values are measured at year $t$. All continuous annual variables are scaled by assets at time $t-1$. Similarly, all average values are averaged for the five-year period $t-4$ through $t$, except the ICW variables, which are averaged for the three-year period $t-2$ through $t$. 5-year average variables include data for years prior to 2004. All continuous average variables are scaled by the average assets from the years $t-5$ and $t-1$. CASH_ETR5 is the five-year average of the annual $C A S H \_E T R$ (taxes paid/(income less special items)). TICW3_COMP3 is an indicator variable equal to one if a firm has a tax internal control weakness and a company-level internal control weakness identified during the sample period; TICW3_ACCT3, OICW3_COMP3 and OICW3_ACCT3 are similarly measured, with OICW representing other non-tax internal control weaknesses and $A C C T$ representing account-level internal control weaknesses. $R O A 5$ is average return on assets; LEV5 is average leverage, FORINC5 is average foreign income; FOROPS5 is an indicator variable equal to one if FORINC5 is nonmissing, non-zero; $B M 5$ is average book-to-market ratio; $A G G R \_L O S S 5$ is an indicator variable equal to one if a firm has a five-year sum of accounting losses; COCF5 is one minus the average operating cash flows; DYR04-DYR06 are indicator variables representing the fiscal years 2004-2006. Annual and average values for $C A S H \_E T R / C A S H \_E T R 5, R O A / R O A 5, L E V / L E V 5$ and BM/BM5 are winsorized at the 1\% and 99\% levels. 
Panel A: Annual Values

\begin{tabular}{|c|c|c|c|c|c|c|c|}
\hline VARIABLE & DESCRIPTION & $\mathrm{N}$ & MEAN & STD DEV & 5 th $\%$ & MEDIAN & 95th \% \\
\hline CASH_ETR & Annual Cash ETR & 3251 & 0.246 & 0.219 & 0.000 & 0.234 & 0.528 \\
\hline TICW_ACCT & Account-level tax internal control weakness & 3351 & 0.007 & 0.081 & 0 & 0.000 & 0 \\
\hline TICW_COMP & Company-level tax internal control weakness & 3351 & 0.029 & 0.167 & 0 & 0.000 & 0 \\
\hline OICW_ACCT & Account-level non-tax internal control weakness & 3351 & 0.016 & 0.126 & 0 & 0.000 & 0 \\
\hline OICW_COMP & Company-level non-tax internal control weakness & 3351 & 0.030 & 0.169 & 0 & 0.000 & 0 \\
\hline ROA & Return on assets & 3351 & 0.110 & 0.102 & -0.014 & 0.093 & 0.294 \\
\hline LEV & Leverage & 3351 & 0.200 & 0.191 & 0.000 & 0.169 & 0.565 \\
\hline FORINC & Foreign Income & 3351 & 0.021 & 0.042 & 0.000 & 0.000 & 0.107 \\
\hline FOROPS & Existence of foreign operations & 3351 & 0.525 & 0.499 & 0 & 1.000 & 1 \\
\hline $\mathrm{BM}$ & Book-to-market ratio & 3351 & 0.443 & 0.242 & 0.118 & 0.413 & 0.862 \\
\hline AGGR_LOSS & Two consecutive years of losses & 3351 & 0.065 & 0.246 & 0 & 0.000 & 1 \\
\hline COCF & One minus operating cash flows & 3351 & 0.878 & 0.092 & 0.716 & 0.892 & 0.991 \\
\hline DYR04 & Indicator equal to 1 if observation from fiscal 2004 & 3351 & 0.289 & 0.454 & 0 & 0.000 & 1 \\
\hline DYR05 & Indicator equal to 1 if observation from fiscal 2005 & 3351 & 0.358 & 0.479 & 0 & 0.000 & 1 \\
\hline DYR06 & Indicator equal to 1 if observation from fiscal 2006 & 3351 & 0.353 & 0.478 & 0 & 0.000 & 1 \\
\hline
\end{tabular}


Panel B: Average Values - Firm-Level Sample

\begin{tabular}{|c|c|c|c|c|c|c|c|}
\hline VARIABLE & DESCRIPTION & $\mathrm{N}$ & MEAN & STD DEV & 5 th $\%$ & MEDIAN & 95th \% \\
\hline CASH_ETR5 & Average Cash ETR & 1286 & 0.230 & 0.173 & 0.000 & 0.231 & 0.426 \\
\hline TICW3_ACCT3 & Account-level tax internal control weakness & 1286 & 0.009 & 0.096 & 0 & 0.000 & 0 \\
\hline TICW3_COMP3 & Company-level tax internal control weakness & 1286 & 0.055 & 0.228 & 0 & 0.000 & 1 \\
\hline OICW3_ACCT3 & Account-level non-tax internal control weakness & 1286 & 0.037 & 0.190 & 0 & 0.000 & 0 \\
\hline OICW3_COMP3 & Company-level non-tax internal control weakness & 1286 & 0.075 & 0.264 & 0 & 0.000 & 1 \\
\hline ROA5 & Average return on assets & 1286 & 0.099 & 0.081 & 0.002 & 0.085 & 0.248 \\
\hline LEV5 & Average leverage & 1286 & 0.209 & 0.175 & 0.000 & 0.183 & 0.546 \\
\hline FORINC5 & Average foreign income & 1286 & 0.018 & 0.034 & 0.000 & 0.001 & 0.089 \\
\hline FOROPS5 & Existence of foreign operations during 5 years & 1286 & 0.555 & 0.497 & 0 & 1.000 & 1 \\
\hline BM5 & Average book-to-market ratio & 1286 & 0.466 & 0.265 & 0.116 & 0.431 & 0.938 \\
\hline AGGR_LOSS5 & Five-year sum of losses & 1286 & 0.069 & 0.254 & 0 & 0.000 & 1 \\
\hline COCF5 & One minus average operating cash flows & 1286 & 0.881 & 0.073 & 0.753 & 0.895 & 0.969 \\
\hline DYR04 & Indicator equal to 1 if observation from fiscal 2004 & 1286 & 0.030 & 0.169 & 0 & 0.000 & 0 \\
\hline DYR05 & Indicator equal to 1 if observation from fiscal 2005 & 1286 & 0.051 & 0.219 & 0 & 0.000 & 1 \\
\hline DYR06 & Indicator equal to 1 if observation from fiscal 2006 & 1286 & 0.920 & 0.272 & 0 & 1.000 & 1 \\
\hline
\end{tabular}


Panel C: Average Values - Overlapping, Annual Sample

\begin{tabular}{|c|c|c|c|c|c|c|c|}
\hline VARIABLE & DESCRIPTION & $\mathrm{N}$ & MEAN & STD DEV & 5 th $\%$ & MEDIAN & 95th \% \\
\hline CASH_ETR5 & Average Cash ETR & 3351 & 0.232 & 0.187 & 0.000 & 0.226 & 0.429 \\
\hline TICW3_ACCT3 & Account-level tax internal control weakness & 3351 & 0.009 & 0.096 & 0 & 0.000 & 0 \\
\hline TICW3_COMP3 & Company-level tax internal control weakness & 3351 & 0.047 & 0.212 & 0 & 0.000 & 0 \\
\hline OICW3_ACCT3 & Account-level non-tax internal control weakness & 3351 & 0.035 & 0.183 & 0 & 0.000 & 0 \\
\hline OICW3_COMP3 & Company-level non-tax internal control weakness & 3351 & 0.056 & 0.229 & 0 & 0.000 & 1 \\
\hline ROA5 & Average return on assets & 3351 & 0.095 & 0.081 & -0.001 & 0.079 & 0.248 \\
\hline LEV5 & Average leverage & 3351 & 0.215 & 0.180 & 0.000 & 0.188 & 0.560 \\
\hline FORINC5 & Average foreign income & 3351 & 0.017 & 0.032 & 0.000 & 0.000 & 0.084 \\
\hline FOROPS5 & Existence of foreign operations during 5 years & 3351 & 0.539 & 0.499 & 0 & 1.000 & 1 \\
\hline BM5 & Average book-to-market ratio & 3351 & 0.483 & 0.289 & 0.113 & 0.436 & 1.007 \\
\hline AGGR_LOSS5 & Five-year sum of losses & 3351 & 0.075 & 0.263 & 0 & 0.000 & 1 \\
\hline COCF5 & One minus average operating cash flows & 3351 & 0.881 & 0.073 & 0.752 & 0.895 & 0.970 \\
\hline DYR04 & Indicator equal to 1 if observation from fiscal 2004 & 3351 & 0.289 & 0.454 & 0 & 0.000 & 1 \\
\hline DYR05 & Indicator equal to 1 if observation from fiscal 2005 & 3351 & 0.358 & 0.479 & 0 & 0.000 & 1 \\
\hline DYR06 & Indicator equal to 1 if observation from fiscal 2006 & 3351 & 0.353 & 0.478 & 0 & 0.000 & 1 \\
\hline
\end{tabular}




\section{TABLE 3}

\section{Summary Statistics by Group for Primary Tests of Hypotheses 1 - 3 (Average Values OnLy)}

The following table provides summary statistics and tests of differences for groups of firms categorized at the firm-level as having a tax ICW, any type of ICW, a non-tax ICW or no ICW. Panel A compares the group of firms with any type of ICW to the group of firms with no ICW. Panel B compares the group of firms with a tax ICW to the group of firms with no ICW. Panel C compares the group of firms with a tax ICW to the group of firms with a non-tax ICW. The total number of observations in this sample across all groups is 1,286 firm-level observations. All average values are averaged for the five-year period $t$ - 4 through $t$, except the ICW variables, which are averaged for the three-year period $t-2$ through $t$. 5 year average variables include data for years prior to 2004. All continuous average variables are scaled by the average assets from the years $t-5$ and $t-1$. CASH_ETR5 equals the five-year sum of taxes paid divided by the five-year sum of income less special items; $R O A 5$ is average return on assets; LEV5 is average leverage, FORINC5 is average foreign income; FOROPS5 is an indicator variable equal to one if FORINC5 is nonmissing, non-zero; BM5 is average book-to-market ratio; $A G G R \_L O S S 5$ is an indicator variable equal to one if a firm has a five-year sum of accounting losses; COCF5 is one minus the average operating cash flows; DYR04-DYR06 are indicator variables representing the fiscal years 2004-2006. Average values for CASH ETR5, ROA5, LEV5 and BM5 are winsorized at the $1 \%$ and $99 \%$ levels. The last two columns in each panel report the two-sided p-values for the difference between the two groups of interest in means and medians, respectively. T-tests are used to test the difference in means and Wilcoxon rank tests, with continuity correction, are used to test the difference in medians. ICW refers to internal control weakness. In Panel C, for comparative purposes, the sample of firms with other, non-tax ICWs is constructed such that no firm has a tax ICW also (i.e. mutual exclusivity). 
Panel A: Firms with internal control weaknesses vs. firms without internal control weaknesses

\begin{tabular}{|c|c|c|c|c|c|c|c|c|}
\hline VARIABLE & $\mathrm{N}$ & MEAN & MEDIAN & $\mathrm{N}$ & MEAN & MEDIAN & MEAN & MEDIAN \\
\hline & \multicolumn{3}{|c|}{ Firms with ICWs } & \multicolumn{3}{|c|}{ Firms without ICWs } & \multicolumn{2}{|c|}{ P-values of differences } \\
\hline CASH_ETR5 & 208 & 0.273 & 0.243 & 1078 & 0.222 & 0.228 & 0.01 & 0.08 \\
\hline ROA5 & 208 & 0.078 & 0.068 & 1078 & 0.103 & 0.088 & 0.01 & 0.01 \\
\hline LEV5 & 208 & 0.186 & 0.158 & 1078 & 0.213 & 0.189 & 0.04 & 0.04 \\
\hline FORINC5 & 208 & 0.013 & 0.003 & 1078 & 0.019 & 0.000 & 0.02 & 0.50 \\
\hline FOROPS5 & 208 & 0.611 & 1.000 & 1078 & 0.545 & 1.000 & 0.08 & N/A \\
\hline BM5 & 208 & 0.522 & 0.478 & 1078 & 0.456 & 0.424 & 0.01 & 0.11 \\
\hline AGGR_LOSS5 & 208 & 0.163 & 0.000 & 1078 & 0.051 & 0.000 & 0.01 & 0.01 \\
\hline COCF5 & 208 & 0.891 & 0.908 & 1078 & 0.879 & 0.893 & 0.03 & 0.08 \\
\hline DYR04 & 208 & 0.019 & 0.000 & 1078 & 0.032 & 0.000 & 0.34 & 0.46 \\
\hline DYR05 & 208 & 0.053 & 0.000 & 1078 & 0.050 & 0.000 & 0.87 & 1.00 \\
\hline DYR06 & 208 & 0.928 & 1.000 & 1078 & 0.918 & 1.000 & 0.64 & N/A \\
\hline
\end{tabular}


Panel B: Firms with tax internal control weaknesses vs. firms without internal control weaknesses

\begin{tabular}{|c|c|c|c|c|c|c|c|c|}
\hline VARIABLE & $\mathrm{N}$ & MEAN & MEDIAN & $\mathrm{N}$ & MEAN & MEDIAN & MEAN & MEDIAN \\
\hline & \multicolumn{3}{|c|}{ Firms with tax ICWs } & \multicolumn{3}{|c|}{ Firms without ICWs } & \multicolumn{2}{|c|}{ P-values of differences } \\
\hline CASH_ETR5 & 83 & 0.308 & 0.261 & 1078 & 0.222 & 0.228 & 0.01 & 0.11 \\
\hline ROA5 & 83 & 0.049 & 0.044 & 1078 & 0.103 & 0.088 & 0.01 & 0.01 \\
\hline LEV5 & 83 & 0.208 & 0.181 & 1078 & 0.213 & 0.189 & 0.80 & 0.83 \\
\hline FORINC5 & 83 & 0.016 & 0.009 & 1078 & 0.019 & 0.000 & 0.50 & 0.01 \\
\hline FOROPS5 & 83 & 0.795 & 1.000 & 1078 & 0.545 & 1.000 & 0.01 & N/A \\
\hline BM5 & 83 & 0.560 & 0.558 & 1078 & 0.456 & 0.424 & 0.01 & 0.02 \\
\hline AGGR_LOSS5 & 83 & 0.313 & 0.000 & 1078 & 0.051 & 0.000 & 0.01 & 0.01 \\
\hline COCF5 & 83 & 0.909 & 0.919 & 1078 & 0.879 & 0.893 & 0.01 & 0.01 \\
\hline DYR04 & 83 & 0.024 & 0.000 & 1078 & 0.032 & 0.000 & 0.71 & 0.96 \\
\hline DYR05 & 83 & 0.048 & 0.000 & 1078 & 0.050 & 0.000 & 0.94 & 0.85 \\
\hline DYR06 & 83 & 0.928 & 1.000 & 1078 & 0.918 & 1.000 & 0.76 & N/A \\
\hline
\end{tabular}


Panel C: Firms with tax internal control weaknesses vs. firms with other non-tax internal control weaknesses

\begin{tabular}{|c|c|c|c|c|c|c|c|c|}
\hline VARIABLE & $\mathrm{N}$ & MEAN & MEDIAN & $\mathrm{N}$ & MEAN & MEDIAN & MEAN & MEDIAN \\
\hline & \multicolumn{3}{|c|}{ Firms with tax ICWs } & \multicolumn{3}{|c|}{ Firms with other ICWs } & \multicolumn{2}{|c|}{ P-values of differences } \\
\hline CASH_ETR5 & 83 & 0.308 & 0.261 & 125 & 0.249 & 0.233 & 0.11 & 0.40 \\
\hline ROA5 & 83 & 0.049 & 0.044 & 125 & 0.097 & 0.082 & 0.01 & 0.01 \\
\hline LEV5 & 83 & 0.208 & 0.181 & 125 & 0.171 & 0.146 & 0.12 & 0.09 \\
\hline FORINC5 & 83 & 0.016 & 0.009 & 125 & 0.010 & 0.000 & 0.27 & 0.01 \\
\hline FOROPS5 & 83 & 0.795 & 1.000 & 125 & 0.488 & 0.000 & 0.01 & N/A \\
\hline BM5 & 83 & 0.560 & 0.558 & 125 & 0.496 & 0.433 & 0.12 & 0.02 \\
\hline AGGR_LOSS5 & 83 & 0.313 & 0.000 & 125 & 0.064 & 0.000 & 0.01 & 0.01 \\
\hline COCF5 & 83 & 0.909 & 0.919 & 125 & 0.878 & 0.892 & 0.01 & 0.01 \\
\hline DYR04 & 83 & 0.024 & 0.000 & 125 & 0.016 & 0.000 & 0.68 & 0.92 \\
\hline DYR05 & 83 & 0.048 & 0.000 & 125 & 0.056 & 0.000 & 0.81 & 0.94 \\
\hline DYR06 & 83 & 0.928 & 1.000 & 125 & 0.928 & 1.000 & 0.99 & N/A \\
\hline
\end{tabular}




\section{TABLE 4}

\section{Pearson Correlation Matrix}

The following table provides Pearson correlations for the average variables in my firm-level sample. Correlations of more than $5 \%$ in absolute values are generally statistically significant at the $5 \%$ level or better. All average values are averaged for the five-year period $t-4$ through $t$, except the ICW variables, which are averaged for the three-year period $t$-2 through $t$. 5-year average variables include data for years prior to 2004 . All continuous average variables are scaled by the average assets from the years $t-5$ and $t-1$. CASH ETR5 equals the five-year sum of taxes paid divided by the five-year sum of income less special items. TICW3_COMP3 is an indicator variable equal to one if a firm has a tax internal control weakness and a company-level internal control weakness identified during the sample period; TICW3 ACCT3, OICW3 COMP3 and $O I C W 3 \_A C C T 3$ are similarly measured, with $O I C W$ representing other non-tax internal control weaknesses and $\bar{A} C C T$ representing account-level internal control weaknesses. ROA5 is average return on assets; LEV5 is average leverage, FORINC5 is average foreign income; FOROPS5 is an indicator variable equal to one if FORINC5 is non-missing, non-zero; BM5 is average book-to-market ratio; $A G G R \_L O S S 5$ is an indicator variable equal to one if a firm has a five-year sum of accounting losses; COCF5 is one minus the average operating cash flows. Average values for CASH ETR5, ROA5, LEV5 and BM5 are winsorized at the 1\% and 99\% levels. ICW refers to internal control weakness.

\begin{tabular}{|c|c|c|c|c|c|c|c|c|c|c|c|}
\hline VARIABLE & $\begin{array}{l}\text { CASH } \\
\text { ETR5 }\end{array}$ & $\begin{array}{l}\text { TICW3 } \\
\text { ACCT3 } \\
\end{array}$ & $\begin{array}{l}\text { TICW3 } \\
\text { COMP3 }\end{array}$ & $\begin{array}{l}\text { OICW3 } \\
\text { ACCT3 }\end{array}$ & $\begin{array}{l}\text { OICW3 } \\
\text { COMP3 }\end{array}$ & ROA5 & LEV5 & FORINC5 & FOROPS5 & BM5 & $\begin{array}{l}\text { AGGR } \\
\text { LOSS5 } \\
\end{array}$ \\
\hline TICW3_ACCT3 & 0.024 & & & & & & & & & & \\
\hline TICW3_COMP3 & 0.116 & -0.024 & & & & & & & & & \\
\hline OICW3_ACCT3 & -0.010 & -0.019 & -0.048 & & & & & & & & \\
\hline OICW3_COMP3 & 0.084 & -0.028 & 0.189 & -0.056 & & & & & & & \\
\hline ROA5 & 0.055 & -0.039 & -0.157 & 0.041 & -0.077 & & & & & & \\
\hline LEV5 & -0.138 & -0.019 & 0.007 & -0.068 & -0.032 & -0.268 & & & & & \\
\hline FORINC5 & -0.016 & 0.013 & -0.019 & -0.045 & -0.081 & 0.258 & -0.106 & & & & \\
\hline FOROPS5 & 0.061 & 0.054 & 0.114 & -0.088 & 0.042 & -0.053 & -0.128 & 0.472 & & & \\
\hline BM5 & 0.020 & 0.025 & 0.089 & 0.007 & 0.049 & -0.449 & 0.050 & -0.251 & -0.162 & & \\
\hline AGGR_LOSS5 & 0.201 & 0.037 & 0.256 & -0.038 & 0.073 & -0.402 & 0.086 & -0.092 & 0.158 & 0.118 & \\
\hline COCF5 & 0.025 & 0.034 & 0.096 & -0.049 & 0.037 & -0.783 & 0.184 & -0.214 & 0.038 & 0.451 & 0.214 \\
\hline
\end{tabular}




\title{
TABLE 5
}

\section{Firm ANALYSIS OF TAX AVOIDANCE \& INTERNAL CONTROL WEAKNESSES}

\author{
Equations (2) and (3) are as follows: \\ CASH_ETR5 $5_{i t}=\beta_{0}+\beta_{1}$ TICW $_{i t}+\beta_{2}$ OICW $_{i t}+\beta_{3} R O A 5_{i t}+\beta_{4} L E V 5_{i t}+\beta_{5}$ FORINC5 $_{i t}+\beta_{6}$ FOROPS5 $_{i t}$ \\ $+\beta_{7} B M 5_{i t}+\beta_{8} A G G \beta_{-} L O S S 5_{i t}+\beta_{9} C O C F 5_{i t}+\Sigma_{t} D Y E A R_{t}+\sum_{j} D I N D_{j}+\varepsilon_{i t}$ \\ $\mathrm{CASH}_{2} \mathrm{ETRS}_{i t}=\beta_{0}+\beta_{1}$ TICW3_ACCT3 ${ }_{i t}+\beta_{2}$ TICW3_COMP3 $3_{i t}+\beta_{3}$ OICW3_ACCT3 ${ }_{i t}+$ \\ $\beta_{4} O I C W 3_{-} C O M P 3_{i t}+\beta_{5}$ ROA5 $_{i t}+\beta_{6}$ LEV5 $_{i t}+\beta_{7}$ FORINC5 $_{i t}+\beta_{8}$ FOROPS5 $_{i t}+\beta_{9}$ BM5 $_{i t}+$ \\ $\beta_{10} A G G R_{-} L O S S 5_{i t}+\beta_{11}$ COCF $_{i t}+\sum_{t}$ DYEAR $_{t}+\Sigma_{j} D I N D_{j}+\varepsilon_{i t}$

The empirical regressions are estimated with one observation per firm during the period 2004-2006. Over $90 \%$ of the observations are measured as at 2006. All average values are averaged for the five-year period $t$ - 4 through $t$, except the ICW variables, which are averaged for the three-year period $t$ - 2 through $t$. 5 -year average variables include data for years prior to 2004. All continuous average variables are scaled by the average assets from the years $t-5$ and $t-1$. CASH_ETR5 equals the five-year sum of taxes paid divided by the five-year sum of income less special items. TICW3 is an indicator variable equal to one if a firm has a tax internal control weakness during the sample period, and $O I C W 3$ is an indicator variable equal to one if a firm has a non-tax internal control weakness during the sample period (and no tax ICW). TICW3 COMP3 is an indicator variable equal to one if a firm has a tax internal control weakness and a company-level internal control weakness identified during the sample period; TICW3_ACCT3, $O I C W 3 \_C O M P 3$ and $O I C W 3 \_A C C T 3$ are similarly measured, with $O I C W$ representing other non-tax internal control weaknesses and $A C C T$ representing account-level internal control weaknesses. ROA5 is average return on assets; LEV 5 is average leverage, FORINC5 is average foreign income; FOROPS5 is an indicator variable equal to one if FORINC5 is non-missing, non-zero; BM5 is average book-to-market ratio; $A G G R \_L O S S 5$ is an indicator variable equal to one if a firm has a five-year sum of accounting losses; COCF 5 is one minus the average operating cash flows; DYR04 and DYR05 are indicator variables representing the fiscal years 2004 and 2005. The DIND indicator variables represent two-digit NAICS industry membership. Average values for CASH_ETR5, ROA5, LEV5 and BM5 are winsorized at the 1\% and $99 \%$ levels. Standard errors have been adjusted for clustering within two-digit industry and are reported in parentheses. $* * * * * *$ refer to significance at the $10 \%, 5 \%$ and $1 \%$ levels, respectively. Significance for all variables with a predicted sign is calculated using a one-tailed test; for all other variables, including unreported year and industry effects, two-tailed tests are calculated. 


\begin{tabular}{|c|c|c|c|c|c|}
\hline \multirow{3}{*}{$\frac{\text { VARIABLE }}{\text { INTERCEPT }}$} & \multirow{2}{*}{$\begin{array}{l}\text { PRED. } \\
\text { SIGN }\end{array}$} & \multicolumn{4}{|c|}{$\underline{\text { DEPENDENT VARIABLE = CASH ETR5 }}$} \\
\hline & & \multicolumn{2}{|c|}{ TEST OF H1 } & \multicolumn{2}{|c|}{ TEST OF H2 \& H3 } \\
\hline & $?$ & $\begin{array}{l}-0.445 \\
(0.191)\end{array}$ & $* *$ & $\begin{array}{l}-0.429 \\
(0.189)\end{array}$ & $* * *$ \\
\hline TICW3 & ? & $\begin{array}{l}0.045 \\
(0.017)\end{array}$ & $* *$ & & \\
\hline OICW3 & & $\begin{array}{l}0.025 \\
(0.016)\end{array}$ & & & \\
\hline TICW3_ACCT3 & ? & & & $\begin{array}{l}0.023 \\
(0.036)\end{array}$ & \\
\hline TICW3_COMP3 & ? & & & $\begin{array}{l}0.043 \\
(0.019)\end{array}$ & $* *$ \\
\hline OICW3_ACCT3 & & & & $\begin{array}{l}-0.021 \\
(0.012)\end{array}$ & \\
\hline OICW3_COMP3 & & & & $\begin{array}{l}0.048 \\
(0.023)\end{array}$ & $*$ \\
\hline ROA5 & - & $\begin{array}{l}0.723 \\
(0.197)\end{array}$ & $* * *$ & $\begin{array}{l}0.721 \\
(0.196)\end{array}$ & $* * *$ \\
\hline LEV5 & - & $\begin{array}{l}-0.105 \\
(0.066)\end{array}$ & $*$ & $\begin{array}{l}-0.106 \\
(0.065)\end{array}$ & $*$ \\
\hline FORINC5 & - & $\begin{array}{l}-0.187 \\
(0.121)\end{array}$ & * & $\begin{array}{l}-0.169 \\
(0.123)\end{array}$ & $*$ \\
\hline FOROPS5 & - & $\begin{array}{l}0.018 \\
(0.011)\end{array}$ & $*$ & $\begin{array}{l}0.016 \\
(0.011)\end{array}$ & $*$ \\
\hline BM5 & - & $\begin{array}{l}0.026 \\
(0.027)\end{array}$ & & $\begin{array}{l}0.026 \\
(0.027)\end{array}$ & \\
\hline AGGR_LOSS5 & + & $\begin{array}{l}0.180 \\
(0.055)\end{array}$ & $* * *$ & $\begin{array}{l}0.179 \\
(0.054)\end{array}$ & $* * *$ \\
\hline COCF5 & + & $\begin{array}{l}0.552 \\
(0.171)\end{array}$ & $* * *$ & $\begin{array}{l}0.548 \\
(0.170)\end{array}$ & $* * *$ \\
\hline $\begin{array}{l}\text { Industry and Year indicators } \\
\text { F-stat } \\
\text { (Probability) }\end{array}$ & & $\begin{array}{l}\text { Industry } \\
5511.450 \\
(0.000)\end{array}$ & $\begin{array}{l}\text { Year } \\
0.130 \\
(0.883)\end{array}$ & $\begin{array}{l}\text { Industry } \\
11837.620 \\
(0.000)\end{array}$ & $\begin{array}{l}\text { Year } \\
0.140 \\
(0.873)\end{array}$ \\
\hline $\begin{array}{l}\text { Adjusted } \mathrm{R}^{2} \\
\text { Number of firms with material weaknesses } \\
\text { Number of total observations }\end{array}$ & & $\begin{array}{l}14.92 \% \\
208 \\
1286\end{array}$ & & $\begin{array}{l}15.30 \% \\
208 \\
1286\end{array}$ & \\
\hline
\end{tabular}




\title{
TABLE 6
}

\section{Firm-Year ANALYSIS of TAX AVOIDANCE \& INTERnal CONTROL WEAKNESSES USING OVERLAPPING, AVERAge VARIABLES}

\author{
Equations (2) and (3) are as follows: \\ CASH_ETR $5_{i t}=\beta_{0}+\beta_{1}$ TICW $_{i t}+\beta_{2}$ OICW $_{i t}+\beta_{3}$ ROA $_{i t}+\beta_{4}$ LEV $_{i t}+\beta_{5}$ FORINC $_{i t}+\beta_{6}$ FOROPS $_{i t}$ \\ $+\beta_{7} B M 5_{i t}+\beta_{8} A G G R_{-}$LOSS5 $_{i t}+\beta_{9}$ COCF $_{i t}+\Sigma_{t} D_{\text {YEAR }}+\Sigma_{j} D I N D_{j}+\varepsilon_{i t}$ \\ (2); \\ CASH_ETR5 $5_{i t}=\beta_{0}+\beta_{1}$ TICW3_ACCT3 ${ }_{i t}+\beta_{2}$ TICW3_COMP3 ${ }_{i t}+\beta_{3} O I C W 3_{-} A C C T 3_{i t}+$ \\ $\beta_{4}$ OICW3_COMP $3_{i t}+\beta_{5}$ ROA5 $_{i t}+\beta_{6}$ LEV5 $_{i t}+\beta_{7}$ FORINC5 $_{i t}+\beta_{8}$ FOROPS5 $5_{i t}+\beta_{9}$ BM5 $_{i t}+$ \\ $\beta_{10} A G G R_{-} L O S S 5_{i t}+\beta_{11} C O C F 5_{i t}+\Sigma_{t} D_{Y E A R_{t}}+\Sigma_{j} D I N D_{j}+\varepsilon_{i t}$

The empirical regressions are estimated with multiple, overlapping observations per firm during the period 2004-2006. Over 90\% of the observations are measured as at 2006. All average values are averaged for the five-year period $t-4$ through $t$, except the ICW variables, which are averaged for the three-year period $t$-2 through $t$. 5-year average variables include data for years prior to 2004. All continuous average variables are scaled by the average assets from the years $t-5$ and $t-1$. CASH_ETR5 equals the five-year sum of taxes paid divided by the five-year sum of income less special items. $\bar{T} I C W 3$ is an indicator variable equal to one if a firm has a tax internal control weakness during the sample period, and $O I C W 3$ is an indicator variable equal to one if a firm has a non-tax internal control weakness during the sample period (and no tax ICW). TICW3_COMP3 is an indicator variable equal to one if a firm has a tax internal control weakness and a company-level internal control weakness identified during the sample period; TICW3_ACCT3, OICW3_COMP3 and OICW3_ACCT3 are similarly measured, with $O I C W$ representing other non-tax internal control weaknesses and $A C C T$ representing account-level internal control weaknesses. ROA5 is average return on assets; LEV5 is average leverage, FORINC5 is average foreign income; FOROPS5 is an indicator variable equal to one if FORINC5 is non-missing, non-zero; $B M 5$ is average book-to-market ratio; $A G G R \_L O S S 5$ is an indicator variable equal to one if a firm has a five-year sum of accounting losses; COCF 5 is one minus the average operating cash flows; DYR04DYR06 are indicator variables representing the fiscal years 2004-2006. Average values for CASH_ETR5, ROA5, LEV 5 and BM5 are winsorized at the $1 \%$ and $99 \%$ levels. Standard errors have been adjusted for two-way clustering within two-digit industry and firm, and are reported in parentheses. $* * * * * *$ refer to significance at the $10 \%, 5 \%$ and $1 \%$ levels, respectively. Significance for all variables with a predicted sign is calculated using a one-tailed test; for all other variables, including unreported year and industry effects, two-tailed tests are calculated. 


\begin{tabular}{|c|c|c|c|c|c|}
\hline \multirow{3}{*}{$\frac{\text { VARIABLE }}{\text { INTERCEPT }}$} & \multirow{2}{*}{$\begin{array}{l}\text { PRED. } \\
\text { SIGN }\end{array}$} & \multicolumn{4}{|c|}{ DEPENDENT VARIABLE = CASH ETR5 } \\
\hline & & \multicolumn{2}{|c|}{ TEST OF H1 } & \multicolumn{2}{|c|}{ TEST OF H2 \& H3 } \\
\hline & ? & $\begin{array}{l}-0.476 \\
(0.117)\end{array}$ & $* * *$ & $\begin{array}{l}-0.465 \\
(0.114)\end{array}$ & $* * *$ \\
\hline TICW3 & ? & $\begin{array}{l}0.052 \\
(0.021)\end{array}$ & $* *$ & & \\
\hline OICW3 & & $\begin{array}{l}0.013 \\
(0.018)\end{array}$ & & & \\
\hline TICW3_ACCT3 & ? & & & $\begin{array}{l}0.069 \\
(0.047)\end{array}$ & \\
\hline TICW3_COMP3 & ? & & & $\begin{array}{l}0.044 \\
(0.020)\end{array}$ & $* *$ \\
\hline OICW3_ACCT3 & & & & $\begin{array}{l}-0.025 \\
(0.016)\end{array}$ & \\
\hline OICW3_COMP3 & & & & $\begin{array}{l}0.038 \\
(0.023)\end{array}$ & * \\
\hline ROA5 & - & $\begin{array}{l}0.611 \\
(0.084)\end{array}$ & $* * *$ & $\begin{array}{l}0.606 \\
(0.084)\end{array}$ & $* * *$ \\
\hline LEV5 & - & $\begin{array}{l}-0.114 \\
(0.056)\end{array}$ & $* *$ & $\begin{array}{l}-0.115 \\
(0.056)\end{array}$ & $* *$ \\
\hline FORINC5 & - & $\begin{array}{l}-0.075 \\
(0.127)\end{array}$ & & $\begin{array}{l}-0.063 \\
(0.129)\end{array}$ & \\
\hline FOROPS5 & - & $\begin{array}{l}0.003 \\
(0.011)\end{array}$ & & $\begin{array}{l}0.001 \\
(0.011)\end{array}$ & \\
\hline BM5 & - & $\begin{array}{l}0.011 \\
(0.019)\end{array}$ & & $\begin{array}{l}0.011 \\
(0.019)\end{array}$ & \\
\hline AGGR_LOSS5 & + & $\begin{array}{l}0.172 \\
(0.056)\end{array}$ & $* * *$ & $\begin{array}{l}0.171 \\
(0.056)\end{array}$ & $* * *$ \\
\hline COCF5 & + & $\begin{array}{l}0.619 \\
(0.113)\end{array}$ & $* * *$ & $\begin{array}{l}0.613 \\
(0.111)\end{array}$ & $* * *$ \\
\hline $\begin{array}{l}\text { Industry and Year indicators } \\
\text { F-stat } \\
\text { (Probability) }\end{array}$ & & $\begin{array}{l}\text { Industry } \\
2826.353 \\
(0.000)\end{array}$ & $\begin{array}{l}\text { Year } \\
0.809 \\
(0.446)\end{array}$ & $\begin{array}{l}\text { Industry } \\
2334.017 \\
(0.000)\end{array}$ & $\begin{array}{l}\text { Year } \\
0.905 \\
(0.405)\end{array}$ \\
\hline $\begin{array}{l}\text { Adjusted } \mathrm{R}^{2} \\
\text { Number of firms with material weaknesses } \\
\text { Number of total observations }\end{array}$ & & $\begin{array}{l}12.01 \% \\
271 \\
3351\end{array}$ & & $\begin{array}{l}12.26 \% \\
271 \\
3351\end{array}$ & \\
\hline
\end{tabular}




\section{TABLE 7}

\section{SUMMARY STATISTICS FOR VARIABLES IN SECTION 5.4 ROBUSTNESS TESTS}

Panels A and B present summary statistics for the firm-level sample of observations, and Panels C and D present summary statistics for the annual sample and overlapping, annual sample of observations. Panels A and C represent all observations in the respective samples, Panels B and D represent the observations with ICWs in the respective samples.

In Panels A and B, GOVERN is a proxy for corporate governance that is calculated as the mean value of a firm's available Gompers et al. (2003) G-Index ratings. Higher values of GOVERN indicate weaker corporate governance. POOR_GOV is an indicator variable equal to one for firms with above median GOVERN scores and zero for firms with at or below median GOVERN scores. CC15 and CC25 are values derived from factor analysis on five proxies of resource constraints: a continuous measure of $A G G R$ LOSS5 (one minus five-year average income before extraordinary items), COCF5, CLEV5 (one minus LEV5), DEBT5 (one minus five-year average debt-to assets ratio) and NRATING5 (indicator of no public bond rating during the five year period from t-4 to t). $C C 15$ is a proxy for constrained resource flows (income and cash) and $C C 25$ is a proxy for constrained debt capacity. CC15_HIGH represents firms with the most constrained resources and is equal to one if an observation is in the top third of the range of $C C 15$ and zero otherwise. Variables for the interaction between $C C 15$ and each of the account-level and companylevel internal control weakness variables are $T A C C T 3^{*} C C 15, T C O M P 3 * C C 15, O A C C T 3{ }^{*} C C 15$ and $O C O M P 3 * C C 15$. Variables for the interaction between $\mathrm{CC} 15 \mathrm{HIGH}$ and each of the account-level and company-level internal control weakness variables are TACCT3*CC15_HIGH, TCOMP3*CC15_HIGH, OACCT3*CC15_HIGH, OCOMP3*CC15_HIGH.

In Panels C and D, BTD1 is the Manzon-Plesko (2002) BTD measure, equal to [US domestic pre-tax income - (current US domestic tax expense / US statutory rate) - state income taxes - other income taxes - equity in earnings] / lagged assets. BTD2 is the total BTD measure as described in Table 1 of Hanlon and Heitzman (2010), equal to [pre-tax income - (current US domestic tax expense + current foreign tax expense) / US statutory rate - change in NOL from t-1 to t] / lagged assets. "WEAK" and "FIXED" variables, based on Ashbaugh-Skaife et al. (2008), are included in the table below. The "FIXED" variables represent remediation of ICWs. WEAK_TAX and WEAK_OTHER are indicator variables equal to one if a firm has a tax ICW or other (non-tax) ICW, respectively, in the current or prior year, and zero otherwise. WEAK_TAX_ACCT, WEAK_TAX_COMP, WEAK_OTHER_ACCT and WEAK_OTHER_COMP are measured similarly, where the general ICWs are separated into account-level and company-level components. TAX_FIXED and ${ }_{-} T_{H E R} F I X E D$ are indicator variables equal to one if a firm has a tax ICW or other ICW, respectively, in the prior year but not the current year, and zero otherwise. TAX_ACCT_FIXED, TAX_COMP_FIXED, OTHER_ACCT_FIXED and OTHER_COMP_FIXED are measured similarly, again where general ICWs are separated into account-level and company-level components. 
Panel A: Average Variables for Full Firm-Level Sample

\begin{tabular}{|c|c|c|c|c|c|c|c|}
\hline VARIABLE & DESCRIPTION & $\mathrm{N}$ & MEAN & STD DEV & 5 th \% & MEDIAN & 95th \% \\
\hline GOVERN & Mean G-Index score & 1181 & 8.936 & 2.456 & 5.000 & 9.000 & 13.000 \\
\hline POOR_GOV & Indicator equal to 1 if mean G-Index above median & 1181 & 0.406 & 0.491 & 0 & 0.000 & 1 \\
\hline CC15 & Factor for constrained resource flows & 1286 & -0.161 & 0.790 & -1 & 0.007 & 1 \\
\hline CC25 & Factor for constrained debt capacity & 1286 & 0.031 & 0.898 & -1 & -0.113 & 1 \\
\hline CC15_HIGH & Indicator equal to 1 if CC15 is in the top percentile & 1286 & 0.333 & 0.471 & 0.000 & 0.000 & 1.000 \\
\hline TACCT3*CC15 & Interaction term: TICW3_ACCT3 \& CC15 & 1286 & 0.002 & 0.048 & 0 & 0.000 & 0 \\
\hline ТСОМР3*CC15 & Interaction term: TICW3_COMP3 \& CC15 & 1286 & 0.015 & 0.186 & 0.000 & 0.000 & 0.000 \\
\hline ОАССТ3*CC15 & Interaction term: OICW3_ACCT3 \& CC15 & 1286 & -0.012 & 0.157 & 0.000 & 0.000 & 0.000 \\
\hline ОСОМР3*СС15 & Interaction term: OICW3_COMP3 \& CC15 & 1286 & 0.002 & 0.226 & 0.000 & 0.000 & 0.000 \\
\hline TACCT3*CC15_HIGH & Interaction term: TICW3_ACCT3 \& CC15_HIGH & 1286 & 0.004 & 0.062 & 0 & 0.000 & 0 \\
\hline TCOMP3*CC15_HIGH & Interaction term: TICW3_COMP3 \& CC15_HIGH & 1286 & 0.031 & 0.174 & 0.000 & 0.000 & 0.000 \\
\hline OACCT3*CC15_HIGH & Interaction term: OICW3_ACCT3 \& CC15_HIGH & 1286 & 0.009 & 0.092 & 0 & 0.000 & 0 \\
\hline OCOMP3*CC15_HIGH & Interaction term: OICW3_COMP3 \& CC15_HIGH & 1286 & 0.033 & 0.180 & 0.000 & 0.000 & 0.000 \\
\hline
\end{tabular}


Panel B: Average Variables for Firm-Level ICW Sample

\begin{tabular}{|c|c|c|c|c|c|c|c|}
\hline VARIABLE & DESCRIPTION & $\mathrm{N}$ & MEAN & STD DEV & 5 th $\%$ & MEDIAN & 95th \% \\
\hline GOVERN & Mean G-Index score & 185 & 8.551 & 2.465 & 5.000 & 8.000 & 13.000 \\
\hline POOR_GOV & Indicator equal to 1 if mean G-Index above median & 185 & 0.351 & 0.479 & 0 & 0.000 & 1 \\
\hline CC15 & Factor for constrained resource flows & 208 & 0.020 & 0.794 & -1 & 0.159 & 1 \\
\hline CC25 & Factor for constrained debt capacity & 208 & 0.208 & 0.924 & -1 & 0.153 & 1 \\
\hline CC15_HIGH & Indicator equal to 1 if CC15 is in the top percentile & 208 & 0.428 & 0.496 & 0.000 & 0.000 & 1.000 \\
\hline ТАССТ3*CC15 & Interaction term: TICW3_ACCT3 \& CC15 & 208 & 0.011 & 0.119 & 0 & 0.000 & 0 \\
\hline TCOMP3*CC15 & Interaction term: TICW3_COMP3 \& CC15 & 208 & 0.094 & 0.454 & -0.310 & 0.000 & 0.840 \\
\hline ОАССТЗ*СС15 & Interaction term: OICW3_ACCT3 \& CC15 & 208 & -0.073 & 0.385 & -0.906 & 0.000 & 0.375 \\
\hline OCOMP3*CC15 & Interaction term: OICW3_COMP3 \& CC15 & 208 & 0.013 & 0.564 & -0.940 & 0.000 & 0.695 \\
\hline TACCT3*CC15_HIGH & Interaction term: TICW3_ACCT3 \& CC15_HIGH & 208 & 0.024 & 0.154 & 0 & 0.000 & 0 \\
\hline TCOMP3*CC15_HIGH & Interaction term: TICW3_COMP3 \& CC15_HIGH & 208 & 0.192 & 0.395 & 0.000 & 0.000 & 1.000 \\
\hline OACCT3*CC15_HIGH & Interaction term: OICW3_ACCT3 \& CC15_HIGH & 208 & 0.053 & 0.224 & 0 & 0.000 & 1 \\
\hline OCOMP3*CC15_HIGH & Interaction term: OICW3_COMP3 \& CC15_HIGH & 208 & 0.207 & 0.406 & 0.000 & 0.000 & 1.000 \\
\hline
\end{tabular}


Panel C: Annual Variables for Full Sample re: Tests of BTDs and Remediation

\begin{tabular}{|c|c|c|c|c|c|c|c|}
\hline VARIABLE & DESCRIPTION & $\mathrm{N}$ & MEAN & STD DEV & 5th \% & MEDIAN & 95th \% \\
\hline BTD1 & Manzon-Plesko book-tax difference & 3355 & -0.042 & 0.094 & -0.229 & -0.012 & 0.061 \\
\hline BTD2 & Alternative book-tax difference & 2077 & 0.008 & 0.114 & 0 & 0.016 & 0 \\
\hline WEAK_TAX & TICW in the current or prior year & 3355 & 0.055 & 0.228 & 0 & 0.000 & 1 \\
\hline WEAK_OTHER & OICW in the current or prior year & 3355 & 0.078 & 0.269 & 0 & 0.000 & 1 \\
\hline TAX_FIXED & TICW in the prior year only & 3355 & 0.018 & 0.133 & 0 & 0.000 & 0 \\
\hline OTHER_FIXED & OICW in the prior year only & 3355 & 0.029 & 0.168 & 0.000 & 0.000 & 0.000 \\
\hline WEAK_TAX_ACCT & TICW_ACCT in the current or prior year & 3355 & 0.014 & 0.116 & 0.000 & 0.000 & 0.000 \\
\hline WEAK_TAX_COMP & TICW_COMP in the current or prior year & 3355 & 0.043 & 0.203 & 0.000 & 0.000 & 0.000 \\
\hline WEAK_OTHER_ACCT & OICW_ACCT in the current or prior year & 3355 & 0.031 & 0.173 & 0 & 0.000 & 0 \\
\hline WEAK_OTHER_COMP & OICW_COMP in the current or prior year & 3355 & 0.049 & 0.216 & 0.000 & 0.000 & 0.000 \\
\hline TAX_ACCT_FIXED & TICW_ACCT in the prior year only & 3355 & 0.005 & 0.071 & 0 & 0.000 & 0 \\
\hline TAX_COMP_FIXED & TICW_COMP in the prior year only & 3355 & 0.015 & 0.120 & 0.000 & 0.000 & 0.000 \\
\hline OTHER_ACCT_FIXED & OICW_ACCT in the prior year only & 3355 & 0.013 & 0.114 & 0.000 & 0.000 & 0.000 \\
\hline OTHER_COMP_FIXED & OICW_COMP in the prior year only & 3355 & 0.018 & 0.133 & 0.000 & 0.000 & 0.000 \\
\hline
\end{tabular}


Panel D: Annual Variables for ICW Sample re: Tests of BTDs and Remediation

\begin{tabular}{|c|c|c|c|c|c|c|c|}
\hline VARIABLE & DESCRIPTION & $\mathrm{N}$ & MEAN & STD DEV & 5 th \% & MEDIAN & 95th \% \\
\hline BTD1 & Manzon-Plesko book-tax difference & 289 & -0.044 & 0.093 & -0.209 & -0.015 & 0.056 \\
\hline BTD2 & Alternative book-tax difference & 172 & -0.031 & 0.154 & 0 & -0.006 & 0 \\
\hline WEAK_TAX & TICW in the current or prior year & 289 & 0.464 & 0.500 & 0 & 0.000 & 1 \\
\hline WEAK_OTHER & OICW in the current or prior year & 289 & 0.606 & 0.490 & 0 & 1.000 & 1 \\
\hline TAX_FIXED & TICW in the prior year only & 289 & 0.035 & 0.183 & 0 & 0.000 & 0 \\
\hline OTHER_FIXED & OICW in the prior year only & 289 & 0.035 & 0.183 & 0.000 & 0.000 & 0.000 \\
\hline WEAK_TAX_ACCT & TICW_ACCT in the current or prior year & 289 & 0.111 & 0.314 & 0.000 & 0.000 & 1.000 \\
\hline WEAK_TAX_COMP & TICW_COMP in the current or prior year & 289 & 0.374 & 0.485 & 0.000 & 0.000 & 1.000 \\
\hline WEAK_OTHER_ACCT & OICW_ACCT in the current or prior year & 289 & 0.228 & 0.421 & 0 & 0.000 & 1 \\
\hline WEAK_OTHER_COMP & OICW_COMP in the current or prior year & 289 & 0.398 & 0.490 & 0.000 & 0.000 & 1.000 \\
\hline TAX_ACCT_FIXED & TICW_ACCT in the prior year only & 289 & 0.010 & 0.102 & 0 & 0.000 & 0 \\
\hline TAX_COMP_FIXED & TICW_COMP in the prior year only & 289 & 0.045 & 0.208 & 0.000 & 0.000 & 0.000 \\
\hline OTHER_ACCT_FIXED & OICW_ACCT in the prior year only & 289 & 0.021 & 0.143 & 0.000 & 0.000 & 0.000 \\
\hline OTHER_COMP_FIXED & OICW_COMP in the prior year only & 289 & 0.035 & 0.183 & 0.000 & 0.000 & 0.000 \\
\hline
\end{tabular}




\section{TABLE 8}

\section{Analysis of Tax Avoidance \& Internal ConTrol Weaknesses with BTD Proxies}

The regression equations are as follows:

$$
\begin{aligned}
& B T D_{i t}=\beta_{0}+\beta_{1} \text { TICW }_{i t}+\beta_{2} \text { OICW }_{i t}+\beta_{3} \text { ROA }_{i t}+\beta_{4} L E V_{i t}+\beta_{5} \text { FORINC }_{i t}+\beta_{6} \text { FOROPS }_{i t}+\beta_{7} \text { BM }_{i t}+ \\
& \beta_{8} A G G R \_L O S S_{i t}+\beta_{9} C O C F_{i t}+\Sigma_{t} D_{Y E A R}+\Sigma_{j} D I N D_{j}+\varepsilon_{i t} \text {; } \\
& B T D_{i t}=\beta_{0}+\beta_{1} T I C W_{-} A C C T_{i t}+\beta_{2} \text { TICW_COMP } P_{i t}+\beta_{3} O I C W_{-} A C C T_{i t}+\beta_{4} O I C W_{-} C O M P_{i t}+\beta_{5} R O A_{i t}
\end{aligned}
$$

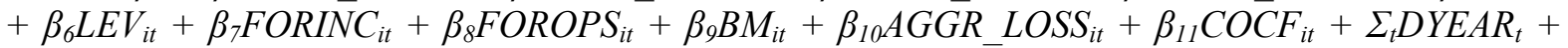

$$
\begin{aligned}
& \Sigma_{j} D I N D_{j}+\varepsilon_{i t}
\end{aligned}
$$

The empirical regressions are estimated with annual observations during the period 2004-2006. $B T D$ refers to one of the two book-tax difference (BTD) proxies, BTD1 and BTD2, which replace CASH_ETR as the dependent variable in the regressions. BTD1 is the Manzon-Plesko (2002) BTD measure, equal to [US domestic pre-tax income - (current US domestic tax expense / US statutory rate) - state income taxes - other income taxes - equity in earnings] / lagged assets. BTD2 is the total BTD measure as described in Table 1 of Hanlon and Heitzman (2010), equal to [pre-tax income - (current US domestic tax expense + current foreign tax expense) / US statutory rate - change in NOL from t-1 to t] / lagged assets. Annual variables are simply the one-year value of the average variables described in previous tables. All continuous annual variables are scaled by assets at time $t$ - 1 . Other than $A G G R \_L O S S$ and $B M$, annual values are measured at year $t$. TICW is an indicator variable equal to one if a firm has a tax internal control weakness in the current period, and $\mathrm{OICW}$ is an indicator variable equal to one if a firm has a nontax internal control weakness in the current period (and no tax ICW). TICW_COMP is an indicator variable equal to one if a firm has a tax internal control weakness and a company-level internal control weakness identified during the current period; $T I C W_{-} A C C T, O I C W_{-} C O M P$ and OICW_ACCT are similarly measured, with $O I C W$ representing other non-tax internal control weaknesses and $A C C T$ representing account-level internal control weaknesses. $R O A$ is return on assets; $L E V$ is leverage, FORINC is foreign income; FOROPS is an indicator variable equal to one if FORINC is non-missing, non-zero; $B M$ is book-to-market ratio, measured at $t-1 ; A G G R \_L O S S$ is an indicator variable equal to one if a firm has a sum of pre-tax accounting losses at time $t-1$ and $t$; COCF is one minus operating cash flows; DYR04 and DYR05 are indicator variables representing the fiscal years 2004 and 2005. The DIND indicator variables represent two-digit NAICS industry membership. Annual values for BTD1, BTD2, $R O A, L E V$ and $B M$ are winsorized at the $1 \%$ and $99 \%$ levels. Standard errors have been adjusted for twoway clustering within two-digit industry and firm, and are reported in parentheses. $* * * * * *$ refer to significance at the $10 \%, 5 \%$ and $1 \%$ levels, respectively. Significance for all variables with a predicted sign is calculated using a one-tailed test; for all other variables, including unreported year and industry effects, two-tailed tests are calculated. 


\begin{tabular}{|c|c|c|c|c|c|}
\hline \multirow{2}{*}{$\frac{\text { VARIABLE }}{\text { INTERCEPT }}$} & \multirow{2}{*}{$\begin{array}{l}\text { PRED. } \\
\text { SIGN } \\
?\end{array}$} & \multicolumn{2}{|c|}{$\begin{array}{l}\text { DV = BTD1 } \\
\text { TEST OF H2 \& H3 }\end{array}$} & \multicolumn{2}{|c|}{$\begin{array}{l}\underline{\mathrm{DV}=\mathrm{BTD} 2} \\
\text { TEST OF H2 \& H3 }\end{array}$} \\
\hline & & $\begin{array}{l}-0.093 \\
(0.051)\end{array}$ & $* *$ & $\begin{array}{l}-0.067 \\
(0.053)\end{array}$ & \\
\hline TICW_ACCT & $?$ & $\begin{array}{l}-0.002 \\
(0.013)\end{array}$ & & $\begin{array}{l}-0.010 \\
(0.037)\end{array}$ & \\
\hline TICW_COMP & ? & $\begin{array}{l}-0.033 \\
(0.011)\end{array}$ & $* * *$ & $\begin{array}{l}-0.009 \\
(0.014)\end{array}$ & \\
\hline OICW_ACCT & & $\begin{array}{l}-0.005 \\
(0.009)\end{array}$ & & $\begin{array}{l}0.001 \\
(0.015)\end{array}$ & \\
\hline OICW_COMP & & $\begin{array}{l}0.000 \\
(0.009)\end{array}$ & & $\begin{array}{l}0.010 \\
(0.015)\end{array}$ & \\
\hline ROA & + & $\begin{array}{l}-0.274 \\
(0.047)\end{array}$ & $* * *$ & $\begin{array}{l}0.448 \\
(0.050)\end{array}$ & $* * *$ \\
\hline LEV & + & $\begin{array}{l}0.043 \\
(0.010)\end{array}$ & $* * *$ & $\begin{array}{l}0.025 \\
(0.012)\end{array}$ & $* *$ \\
\hline FORINC & + & $\begin{array}{l}0.217 \\
(0.054)\end{array}$ & $* * *$ & $\begin{array}{l}0.092 \\
(0.090)\end{array}$ & \\
\hline FOROPS & + & $\begin{array}{l}0.083 \\
(0.004)\end{array}$ & $* * *$ & $\begin{array}{l}-0.003 \\
(0.006)\end{array}$ & \\
\hline $\mathrm{BM}$ & + & $\begin{array}{l}0.013 \\
(0.010)\end{array}$ & & $\begin{array}{l}0.047 \\
(0.013)\end{array}$ & $* * *$ \\
\hline AGGR_LOSS & - & $\begin{array}{l}-0.063 \\
(0.007)\end{array}$ & $* * *$ & $\begin{array}{l}-0.083 \\
(0.010)\end{array}$ & $* * *$ \\
\hline COCF & - & $\begin{array}{l}0.063 \\
(0.039)\end{array}$ & $*$ & $\begin{array}{l}0.030 \\
(0.055)\end{array}$ & \\
\hline $\begin{array}{l}\text { Industry and Year indicators } \\
\text { F-stat } \\
\text { (Probability) }\end{array}$ & & $\begin{array}{l}\text { Industry } \\
5.250 \\
(0.000)\end{array}$ & $\begin{array}{l}\text { Year } \\
9.460 \\
(0.000)\end{array}$ & $\begin{array}{l}\text { Industry } \\
5.340 \\
(0.000)\end{array}$ & $\begin{array}{l}\text { Year } \\
0.290 \\
(0.746)\end{array}$ \\
\hline $\begin{array}{l}\text { Adjusted } \mathrm{R}^{2} \\
\text { Number of material weakness observations } \\
\text { Number of total observations }\end{array}$ & & $\begin{array}{l}39.06 \% \\
289 \\
3355\end{array}$ & & $\begin{array}{l}34.18 \% \\
199 \\
2417\end{array}$ & \\
\hline
\end{tabular}




\title{
TABLE 9
}

\section{Firm Analysis of Tax Avoidance With Alternative INTERnAL Control WEAKNESS CATEGORIZATIONS}

\author{
Equation (3) is as follows: \\ CASH_ETR5 $_{i t}=\beta_{0}+\beta_{1}$ TICW3_ACCT3 $i t+\beta_{2}$ TICW3_COMP3 $3_{i t}+\beta_{3}$ OICW3_ACCT3 ${ }_{i t}+$ \\ $\beta_{4} O I C W 3_{-} C O M P 3_{i t}+\beta_{5}$ ROA5 $_{i t}+\beta_{6}$ LEV5 $_{i t}+\beta_{7}$ FORINC5 $_{i t}+\beta_{8} F O R O P S 5_{i t}+\beta_{9}$ BM5 $_{i t}+$ \\ $\beta_{10} A G G R_{-} L O S S 5_{i t}+\beta_{11}$ COCF $_{i t}+\sum_{t}$ DYEAR $_{t}+\sum_{j} D I N D_{j}+\varepsilon_{i t}$.
}

In this table, the empirical regressions are estimated with two alternative classification methods for distinguishing account-level and company-level ICWs. Alternative 1 does not aggregate multiple accountlevel issues (i.e. three or more individual account-level issues) into a company-level ICW. Alternative 2 uses a classification scheme based on guidance from Moody's Investor Group. Alternative 3 uses the Moody's classification scheme but like Alternative 1, does not aggregate multiple account-level issues. These alternatives do not alter the total number of ICWs, simply the classification across account-level and company-level ICW variables.

The regressions use one observation per firm during the period 2004-2006 and over $90 \%$ of the observations are measured as at 2006. All average values are averaged for the five-year period $t-4$ through $t$, except the ICW variables, which are averaged for the three-year period $t$-2 through $t$. 5-year average variables include data for years prior to 2004. All continuous average variables are scaled by the average assets from the years $t-5$ and $t-1$. $C A S H \_E T R 5$ equals the five-year sum of taxes paid divided by the fiveyear sum of income less special items. $T I C W 3$ _COMP3 is an indicator variable equal to one if a firm has a tax internal control weakness and a company-level internal control weakness identified during the sample period; TICW3 ACCT3, OICW3_COMP3 and OICW3_ACCT3 are similarly measured, with $O I C W$ representing other non-tax internal control weaknesses and $A C C T$ representing account-level internal control weaknesses. ROA5 is average return on assets; LEV5 is average leverage, FORINC5 is average foreign income; FOROPS5 is an indicator variable equal to one if FORINC5 is non-missing, nonzero; BM5 is average book-to-market ratio; $A G G R \_L O S S 5$ is an indicator variable equal to one if a firm has a five-year sum of accounting losses; COCF5 is one minus the average operating cash flows; DYR04 and DYR05 are indicator variables representing the fiscal years 2004 and 2005. The DIND indicator variables represent two-digit NAICS industry membership. Average values for CASH_ETR5, ROA5, LEV5 and BM5 are winsorized at the $1 \%$ and $99 \%$ levels. Standard errors have been adjusted for clustering within two-digit industry and are reported in parentheses. $* * * * * *$ refer to significance at the $10 \%, 5 \%$ and $1 \%$ levels, respectively. Significance for all variables with a predicted sign is calculated using a one-tailed test; for all other variables, including unreported year and industry effects, two-tailed tests are calculated. 


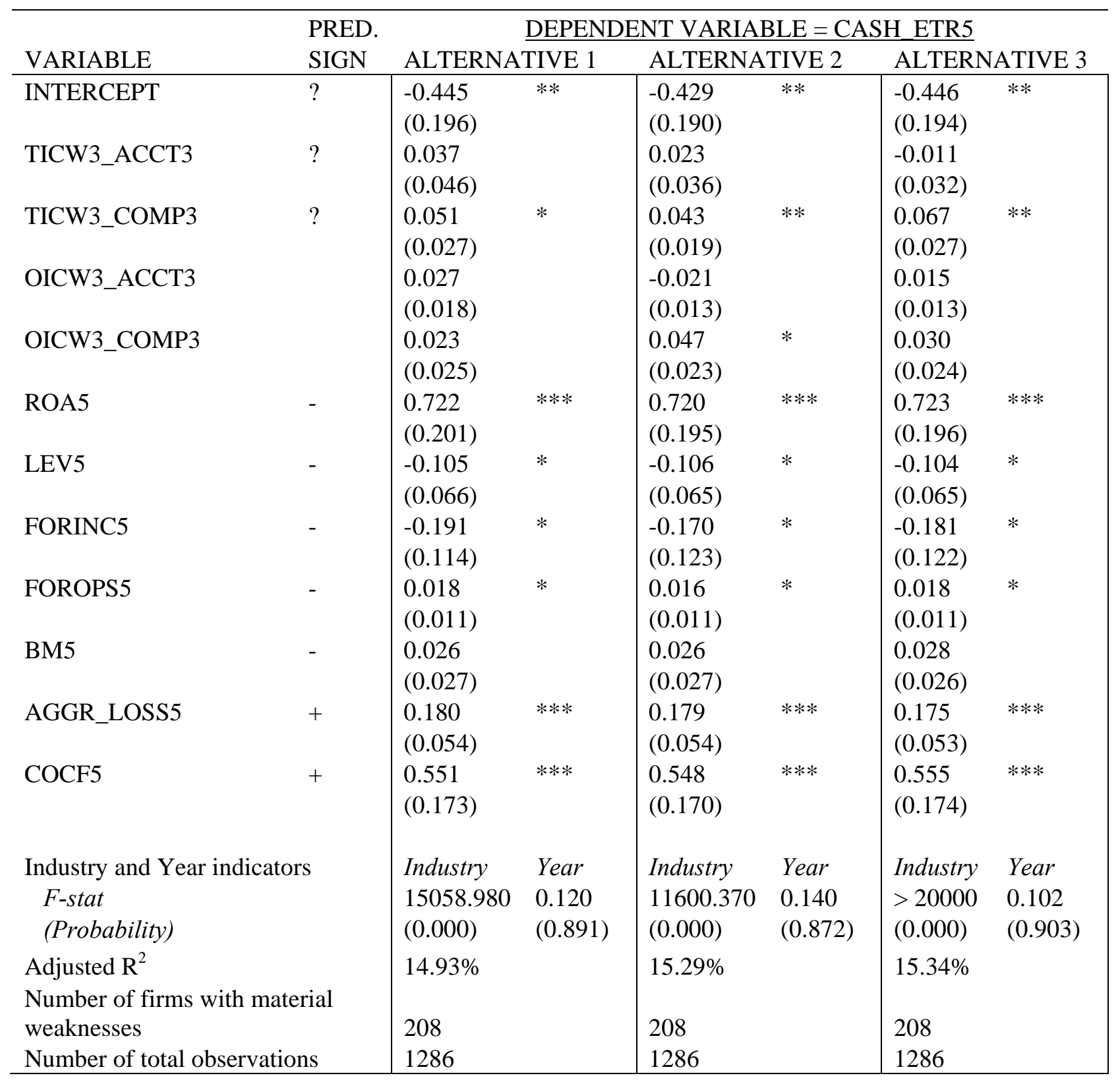


TABLE 10

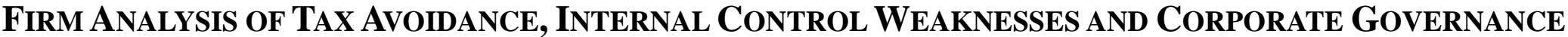

The regression equations are as follows:

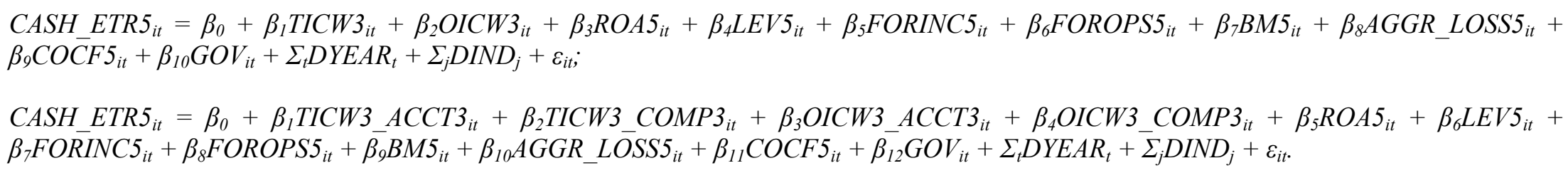

The empirical regressions are estimated with one observation per firm during the period 2004-2006. Over 90\% of the observations are measured as at 2006. All average values are averaged for the five-year period $t$-4 through $t$, except the ICW variables, which are averaged for the three-year period $t$-2 through $t$. 5-year average variables include data for years prior to 2004. All continuous average variables are scaled by the average assets from the years $t-5$ and $t-1$. CASH_ETR5 equals the five-year sum of taxes paid divided by the five-year sum of income less special items. TICW3 is an indicator variable equal to one if a firm has a tax internal control weakness during the sample period, and $O I C W 3$ is an indicator variable equal to one if a firm has a non-tax internal control weakness during the sample period (and no tax ICW). TICW3_COMP3 is an indicator variable equal to one if a firm has a tax internal control weakness and a company-level internal control weakness identified during the sample period; TICW3_ACCT3,OICW3_COMP3 and OICW3_ACCT3 are similarly measured, with $O I C W$ representing other non-tax internal control weaknesses and $A C C T$ representing account-level internal control weaknesses. ROA5 is average return on assets; $L E V 5$ is average leverage, FORINC5 is average foreign income; FOROPS5 is an indicator variable equal to one if FORINC5 is non-missing, non-zero; BM5 is average book-to-market ratio; $A G G R$ LOSS5 is an indicator variable equal to one if a firm has a five-year sum of accounting losses; $C O C F 5$ is one minus the average operating cash flows. $G O V$ represents one of the two corporate governance variables used in the table below, which are GOVERN and POOR_GOV. GOVERN is a proxy for corporate governance that is calculated as the mean value of a firm's available Gompers et al. (2003) G-Index ratings. Higher values of GOVERN indicate weaker corporate governance. POOR_GOV is an indicator variable equal to one for firms with above median GOVERN scores and zero for firms with at or below median GOVERN scores. DYR04 and DYR05 are indicator variables representing the fiscal years 2004 and 2005 and the $D I N D$ indicator variables represent two-digit NAICS industry membership. Average values for CASH_ETR5, ROA5, LEV5 and BM5 are winsorized at the 1\% and 99\% levels. Standard errors have been adjusted for clustering within two-digit industry and are reported in parentheses. ****** refer to significance at the $10 \%, 5 \%$ and $1 \%$ levels, respectively. Significance for all variables with a predicted sign is calculated using a one-tailed test; for all other variables, including unreported year and industry effects, two-tailed tests are calculated. 


\begin{tabular}{|c|c|c|c|c|c|c|c|c|c|}
\hline \multirow{3}{*}{$\frac{\text { VARIABLE }}{\text { INTERCEPT }}$} & \multirow{2}{*}{$\begin{array}{l}\text { PRED. } \\
\text { SIGN }\end{array}$} & \multicolumn{8}{|c|}{ DEPENDENT VARIABLE = CASH_ETR5 } \\
\hline & & \multicolumn{2}{|c|}{ TEST OF H1 } & \multicolumn{2}{|c|}{ TEST OF H2 \& H3 } & \multicolumn{2}{|c|}{ TEST OF H1 } & \multicolumn{2}{|c|}{ TEST OF H2 \& H3 } \\
\hline & $?$ & $\begin{array}{l}-0.548 \\
(0.235)\end{array}$ & $* *$ & $\begin{array}{l}-0.429 \\
(0.189)\end{array}$ & $* *$ & $\begin{array}{l}-0.530 \\
(0.230)\end{array}$ & $* *$ & $\begin{array}{l}-0.513 \\
(0.228)\end{array}$ & $* *$ \\
\hline TICW3 & ? & $\begin{array}{l}0.050 \\
(0.019)\end{array}$ & $* *$ & & & $\begin{array}{l}0.049 \\
(0.019)\end{array}$ & $* *$ & & \\
\hline OICW3 & & $\begin{array}{l}0.035 \\
(0.016)\end{array}$ & $* *$ & & & $\begin{array}{l}0.035 \\
(0.016)\end{array}$ & $* *$ & & \\
\hline TICW3_ACCT3 & ? & & & $\begin{array}{l}0.023 \\
(0.036)\end{array}$ & & & & $\begin{array}{l}-0.002 \\
(0.034)\end{array}$ & \\
\hline TICW3_COMP3 & ? & & & $\begin{array}{l}0.043 \\
(0.019)\end{array}$ & $* *$ & & & $\begin{array}{l}0.050 \\
(0.020)\end{array}$ & $* *$ \\
\hline OICW3_ACCT3 & & & & $\begin{array}{l}-0.021 \\
(0.012)\end{array}$ & & & & $\begin{array}{l}-0.022 \\
(0.016)\end{array}$ & \\
\hline OICW3_COMP3 & & & & $\begin{array}{l}0.048 \\
(0.023)\end{array}$ & $* *$ & & & $\begin{array}{l}0.060 \\
(0.022)\end{array}$ & $* *$ \\
\hline ROA5 & - & $\begin{array}{l}0.793 \\
(0.217)\end{array}$ & $* * *$ & $\begin{array}{l}0.721 \\
(0.196)\end{array}$ & $* * *$ & $\begin{array}{l}0.793 \\
(0.218)\end{array}$ & $* * *$ & $\begin{array}{l}0.796 \\
(0.214)\end{array}$ & $* * *$ \\
\hline LEV5 & - & $\begin{array}{l}-0.110 \\
(0.063)\end{array}$ & $* *$ & $\begin{array}{l}-0.106 \\
(0.065)\end{array}$ & $* *$ & $\begin{array}{l}-0.111 \\
(0.063)\end{array}$ & $* *$ & $\begin{array}{l}-0.115 \\
(0.062)\end{array}$ & $* *$ \\
\hline FORINC5 & - & $\begin{array}{l}-0.220 \\
(0.137)\end{array}$ & $*$ & $\begin{array}{l}-0.169 \\
(0.123)\end{array}$ & $*$ & $\begin{array}{l}-0.223 \\
(0.137)\end{array}$ & * & $\begin{array}{l}-0.205 \\
(0.139)\end{array}$ & * \\
\hline FOROPS5 & - & $\begin{array}{l}0.013 \\
(0.012)\end{array}$ & & $\begin{array}{l}0.016 \\
(0.011)\end{array}$ & & $\begin{array}{l}0.013 \\
(0.012)\end{array}$ & & $\begin{array}{l}0.012 \\
(0.012)\end{array}$ & \\
\hline BM5 & - & $\begin{array}{l}0.028 \\
(0.024)\end{array}$ & & $\begin{array}{l}0.026 \\
(0.027)\end{array}$ & & $\begin{array}{l}0.027 \\
(0.024)\end{array}$ & & $\begin{array}{l}0.028 \\
(0.024)\end{array}$ & \\
\hline AGGR_LOSS5 & + & $\begin{array}{l}0.182 \\
(0.060)\end{array}$ & $* * *$ & $\begin{array}{l}0.179 \\
(0.054)\end{array}$ & $* * *$ & $\begin{array}{l}0.181 \\
(0.059)\end{array}$ & $* * *$ & $\begin{array}{l}0.180 \\
(0.058)\end{array}$ & $* * *$ \\
\hline COCF5 & + & $\begin{array}{l}0.636 \\
(0.216)\end{array}$ & $* * *$ & $\begin{array}{l}0.633 \\
(0.215)\end{array}$ & $* * *$ & $\begin{array}{l}0.637 \\
(0.217)\end{array}$ & $* * *$ & $\begin{array}{l}0.635 \\
(0.217)\end{array}$ & $* * *$ \\
\hline GOVERN & + & $\begin{array}{l}0.002 \\
(0.001)\end{array}$ & $* *$ & $\begin{array}{l}0.003 \\
(0.001)\end{array}$ & $* *$ & & & & \\
\hline
\end{tabular}




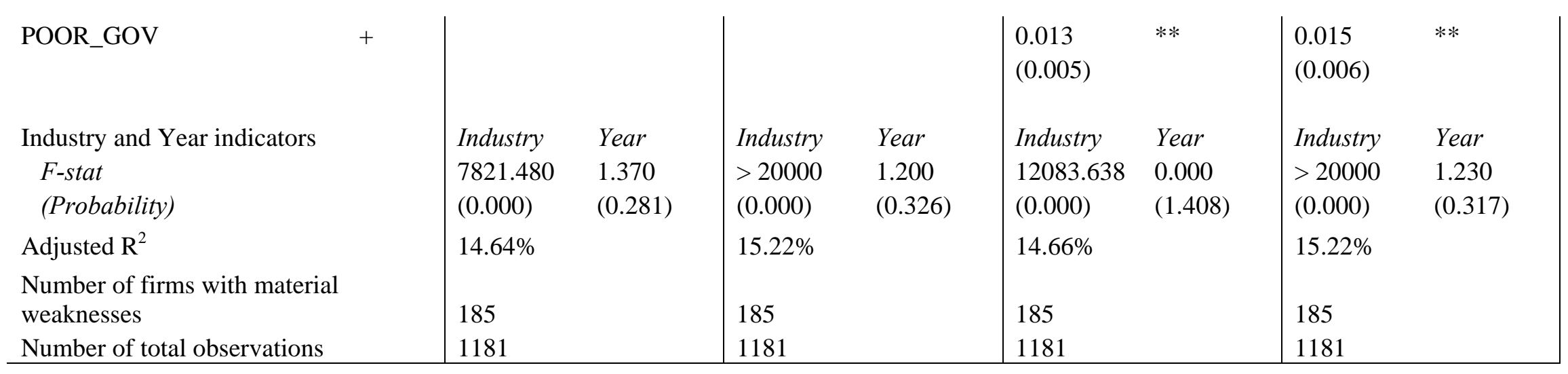




\section{TABLE 11}

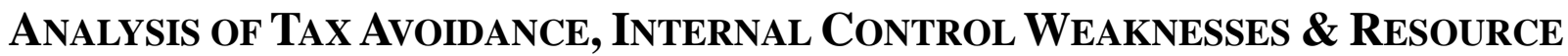 CONSTRAINT FACTORS}

In Panel A of the table below, $C C 15$ and $C C 25$ are derived from factor analysis on five proxies of resource constraints: a continuous measure of $A G G R \_L O S S 5$ (one minus five-year average income before extraordinary items), COCF5, CLEV5 (one minus LEV5), DEBT5 (one minus five-year average debt-to assets ratio) and NRATING5 (indicator of no public bond rating during the five year period from t-4 to t). $C C 15$ is a proxy for constrained resource flows (income and cash) and CC25 is a proxy for constrained debt capacity.

In Panel B of the table below, $C C 15$ and $C C 25$ are included in the following regression equations:

$$
\begin{aligned}
& \text { CASH_ETR5 } 5_{i t}=\beta_{0}+\beta_{1} \text { TICW }_{i t}+\beta_{2} \text { OICW }_{i t}+\beta_{3} \text { ROA }_{i t}+\beta_{4} \text { LEV }_{i t}+\beta_{5} \text { FORINC5 }_{i t}+\beta_{6} \text { FOROPS5 }_{i t} \\
& +\beta_{7} B M 5_{i t}+\beta_{8} A G G R \_L O S S 5_{i t}+\beta_{9} C O C F 5_{i t}+\beta_{10} C C 15_{i t}+\beta_{11} C C 25_{i t}+\Sigma_{t} D Y E A R_{t}+\Sigma_{j} D I N D_{j}+\varepsilon_{i t} \text {; } \\
& \text { CASH_ETR5 } 5_{i t}=\beta_{0}+\beta_{1} \text { TICW3_ACCT3 }{ }_{i t}+\beta_{2} \text { TICW3_COMP3 } 3_{i t}+\beta_{3} \text { OICW3_ACCT3 }{ }_{i t}+ \\
& \beta_{4} O I C W 3_{-} C O M P 3_{i t}+\beta_{5} \text { ROA5 }_{i t}+\beta_{6} \text { LEV5 }_{i t}+\beta_{7} \text { FORINC5 }_{i t}+\beta_{8} \text { FOROPS5 } i t+\beta_{9} \text { BM5 }_{i t}+ \\
& \beta_{10} A G G R_{-} L O S S 5_{i t}+\beta_{11} C O C F 5_{i t}+\beta_{12} C C 15_{i t}+\beta_{13} C C 25_{i t}+\Sigma_{t} D Y E A R_{t}+\Sigma_{j} D I N D_{j}+\varepsilon_{i t} .
\end{aligned}
$$

The empirical regressions are estimated with one observation per firm during the period 2004-2006. Over $90 \%$ of the observations are measured as at 2006. All average values are averaged for the five-year period $t-4$ through $t$, except the ICW variables, which are averaged for the three-year period $t-2$ through $t$. 5 -year average variables include data for years prior to 2004. All continuous average variables are scaled by the average assets from the years $t-5$ and $t-1$. CASH_ETR5 equals the five-year sum of taxes paid divided by the five-year sum of income less special items. TICW3 is an indicator variable equal to one if a firm has a tax internal control weakness during the sample period, and $O I C W 3$ is an indicator variable equal to one if a firm has a non-tax internal control weakness during the sample period (and no tax ICW). TICW3 COMP3 is an indicator variable equal to one if a firm has a tax internal control weakness and a company-level internal control weakness identified during the sample period; TICW3_ACCT3, $O I C W 3 \_C O M P 3$ and $O I C W 3 \_A C C T 3$ are similarly measured, with $O I C W$ representing other non-tax internal control weaknesses and $A C C T$ representing account-level internal control weaknesses. $R O A 5$ is average return on assets; LEV 5 is average leverage, FORINC5 is average foreign income; FOROPS5 is an indicator variable equal to one if FORINC5 is non-missing, non-zero; BM5 is average book-to-market ratio; $A G G R \_L O S S 5$ is an indicator variable equal to one if a firm has a five-year sum of accounting losses; $C O C F 5$ is one minus the average operating cash flows. $C C 15$ and $C C 25$ are as described above. DYR04 and DYR05 are indicator variables representing the fiscal years 2004 and 2005 and the DIND indicator variables represent two-digit NAICS industry membership. Average values for CASH_ETR5, ROA5, LEV 5 and BM5 are winsorized at the $1 \%$ and $99 \%$ levels. Standard errors have been adjusted for clustering within two-digit industry and are reported in parentheses. $* * * * * *$ refer to significance at the $10 \%, 5 \%$ and $1 \%$ levels, respectively. Significance for all variables with a predicted sign is calculated using a one-tailed test; for all other variables, including unreported year and industry effects, two-tailed tests are calculated. 
Panel A - Factor Analysis (Principal-Component Factors) of Resource Constraint Proxies

\begin{tabular}{|c|c|c|}
\hline VARIABLE & $\begin{array}{l}\text { CC15 - RESOURCE } \\
\text { FLOWS }\end{array}$ & $\begin{array}{l}\text { CC25 - DEBT } \\
\text { CAPACITY }\end{array}$ \\
\hline \multicolumn{3}{|l|}{ Factor loadings (rotated): } \\
\hline AGGR_LOSS5 (continuous) & 0.925 & -0.030 \\
\hline COCF5 & 0.919 & -0.093 \\
\hline CLEV5 & -0.099 & 0.804 \\
\hline DEBT5 & 0.019 & 0.534 \\
\hline NRATING5 & -0.090 & 0.742 \\
\hline Eigenvalue & 1.720 & 1.492 \\
\hline \multicolumn{3}{|l|}{ Scoring coefficients: } \\
\hline AGGR_LOSS5 (continuous) & 0.548 & 0.071 \\
\hline COCF5 & 0.539 & 0.028 \\
\hline CLEV5 & 0.021 & 0.543 \\
\hline DEBT5 & 0.064 & 0.369 \\
\hline NRATING5 & 0.020 & 0.501 \\
\hline
\end{tabular}


Panel B - Estimation of Equations (2) and (3) with Factors

\begin{tabular}{|c|c|c|c|c|c|}
\hline \multirow{2}{*}{ VARIABLE } & \multirow{2}{*}{$\begin{array}{l}\text { PRED } \\
\text { SIGN }\end{array}$} & \multicolumn{4}{|c|}{$\underline{\text { DEPENDENT VARIABLE }=\text { CASH_ETR5 }}$} \\
\hline & & TEST OF & & TEST OF & 2 \& H3 \\
\hline INTERCEPT & ? & $\begin{array}{l}0.024 \\
(0.033)\end{array}$ & & $\begin{array}{l}0.037 \\
(0.034)\end{array}$ & \\
\hline TICW3 & ? & $\begin{array}{l}0.076 \\
(0.026)\end{array}$ & $* * *$ & & \\
\hline OICW3 & & $\begin{array}{l}0.024 \\
(0.016)\end{array}$ & & & \\
\hline TICW3_ACCT3 & ? & & & $\begin{array}{l}0.029 \\
(0.012)\end{array}$ & $* *$ \\
\hline TICW3_COMP3 & ? & & & $\begin{array}{l}0.078 \\
(0.033)\end{array}$ & $* *$ \\
\hline OICW3_ACCT3 & & & & $\begin{array}{l}-0.022 \\
(0.011)\end{array}$ & $*$ \\
\hline OICW3_COMP3 & & & & $\begin{array}{l}0.046 \\
(0.024)\end{array}$ & $*$ \\
\hline ROA5 & - & $\begin{array}{l}0.847 \\
(0.247)\end{array}$ & $* * *$ & $\begin{array}{l}0.850 \\
(0.247)\end{array}$ & $* * *$ \\
\hline FORINC5 & - & $\begin{array}{l}-0.198 \\
(0.133)\end{array}$ & & $\begin{array}{l}-0.179 \\
(0.137)\end{array}$ & \\
\hline FOROPS5 & - & $\begin{array}{l}0.026 \\
(0.013)\end{array}$ & $* *$ & $\begin{array}{l}0.024 \\
(0.013)\end{array}$ & $* *$ \\
\hline BM5 & - & $\begin{array}{l}0.021 \\
(0.025)\end{array}$ & & $\begin{array}{l}0.021 \\
(0.025)\end{array}$ & \\
\hline CC15 & + & $\begin{array}{l}0.080 \\
(0.028)\end{array}$ & $* * *$ & $\begin{array}{l}0.080 \\
(0.028)\end{array}$ & $* * *$ \\
\hline CC25 & + & $\begin{array}{l}0.012 \\
(0.012)\end{array}$ & & $\begin{array}{l}0.012 \\
(0.011)\end{array}$ & \\
\hline $\begin{array}{l}\text { Industry and Year indicators } \\
\qquad \begin{array}{l}\text { F-stat } \\
\text { (Probability) }\end{array}\end{array}$ & & $\begin{array}{l}\text { Industry } \\
6600.850 \\
(0.000)\end{array}$ & $\begin{array}{l}\text { Year } \\
0.120 \\
(0.891)\end{array}$ & $\begin{array}{l}\text { Industry } \\
10374.140 \\
(0.000)\end{array}$ & $\begin{array}{l}\text { Year } \\
0.110 \\
(0.894)\end{array}$ \\
\hline $\begin{array}{l}\text { Adjusted } \mathrm{R}^{2} \\
\text { Number of firms with material weaknesses } \\
\text { Number of total observations }\end{array}$ & & $\begin{array}{l}10.40 \% \\
208 \\
1286\end{array}$ & & $\begin{array}{l}10.90 \% \\
208 \\
1286 \\
\end{array}$ & \\
\hline
\end{tabular}




\section{TABLE 12}

\section{ANALYSIS OF TAX AVOIDANCE AND THE INTERACTION BETWEEN INTERNAL \\ Control Weaknesses \& Resource Constraints}

The regression equations are as follows:

CASH_ETR5 $5_{i t}=\beta_{0}+\beta_{1}$ TICW3_ACCT3 ${ }_{i t}+\beta_{2}$ TICW3_COMP3 $3_{i t}+\beta_{3}$ OICW3_ACCT3 $3_{i t}+$ $\beta_{4} O I C W 3_{2} C O M P 3_{i t}+\beta_{5} C C 15_{i t}+\beta_{6} \overline{T A C C T 3}^{*} C C 15_{i t}+\beta_{7} T C O M P 3 * C C 15_{i t}+\beta_{8} O A C C T 3 * C C 15_{i t}+$ $\beta_{9}$ OCOMP $3 * C C 15_{i t}+\beta_{10} R O A 5_{i t}+\beta_{11}$ LEV5 $_{i t}+\beta_{12}$ FORINC5 $_{i t}+\beta_{13}$ FOROPS5 $_{i t}+\beta_{14}$ BMS $_{i t}+$ $\beta_{15} A G G R_{-} L O S S 5_{i t}+\beta_{16} C_{1 O C F 5_{i t}}+\Sigma_{t} D_{1 Y E A R_{t}}+\Sigma_{j} D I N D_{j}+\varepsilon_{i t}$;

CASH_ETR5 $5_{i t}=\beta_{0}+\beta_{1}$ TICW3_ACCT3 ${ }_{i t}+\beta_{2}$ TICW3_COMP3 $3_{i t}+\beta_{3}$ OICW3_ACCT3 ${ }_{i t}+$

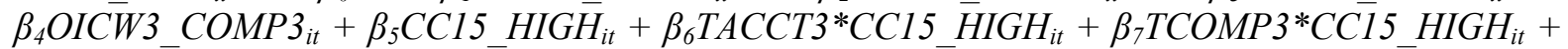

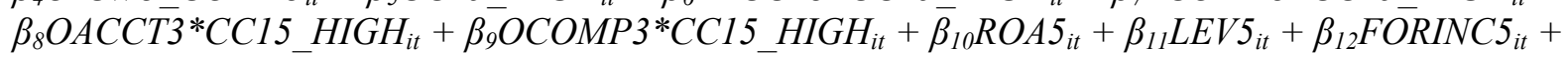
$\beta_{13}$ FOROPS5 $_{i t}+\bar{\beta}_{14}$ BMS $_{i t}+\beta_{15} A G G R_{-} L O S S 5_{i t}+\beta_{16}$ COCF $_{i t}+\Sigma_{t} D Y E A R_{t}+\sum_{j} D_{I N D_{j}}+\varepsilon_{i t}$.

The empirical regressions are estimated with one observation per firm during the period 2004-2006. Over $90 \%$ of the observations are measured as at 2006. All average values are averaged for the five-year period $t$ - 4 through $t$, except the ICW variables, which are averaged for the three-year period $t$ - 2 through $t$. 5 -year average variables include data for years prior to 2004. All continuous average variables are scaled by the average assets from the years $t-5$ and $t-1$. CASH_ETR5 equals the five-year sum of taxes paid divided by the five-year sum of income less special items. TICW3_COMP3 is an indicator variable equal to one if a firm has a tax internal control weakness and a company-level internal control weakness identified during the sample period; TICW3_ACCT3, OICW3_COMP3 and OICW3_ACCT3 are similarly measured, with $O I C W$ representing other non-tax internal control weaknesses and $A C C T$ representing account-level internal control weaknesses. CC15 is a continuous proxy for constrained resource flows (income and cash) derived from factor analysis presented in Table 11. CC15_HIGH is a discrete proxy that represents firms with the most constrained resources and is equal to one if an observation is in the top third of the range of $C C 15$ and zero otherwise. Variables for the interaction between $C C 15$ and each of the account-level and company-level internal control weakness variables are $T A C C T 3 * C C 15$, TCOMP $3 * C C 15$, OACCT ${ }^{*} C C 15$ and $O C O M P 3 * C C 15$. Variables for the interaction between CC15_HIGH and each of the account-level and company-level internal control weakness variables are TACCT3*CC15_HIGH, TCOMP3*CC15_HIGH,OACCT3*CC15_HIGH, OCOMP3*CC15_HIGH. For the regression including $C C 15$, all observations with available data are included. For the regression including $\mathrm{CC}_{15} \mathrm{HIGH}$, firms with the least constrained resources (i.e. the bottom third of the range of CC15) are also included in this analysis but firms with an intermediate level of constrained resources (i.e. the middle third of the range of $C C 15$ ) are excluded from the regression.

ROA5 is average return on assets; LEV5 is average leverage, FORINC5 is average foreign income; FOROPS5 is an indicator variable equal to one if FORINC5 is non-missing, non-zero; BM5 is average book-to-market ratio; $A G G R \_L O S S 5$ is an indicator variable equal to one if a firm has a five-year sum of accounting losses; COCF5 is one minus the average operating cash flows. DYR04 and DYR05 are indicator variables representing the fiscal years 2004 and 2005 and the $D I N D$ indicator variables represent two-digit NAICS industry membership. Average values for CASH_ETR5, ROA5, LEV5 and BM5 are winsorized at the $1 \%$ and $99 \%$ levels. Standard errors have been adjusted for clustering within two-digit industry and are reported in parentheses. $* * * * * *$ refer to significance at the $10 \%, 5 \%$ and $1 \%$ levels, respectively. Significance for all variables with a predicted sign is calculated using a one-tailed test; for all other variables, including unreported year and industry effects, two-tailed tests are calculated. 


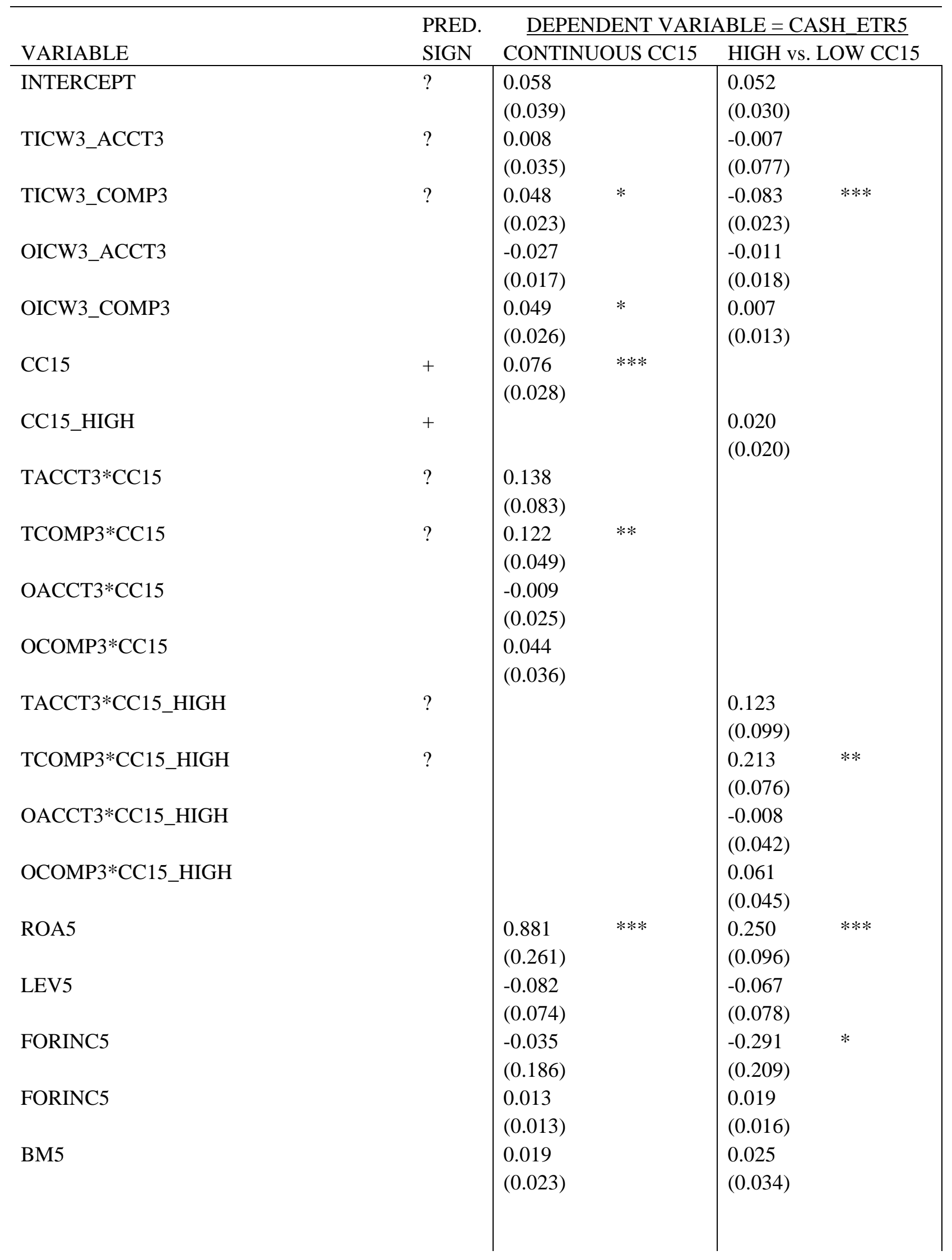


Industry and Year indicators

F-stat

(Probability)

Adjusted $\mathrm{R}^{2}$

Number of firms with material weaknesses

\begin{tabular}{ll|ll} 
Industry & Year & Industry & Year \\
$>20000$ & 0.005 & $>20000$ & 0.057 \\
$(0.000)$ & $(0.995)$ & $(0.000)$ & $(0.944)$ \\
$13.18 \%$ & & $10.03 \%$ & \\
208 & & 145 & \\
1286 & & 857 &
\end{tabular}

Number of total observations 


\title{
TABLE 13
}

\section{ANALYSis OF TAX AVOIDANCE \& REMEDiATION OF INTERNAL CONTROL WEAKNESSES}

The regression equations for Panels $\mathrm{A}$ and $\mathrm{B}$ are as follows:

\begin{abstract}
$D V_{i t}=\beta_{0}+\beta_{1}$ WEAK_TAX $X_{i t}+\beta_{2}$ WEAK_OTHER ${ }_{i t}+\beta_{3}$ TAX_FIXED ${ }_{i t}+\beta_{4} O T H E R \_F I X E D_{i t}+\beta_{5} R O A_{i t}$ $+\beta_{6} L E V_{i t}+\beta_{7}$ FORIN $\bar{C}_{i t}+\beta_{8}$ FOROP $\bar{S}_{i t}+\beta_{9} B M_{i t}+\beta_{10} A \bar{G} G R_{-} L O S S_{i t}+\beta_{11} C O \bar{C} F_{i t}+\sum_{t} D Y E A R_{t}+$ $\Sigma_{j} D I N D_{j}+\varepsilon_{i t}$;

$D V_{i t}=\beta_{0}+\beta_{1}$ WEAK_TAX_ACCT $T_{i t}+\beta_{2}$ WEAK_TAX_COMP ${ }_{i t}+\beta_{3}$ WEAK_OTHER_ACCT $T_{i t}+$ $\beta_{4}$ WEAK_OTHER_COMP ${ }_{i t}+\beta_{5} T A X \_A C C T \_F I X E D_{i t}+\beta_{6} T A X \_C O M P \_F I X E D_{i t}+$ $\beta_{7}$ OTHER_ACCT_FIXED $D_{i t}+\beta_{8}$ OTHER_COMP_FIXED $D_{i t}+\beta_{9} R O A_{i t}+\beta_{10} \overline{L E} V_{i t}+\bar{\beta}_{11} F$ FORINC $C_{i t}+$ $\beta_{12} F_{O R O P} \bar{P} S_{i t}+\beta_{13} \overline{B M}_{i t}+\beta_{14} A G G R_{-} L O S \overline{S S}_{i t}+\beta_{15} \overline{C O C F}_{i t}+\sum_{t} D Y E A R_{t}+\sum_{j} D I N D_{j}+\varepsilon_{i t}$
\end{abstract}

The regression equations for Panel C are as follows:

CASH_ETR $5_{i t}=\beta_{0}+\beta_{1}$ WEAK_TAX ${ }_{i t}+\beta_{2}$ WEAK_OTHER ${ }_{i t}+\beta_{3}$ TAX_FIXED $D_{i t}+\beta_{4}$ OTHER_FIXED ${ }_{i t}$ $+\beta_{5} R \overline{R O A} A_{i t}+\beta_{6} L E V_{i t}+\beta_{7} F O \bar{R} I N C_{i t}+\beta_{8} F O R O \bar{P} S_{i t}+\beta_{9} B M_{i t}+\beta_{10} A G G R \_L O S S_{i t}+\beta_{11} \overline{C O C F_{i t}}+$ $\Sigma_{t} D Y E A R_{t}+\Sigma_{j} D I N D_{j}+\varepsilon_{i t}$;

$C A S H \_E T R 5_{i t}=\beta_{0}+\beta_{1} W E A K_{-} T A X \_A C C T_{i t}+\beta_{2} W E A K_{-} T A X \_C O M P_{i t}+\beta_{3} W E A K \_O T H E R \_A C C T_{i t}$ $+\beta_{4}$ WEAK_OTHER_COMP ${ }_{i t}+\beta_{5}$ TAX_ACCT_FIXED ${ }_{i t}+\beta_{6}$ TAX_COMP_FIXED $D_{i t}+$ $\beta_{7}$ OTHER_ACCT_FIXED $D_{i t}+\beta_{8}$ OTHER_COMP_FIXED $\bar{D}_{i t}+\beta_{9} R O A 5_{i t}+\beta_{10} L E \bar{V} 5_{i t}+\beta_{11}{ }_{F O R I N C 5_{i t}}+$ $\beta_{12}$ FOROPS5 $_{i t}+\bar{\beta}_{13}$ BMS $_{i t}+\beta_{14} A G G R_{-}{ }_{L} O S S 5_{i t}+\beta_{15}$ COCF $_{i t}+\sum_{t} D Y E A R_{t}+\sum_{j} D I N D_{j}+\varepsilon_{i t}$.

In Panels A and B, the first two empirical regressions are estimated with annual observations during the period 2004-2006. In Panel C, the second two empirical regressions are estimated with annual, overlapping observations of average values during the period 2004-2006. The "WEAK" and "FIXED" variables are based on annual or two-year values, however. $D V$ refers to one of two annual tax avoidance proxies, which are BTD1 or CASH_ETR. BTD1 is the Manzon-Plesko (2002) BTD measure, equal to [US domestic pre-tax income - (current US domestic tax expense / US statutory rate) - state income taxes other income taxes - equity in earnings] / lagged assets. $C A S H \_E T R$ equals taxes paid divided by [income less special items]. $C A S H \_E T R 5$ equals the five-year sum of taxes paid divided by the five-year sum of income less special items. "WEAK" and "FIXED" variables are based on Ashbaugh-Skaife et al. (2008). The "FIXED" variables represent remediation of ICWs. WEAK_TAX and WEAK_OTHER are indicator variables equal to one if a firm has a tax ICW or other (non-tax) ICW, respectively, in the current or prior year, and zero otherwise. WEAK_TAX_ACCT, WEAK_TAX_COMP, WEAK_OTHER_ACCT and WEAK_OTHER_COMP are measured similarly, where the general ICWs are separated into account-level and company-level components. TAX_FIXED and OTHER_FIXED are indicator variables equal to one if a firm has a tax ICW or other ICW, respectively, in the prior year but not the current year, and zero otherwise. TAX_ACCT_FIXED, TAX_COMP_FIXED, OTHER_ACCT_FIXED and OTHER_COMP_FIXED are measured similarly, again where general ICWs are separated into accountlevel and company-level components.

Annual independent variables are simply the one-year value of the average variables. AGGR_LOSS is a sum of values at time $t-1$ and $t, B M$ is measured at $t-1$, and all other annual values are measured at year $t$. All continuous annual variables are scaled by assets at time $t$ - 1 . Similarly, all average values are 
averaged for the five-year period $t-4$ through $t$. 5-year average variables include data for years prior to 2004. All continuous average variables are scaled by the average assets from the years $t-5$ and $t-1$. ROA5 is average return on assets; LEV5 is average leverage, FORINC5 is average foreign income; FOROPS5 is an indicator variable equal to one if FORINC5 is non-missing, non-zero; BM5 is average book-to-market ratio; $A G G R \_L O S S 5$ is an indicator variable equal to one if a firm has a five-year sum of accounting losses; COCF 5 is one minus the average operating cash flows. DYR04 and DYR05 are indicator variables representing the fiscal years 2004 and 2005 and the $D I N D$ indicator variables represent two-digit NAICS industry membership. Annual and average values for $C A S H \_E T R / C A S H \_E T R 5, B T D 1, R O A / R O A 5$, $L E V / L E V 5$ and $B M / B M 5$ are winsorized at the $1 \%$ and $99 \%$ levels. Standard errors have been adjusted for clustering within two-digit industry and are reported in parentheses. $* * * * * *$ refer to significance at the $10 \%, 5 \%$ and $1 \%$ levels, respectively. Significance for all variables with a predicted sign is calculated using a one-tailed test; for all other variables, including unreported year and industry effects, two-tailed tests are calculated. 
Panel A - Annual Tests with CASH_ETR as DV

\begin{tabular}{|c|c|c|c|c|c|}
\hline \multirow{2}{*}{$\begin{array}{l}\text { VARIABLE } \\
\text { INTERCEPT }\end{array}$} & \multicolumn{3}{|l|}{ PRED. } & \multicolumn{2}{|c|}{ ACCT \& COMP ICWs } \\
\hline & ? & $\begin{array}{l}-0.258 \\
(0.104)\end{array}$ & $* *$ & $\begin{array}{l}-0.251 \\
(0.102)\end{array}$ & \\
\hline WEAK_TAX & ? & $\begin{array}{l}0.074 \\
(0.022)\end{array}$ & $* * *$ & & \\
\hline WEAK_OTHER & & $\begin{array}{l}0.033 \\
(0.015)\end{array}$ & $* *$ & & \\
\hline TAX_FIXED & ? & $\begin{array}{l}-0.073 \\
(0.025)\end{array}$ & $* * *$ & & \\
\hline OTHER_FIXED & & $\begin{array}{l}-0.036 \\
(0.025)\end{array}$ & & & \\
\hline WEAK_TAX_ACCT & ? & & & $\begin{array}{l}0.018 \\
(0.019)\end{array}$ & \\
\hline WEAK_TAX_COMP & ? & & & $\begin{array}{l}0.095 \\
(0.029)\end{array}$ & $* * *$ \\
\hline WEAK_OTHER_ACCT & & & & $\begin{array}{l}-0.006 \\
(0.035)\end{array}$ & \\
\hline WEAK_OTHER_COMP & & & & $\begin{array}{l}0.056 \\
(0.017)\end{array}$ & $* * *$ \\
\hline TAX_ACCT_FIXED & ? & & & $\begin{array}{l}-0.059 \\
(0.035)\end{array}$ & \\
\hline TAX_COMP_FIXED & ? & & & $\begin{array}{l}-0.092 \\
(0.044)\end{array}$ & $*$ \\
\hline OTHER_ACCT_FIXED & & & & $\begin{array}{l}0.014 \\
(0.057)\end{array}$ & \\
\hline OTHER_COMP_FIXED & & & & $\begin{array}{l}-0.080 \\
(0.032)\end{array}$ & $* *$ \\
\hline ROA & - & $\begin{array}{l}0.234 \\
(0.075)\end{array}$ & $* * *$ & $\begin{array}{l}0.721 \\
(0.196)\end{array}$ & $* * *$ \\
\hline LEV & - & $\begin{array}{l}-0.151 \\
(0.073)\end{array}$ & $* *$ & $\begin{array}{l}-0.106 \\
(0.065)\end{array}$ & $* *$ \\
\hline FORINC & - & $\begin{array}{l}-0.177 \\
(0.091)\end{array}$ & $* *$ & $\begin{array}{l}-0.169 \\
(0.123)\end{array}$ & $* *$ \\
\hline FOROPS & - & $\begin{array}{l}0.007 \\
(0.011)\end{array}$ & & $\begin{array}{l}0.016 \\
(0.011)\end{array}$ & $*$ \\
\hline BM & - & $\begin{array}{l}-0.016 \\
(0.018)\end{array}$ & & $\begin{array}{l}0.026 \\
(0.027)\end{array}$ & \\
\hline AGGR_LOSS & + & $\begin{array}{l}0.101 \\
(0.036)\end{array}$ & $* * *$ & $\begin{array}{l}0.179 \\
(0.054)\end{array}$ & $* * *$ \\
\hline COCF & + & $\begin{array}{l}0.458 \\
(0.088)\end{array}$ & $* * *$ & $\begin{array}{l}0.548 \\
(0.170)\end{array}$ & $* * *$ \\
\hline
\end{tabular}


Industry and Year indicators

F-stat

(Probability)

Adjusted $\mathrm{R}^{2}$

Number of material weakness observations

Number of total observations

\begin{tabular}{|ll|ll|} 
Industry & Year & Industry & Year \\
$>20000$ & 43.752 & $>20000$ & 39.076 \\
$(0.000)$ & $(0.000)$ & $(0.000)$ & $(0.000)$ \\
$9.86 \%$ & & $10.04 \%$ & \\
300 & & 300 & \\
4313 & & 4313 & \\
\hline
\end{tabular}


$\underline{\text { Panel B - Annual Tests with BTD1 as DV }}$

\begin{tabular}{|c|c|c|c|c|c|}
\hline \multirow{2}{*}{$\begin{array}{l}\text { VARIABLE } \\
\text { INTERCEPT }\end{array}$} & \multicolumn{3}{|c|}{ PRED. } & \multicolumn{2}{|c|}{ ACCT \& COMP ICWs } \\
\hline & $?$ & $\begin{array}{l}-0.091 \\
(0.039)\end{array}$ & $* *$ & $\begin{array}{l}-0.093 \\
(0.038)\end{array}$ & \\
\hline WEAK_TAX & $?$ & $\begin{array}{l}-0.026 \\
(0.008)\end{array}$ & $* * *$ & & \\
\hline WEAK_OTHER & & $\begin{array}{l}-0.002 \\
(0.005)\end{array}$ & $* *$ & & \\
\hline TAX_FIXED & $?$ & $\begin{array}{l}0.020 \\
(0.010)\end{array}$ & $*$ & & \\
\hline OTHER_FIXED & & $\begin{array}{l}-0.007 \\
(0.009)\end{array}$ & & & \\
\hline WEAK_TAX_ACCT & $?$ & & & $\begin{array}{l}-0.002 \\
(0.010)\end{array}$ & \\
\hline WEAK_TAX_COMP & $?$ & & & $\begin{array}{l}-0.033 \\
(0.010)\end{array}$ & $* * *$ \\
\hline WEAK_OTHER_ACCT & & & & $\begin{array}{l}-0.005 \\
(0.011)\end{array}$ & \\
\hline WEAK_OTHER_COMP & & & & $\left(\begin{array}{l}0.000 \\
(0.007)\end{array}\right.$ & $* * *$ \\
\hline TAX_ACCT_FIXED & $?$ & & & $\begin{array}{l}0.019 \\
(0.031)\end{array}$ & \\
\hline TAX_COMP_FIXED & $?$ & & & $\begin{array}{l}0.030 \\
(0.010)\end{array}$ & $* * *$ \\
\hline OTHER_ACCT_FIXED & & & & $\begin{array}{l}-0.010 \\
(0.013)\end{array}$ & \\
\hline OTHER_COMP_FIXED & & & & $\left(\begin{array}{l}-0.004 \\
(0.010)\end{array}\right.$ & \\
\hline ROA & + & $\begin{array}{l}-0.276 \\
(0.080)\end{array}$ & $* * *$ & $\begin{array}{l}-0.274 \\
(0.079)\end{array}$ & $* * *$ \\
\hline LEV & + & $\begin{array}{l}0.043 \\
(0.016)\end{array}$ & $* * *$ & $\begin{array}{l}0.043 \\
(0.016)\end{array}$ & $* * *$ \\
\hline FORINC & + & $\begin{array}{l}0.216 \\
(0.091)\end{array}$ & $* *$ & $\begin{array}{l}0.217 \\
(0.091)\end{array}$ & $* *$ \\
\hline FOROPS & + & $\begin{array}{l}0.084 \\
(0.006)\end{array}$ & $* * *$ & $\begin{array}{l}0.083 \\
(0.006)\end{array}$ & $* * *$ \\
\hline BM & + & $\begin{array}{l}0.013 \\
(0.009)\end{array}$ & $*$ & $\begin{array}{l}0.012 \\
(0.009)\end{array}$ & $*$ \\
\hline AGGR_LOSS & - & $\begin{array}{l}-0.063 \\
(0.010)\end{array}$ & $* * *$ & $\begin{array}{l}-0.063 \\
(0.010)\end{array}$ & $* * *$ \\
\hline COCF & - & $\begin{array}{l}0.062 \\
(0.040)\end{array}$ & $*$ & $\begin{array}{l}0.064 \\
(0.040)\end{array}$ & $*$ \\
\hline
\end{tabular}


Industry and Year indicators

\begin{tabular}{|ll|ll|} 
Industry & Year & Industry & Year \\
$>20000$ & 12.278 & $>20000$ & 16.225 \\
$(0.000)$ & $(0.001)$ & $(0.000)$ & $(0.000)$ \\
$39.02 \%$ & & $39.12 \%$ & \\
289 & & 289 & \\
3355 & & 3355 & \\
\hline
\end{tabular}


Panel C - Overlapping, Annual Tests with CASH_ETR5 as DV

\begin{tabular}{|c|c|c|c|c|c|}
\hline \multirow{2}{*}{$\begin{array}{l}\text { VARIABLE } \\
\text { INTERCEPT }\end{array}$} & \multicolumn{3}{|l|}{ PRED. } & \multicolumn{2}{|c|}{ ACCT \& COMP ICWs } \\
\hline & $?$ & $\begin{array}{l}-0.475 \\
(0.115)\end{array}$ & $* * *$ & $\begin{array}{l}-0.462 \\
(0.111)\end{array}$ & \\
\hline WEAK_TAX & $?$ & $\begin{array}{l}0.070 \\
(0.032)\end{array}$ & $* *$ & & \\
\hline WEAK_OTHER & & $\begin{array}{l}0.008 \\
(0.014)\end{array}$ & & & \\
\hline TAX_FIXED & $?$ & $\begin{array}{l}-0.035 \\
(0.046)\end{array}$ & & & \\
\hline OTHER_FIXED & & $\begin{array}{l}0.011 \\
(0.023)\end{array}$ & & & \\
\hline WEAK_TAX_ACCT & $?$ & & & $\begin{array}{l}0.142 \\
(0.073)\end{array}$ & $*$ \\
\hline WEAK_TAX_COMP & $?$ & & & $\begin{array}{l}0.051 \\
(0.024)\end{array}$ & $* *$ \\
\hline WEAK_OTHER_ACCT & & & & $\begin{array}{l}-0.029 \\
(0.020)\end{array}$ & \\
\hline WEAK_OTHER_COMP & & & & $\begin{array}{l}0.029 \\
(0.017)\end{array}$ & \\
\hline TAX_ACCT_FIXED & $?$ & & & $\begin{array}{l}-0.134 \\
(0.077)\end{array}$ & * \\
\hline TAX_COMP_FIXED & $?$ & & & $\begin{array}{l}-0.019 \\
(0.046)\end{array}$ & \\
\hline OTHER_ACCT_FIXED & & & & $\begin{array}{l}-0.003 \\
(0.017)\end{array}$ & \\
\hline OTHER_COMP_FIXED & & & & $\begin{array}{l}0.029 \\
(0.039)\end{array}$ & \\
\hline ROA5 & - & $\begin{array}{l}0.613 \\
(0.084)\end{array}$ & $* * *$ & $\begin{array}{l}0.607 \\
(0.082)\end{array}$ & $* * *$ \\
\hline LEV5 & - & $\begin{array}{l}-0.115 \\
(0.056)\end{array}$ & $* *$ & $\begin{array}{l}-0.115 \\
(0.056)\end{array}$ & $* *$ \\
\hline FORINC5 & - & $\begin{array}{l}-0.082 \\
(0.127)\end{array}$ & & $\begin{array}{l}-0.074 \\
(0.129)\end{array}$ & \\
\hline FOROPS5 & - & $\begin{array}{l}0.003 \\
(0.011)\end{array}$ & & $\begin{array}{l}0.002 \\
(0.012)\end{array}$ & \\
\hline BM5 & - & $\begin{array}{l}0.011 \\
(0.019)\end{array}$ & & $\begin{array}{l}0.011 \\
(0.019)\end{array}$ & \\
\hline AGGR_LOSS5 & + & $\begin{array}{l}0.171 \\
(0.055)\end{array}$ & $* * *$ & $\begin{array}{l}0.169 \\
(0.055)\end{array}$ & $* * *$ \\
\hline COCF5 & + & $\begin{array}{l}0.621 \\
(0.113)\end{array}$ & $* * *$ & $\begin{array}{l}0.611 \\
(0.109)\end{array}$ & $* * *$ \\
\hline
\end{tabular}


Industry and Year indicators

F-stat

(Probability)

Adjusted $\mathrm{R}^{2}$

Number of material weakness observations

Number of total observations

\begin{tabular}{|ll|ll|} 
Industry & Year & Industry & Year \\
$>20000$ & 0.717 & $>20000$ & 0.811 \\
$(0.000)$ & $(0.502)$ & $(0.000)$ & $(0.461)$ \\
$12.12 \%$ & & $12.50 \%$ & \\
271 & & 271 & \\
3351 & & 3351 &
\end{tabular}




\section{TABLE 14}

\section{SUMMARY STATISTICS FOR VARIABLES IN CHAPTER 6 TESTS}

Panels A and B present summary statistics for the monthly abnormal returns $(R)$ and Fama-French (1993) four factors used in Chapter 6 tests. Panel C presents mean, median and quintile cut-off values (C1-C4) for the tax avoidance proxies that are ranked to give tax aggressiveness indicator variables.

$X R E T$ is the firm's monthly stock return less the monthly risk-free rate. The $M R F, S M B, H M L$ and $U M D$ variables are the Fama-French factor loadings representing the excess market return, the size premium, the book-to-market premium and the momentum premium, respectively. CASH_ETR5 (in-sample) equals the five-year sum of taxes paid divided by the five-year sum of income less special items, estimated with one observation per firm during the period 2004-2006. Over 90\% of the observations are measured as at 2006. CASH_ETR5 (out-of-sample) equals the five-year sum of taxes paid divided by the five-year sum of income less special items, estimated based on the firm-level value as at 2003. CASH ETR equals taxes paid divided by [income less special items] estimated annually. BTD1 is the Manzon-Plesko (2002) BTD measure, also estimated annually, equal to [US domestic pre-tax income - (current US domestic tax expense / US statutory rate) - state income taxes - other income taxes - equity in earnings] / lagged assets. $P R O B \_T S$ is the predicted probability that a firm engages in tax sheltering, based on Wilson's (2009) tax shelter prediction model. Values of $P R O B_{-} T S$ range from 0 to 1. Additional description of Wilson's (2009) tax shelter prediction model is available in subsection 6.2.1 of this dissertation.

Panel A: Monthly Variables for Sample Firms (with Available In-Sample CASH_ETR5)

\begin{tabular}{llllllll}
\hline VARIABLE & DESCRIPTION & N & MEAN & STD DEV & 5th \% & MEDIAN & 95th \% \\
\hline XRET & A firm's excess return (over risk-free rate) & 48477 & 0.014 & 0.093 & -0.128 & 0.011 & 0.163 \\
MRF & Fama-French factor: market premium & 48477 & 0.008 & 0.023 & 0 & 0.014 & 0 \\
SMB & Fama-French factor: size premium & 48477 & 0.002 & 0.023 & -0.039 & -0.004 & 0.041 \\
HML & Fama-French factor: book-to-market premium & 48477 & 0.008 & 0.016 & 0 & 0.005 & 0 \\
UMD & Fama-French factor: momentum premium & 48477 & 0.002 & 0.024 & -0.037 & 0.004 & 0.035 \\
\hline
\end{tabular}


Panel B: Monthly Variables for Sample Firms (with Available Out-Of-Sample CASH_ETR5)

\begin{tabular}{llllllll}
\hline VARIABLE & DESCRIPTION & N & MEAN & STD DEV & 5th \% & MEDIAN & 95th \% \\
\hline XRET & A firm's excess return (over risk-free rate) & 40363 & 0.013 & 0.089 & -0.124 & 0.011 & 0.156 \\
MRF & Fama-French factor: market premium & 40363 & 0.008 & 0.023 & 0 & 0.014 & 0 \\
SMB & Fama-French factor: size premium & 40363 & 0.002 & 0.023 & -0.039 & -0.004 & 0.041 \\
HML & Fama-French factor: book-to-market premium & 40363 & 0.008 & 0.016 & 0 & 0.005 & 0 \\
UMD & Fama-French factor: momentum premium & 40363 & 0.002 & 0.024 & -0.037 & 0.004 & 0.035 \\
\hline
\end{tabular}

Panel C: Mean, Median and Quintile Cut-off (C\#) Values for Tax Aggressiveness

\begin{tabular}{|c|c|c|c|c|c|c|c|}
\hline VARIABLE & DESCRIPTION & MEAN & MEDIAN & $\mathrm{C} 1$ & $\mathrm{C} 2$ & $\mathrm{C} 3$ & $\mathrm{C} 4$ \\
\hline $\begin{array}{l}\text { CASH_ETR5 } \\
\text { (in-sample) }\end{array}$ & $\begin{array}{l}\text { Firm-level CASH_ETR5 value in 2004-2006 } \\
\text { period }\end{array}$ & 0.230 & 0.231 & 0.109 & 0.198 & 0.261 & 0.326 \\
\hline $\begin{array}{l}\text { CASH_ETR5 } \\
\text { (out-of-sample) }\end{array}$ & $\begin{array}{l}\text { Firm-level CASH_ETR5 value at end of } 2003 \\
\text { fiscal period }\end{array}$ & 0.249 & 0.243 & 0.112 & 0.206 & 0.271 & 0.337 \\
\hline CASH_ETR & $\begin{array}{l}\text { Annual CASH_ETR value during 2004-2006 } \\
\text { period }\end{array}$ & 0.245 & 0.235 & 0.084 & 0.188 & 0.273 & 0.354 \\
\hline BTD1 & Annual Manzon-Plesko BTD & -0.046 & -0.015 & -0.106 & -0.032 & -0.004 & 0.015 \\
\hline PROB_TS & Annual Wilson probability of tax shelter activity & 0.759 & 0.882 & 0.509 & 0.810 & 0.916 & 0.961 \\
\hline
\end{tabular}


TABLE 15

\section{Analysis of Abnormal Stock Returns Conditional on Tax AgGResSiveness AND COMPANY-LeVel TAX-Related INTERNAL CONTROL QUALITY}

Equation (4), presented in Panel A, is as follows:

$$
\begin{aligned}
& R_{i t}=\beta_{0}+\beta_{1} T I C W C^{*} T A G_{i}+\beta_{2} T I C W C^{*} N O N_{-} T A G_{i}+\beta_{3} T I C S C * N O N_{-} T A G_{i}+b M R F_{t}+s S M B_{t}+ \\
& h H M L_{t}+w U M D_{t}+\varepsilon_{i t}
\end{aligned}
$$

In Panel B, the following alternative regression to Equation (4) is presented:

$$
R_{i t}=\beta_{0}+\beta_{1} T I C W C_{i}+\beta_{2} T A G_{i}+\beta_{3} T I C W C^{*} T A G_{i}+b M R F_{t}+s S M B_{t}+h H M L_{t}+w U M D_{t}+\varepsilon_{i t}
$$

$R$ is measured with $X R E T$, a firm's monthly stock return less the monthly risk-free rate during the period 2004-2006. Tax aggressiveness is determined by ranking firms according to their value of CASH_ETR5 or $C A S H \_E T R$. TAG is a dichotomous variable representing tax aggressiveness, equal to 1 if a firm's CASH_ETR5 or CASH_ETR estimate is in the bottom quintile, 0 otherwise. NON_TAG represents "control firms" that are not highly tax aggressive and is coded as 1 if a firm's CASH_ETR5 or CASH_ETR estimate is not in the bottom quintile, 0 otherwise. For column 1 of the table, $C A S{ }_{-} H_{-} E T R 5$ (in-sample) equals the five-year sum of taxes paid divided by the five-year sum of income less special items, estimated with one observation per firm during the period 2004-2006. Over 90\% of the observations are measured as at 2006. For column 2 of the table, CASH_ETR5 (out-of-sample) equals the five-year sum of taxes paid divided by the five-year sum of income less special items, estimated based on the firm-level value as at 2003. For column 3 of the table, CASH_ETR equals taxes paid divided by [income less special items] estimated annually for the period 2004-2006. In columns 1 and 2, TICWC equals the firm-level value of TICW5_COMP5 during the period 2004-2006. In column 3, TICWC equals the annual firm-year value of $T I C W_{-}$COMP for each year during the sample period 2004-2006. TICSC is equal to one minus $T I C W C$.

The intercept in the Panel A regression represents tax aggressive firms that do not disclose a company-level tax ICW at the firm or firm-year level. TICWC*TAG is an interaction variable that represents tax aggressive firms that disclose a company-level tax ICW at the firm or firm-year level. $T I C W C^{*} N O N \_T A G$ is also an interaction variable that represents non-tax aggressive firms that disclose a company-level tax ICW at the firm or firm-year level. TICSC*NON_TAG is an interaction variable that represents non-tax aggressive firms that do not disclose a company-level tax ICW at the firm or firm-year level (i.e. TICSC reflects strong internal control). The $M R F, S M B, H M L$ and $U M D$ variables are the Fama-French (1993) factor loadings representing the excess market return, the size premium, the book-tomarket premium and the momentum premium, respectively. ****** refer to significance at the $10 \%, 5 \%$

and $1 \%$ levels, respectively. Significance for all variables is calculated using a two-tailed test. For Panel A, post-estimation F-tests are presented that examine Hypotheses 4 and 5. 
Panel A - Regressions of Equation (4)

\begin{tabular}{|c|c|c|c|c|c|c|}
\hline \multirow{3}{*}{$\frac{\text { VARIABLE }}{\text { INTERCEPT }}$} & \multicolumn{6}{|c|}{ DEPENDENT VARIABLE $=\mathrm{R}=$ EXCESS RETURN $(\mathrm{RET}-\mathrm{RF})$} \\
\hline & \multicolumn{2}{|c|}{$\begin{array}{l}\text { IN-SAMPLE } \\
\text { CASH_ETR5 }\end{array}$} & \multicolumn{2}{|c|}{$\begin{array}{l}\text { OUT-OF-SAMPLE } \\
\text { CASH_ETR5 }\end{array}$} & \multicolumn{2}{|c|}{$\begin{array}{l}\text { IN-SAMPLE } \\
\text { CASH_ETR } \\
\end{array}$} \\
\hline & $\begin{array}{l}0.0066 \\
(0.0010)\end{array}$ & $* * *$ & $\begin{array}{l}0.0057 \\
(0.0010)\end{array}$ & $* * *$ & $\begin{array}{l}0.0083 \\
(0.0011)\end{array}$ & $* * *$ \\
\hline TICWC*TAG & $\begin{array}{l}-0.0095 \\
(0.0045)\end{array}$ & $* *$ & $\begin{array}{l}-0.0043 \\
(0.0052)\end{array}$ & & $\begin{array}{l}-0.0064 \\
(0.0049)\end{array}$ & \\
\hline TICWC*NON_TAG & $\begin{array}{l}-0.0101 \\
(0.0024)\end{array}$ & $* * *$ & $\begin{array}{l}-0.0096 \\
(0.0025)\end{array}$ & $* * *$ & $\begin{array}{l}-0.0049 \\
(0.0021)\end{array}$ & $* *$ \\
\hline TICSC*NON_TAG & $\begin{array}{l}-0.0023 \\
(0.0011)\end{array}$ & $* *$ & $\begin{array}{l}-0.0024 \\
(0.0011)\end{array}$ & $* *$ & $\begin{array}{l}-0.0034 \\
(0.0011)\end{array}$ & $* * *$ \\
\hline MRF & $\begin{array}{l}1.0030 \\
(0.0257)\end{array}$ & $* * *$ & $\begin{array}{l}0.9834 \\
(0.0270)\end{array}$ & $* * *$ & $\left(\begin{array}{l}0.9913 \\
(0.0255)\end{array}\right.$ & $* * *$ \\
\hline SMB & $\begin{array}{l}0.5797 \\
(0.0299)\end{array}$ & $* * *$ & $\begin{array}{l}0.5557 \\
(0.0316)\end{array}$ & $* * *$ & $\mid \begin{array}{l}0.5713 \\
(0.0299)\end{array}$ & $* * *$ \\
\hline HML & $\left(\begin{array}{l}0.0387 \\
(0.0307)\end{array}\right.$ & & $\begin{array}{l}0.0485 \\
(0.0319)\end{array}$ & & $\begin{array}{l}0.0067 \\
(0.0305)\end{array}$ & \\
\hline UMD & $\begin{array}{l}-0.0344 \\
(0.0223)\end{array}$ & & $\begin{array}{l}-0.0402 \\
(0.0234)\end{array}$ & * & $\begin{array}{l}-0.0176 \\
(0.0221)\end{array}$ & \\
\hline $\begin{array}{l}\text { F-tests for Hypotheses } 4 \text { \& } 5 \\
\text { F-stat } \\
\text { (Probability) }\end{array}$ & $\begin{array}{l}H 4 \\
10.302 \\
(0.000)\end{array}$ & $\begin{array}{l}H 5 \\
0.012 \\
(0.912)\end{array}$ & $\begin{array}{l}H 4 \\
7.254 \\
(0.001)\end{array}$ & $\begin{array}{l}H 5 \\
0.885 \\
(0.347)\end{array}$ & $\begin{array}{l}H 4 \\
3.602 \\
(0.027)\end{array}$ & $\begin{array}{l}H 5 \\
0.080 \\
(0.777)\end{array}$ \\
\hline $\begin{array}{l}\text { Adjusted } \mathrm{R}^{2} \\
\text { Number of total observations }\end{array}$ & $\begin{array}{l}13.30 \% \\
48477\end{array}$ & & $\begin{array}{l}13.60 \% \\
40363\end{array}$ & & $\begin{array}{l}13.62 \% \\
47094\end{array}$ & \\
\hline
\end{tabular}


Panel B - Regressions of Alternative Equation (4)

\begin{tabular}{|c|c|c|c|c|c|c|}
\hline \multirow{3}{*}{$\frac{\text { VARIABLE }}{\text { INTERCEPT }}$} & \multicolumn{6}{|c|}{$\underline{\text { DEPENDENT VARIABLE }=\mathrm{R}=\text { EXCESS RETURN }(\mathrm{RET}-\mathrm{RF})}$} \\
\hline & \multicolumn{2}{|c|}{$\begin{array}{l}\text { IN-SAMPLE } \\
\text { CASH_ETR5 }\end{array}$} & \multicolumn{2}{|c|}{$\begin{array}{l}\text { OUT-OF-SAMPLE } \\
\text { CASH_ETR5 }\end{array}$} & \multicolumn{2}{|c|}{$\begin{array}{l}\text { IN-SAMPLE } \\
\text { CASH_ETR }\end{array}$} \\
\hline & $\begin{array}{l}0.0044 \\
(0.0005)\end{array}$ & $* * *$ & $\begin{array}{l}0.0033 \\
(0.0006\end{array}$ & $* * *$ & $\begin{array}{l}0.0048 \\
(0.0005)\end{array}$ & $* * *$ \\
\hline TICWC & $\begin{array}{l}-0.0078 \\
(0.0022)\end{array}$ & $* * *$ & $\begin{array}{l}-0.0071 \\
(0.0024\end{array}$ & $* * *$ & $\begin{array}{l}-0.0036 \\
(0.0020)\end{array}$ & $*$ \\
\hline TAG & $\begin{array}{l}0.0023 \\
(0.0011)\end{array}$ & $* *$ & $\begin{array}{l}0.0024 \\
(0.0011\end{array}$ & $* *$ & $\begin{array}{l}0.0038 \\
(0.0012)\end{array}$ & $* * *$ \\
\hline TICWC*TAG & $\begin{array}{l}-0.0017 \\
(0.0050)\end{array}$ & & $\begin{array}{l}0.0028 \\
(0.0057\end{array}$ & & $\begin{array}{l}-0.0031 \\
(0.0053)\end{array}$ & \\
\hline MRF & $\begin{array}{l}1.0030 \\
(0.0257)\end{array}$ & $* * *$ & $\begin{array}{l}0.9834 \\
(0.0270\end{array}$ & $* * *$ & $\begin{array}{l}0.9912 \\
(0.0255)\end{array}$ & \\
\hline SMB & $\begin{array}{l}0.5797 \\
(0.0299)\end{array}$ & $* * *$ & $\begin{array}{l}0.5557 \\
(0.0316\end{array}$ & $* * *$ & $\begin{array}{l}0.5713 \\
(0.0299)\end{array}$ & $* * *$ \\
\hline HML & $\begin{array}{l}0.0387 \\
(0.0307)\end{array}$ & & $\begin{array}{l}0.0485 \\
(0.0319\end{array}$ & & $\begin{array}{l}0.0067 \\
(0.0305)\end{array}$ & \\
\hline UMD & $\begin{array}{l}-0.0344 \\
(0.0223)\end{array}$ & & $\begin{array}{l}-0.0402 \\
(0.0234\end{array}$ & $*$ & $\begin{array}{l}-0.0175 \\
(0.0221)\end{array}$ & \\
\hline $\begin{array}{l}\text { Adjusted } \mathrm{R}^{2} \\
\text { Number of total observations }\end{array}$ & $\begin{array}{l}13.30 \% \\
48477\end{array}$ & & $\begin{array}{l}13.60 \% \\
40363\end{array}$ & & $\begin{array}{l}13.62 \% \\
47094 \\
\end{array}$ & \\
\hline
\end{tabular}


TABLE 16

Analysis of Abnormal Stock Returns Conditional on Tax Aggressiveness and General/TaXRELATED INTERNAL CONTROL QUALITY

The regression equations are as follows:

$$
\begin{aligned}
& R_{i t}=\beta_{0}+\beta_{I} I C W^{*} T A G_{i}+\beta_{2} I C W^{*} N O N \_T A G_{i}+\beta_{3} I C S^{*} N O N \_T A G_{i}+b M R F_{t}+s S M B_{t}+h H M L_{t}+w U M D_{t}+\varepsilon_{i t} \\
& R_{i t}=\beta_{0}+\beta_{1} T I C W^{*} T A G_{i}+\beta_{2} T I C W^{*} N O N_{-} T A G_{i}+\beta_{3} T I C S^{*} N O N_{-} T A G_{i}+b M R F_{t}+s S M B_{t}+h H M L_{t}+w U M D_{t}+\varepsilon_{i t} .
\end{aligned}
$$

$R$ is measured with $X R E T$, a firm's monthly stock return less the monthly risk-free rate during the period 2004-2006. Tax aggressiveness is determined by ranking firms according to their value of $C A S H_{-} E T R 5 . T A G$ is a dichotomous variable representing tax aggressiveness, equal to 1 if a firm's CASH_ETR5 estimate is in the bottom quintile, 0 otherwise. NON_TAG represents "control firms" that are not highly tax aggressive and is coded as 1 if a firm's $C A S H \_E T R 5$ estimate is not in the bottom quintile, $\overline{0}$ otherwise. For columns 1 and 3 of the table, CASH_ETR5 (in-sample) equals the five-year sum of taxes paid divided by the five-year sum of income less special items, estimated with one observation per firm during the period 2004-2006. Over 90\% of the observations are measured as at 2006. For columns 2 and 4 of the table, CASH_ETR5 (out-of-sample) equals the five-year sum of taxes paid divided by the five-year sum of income less special items, estimated based on the firm-level value as at 2003. In columns 1 and 2, ICW equals one if the firm-level value of $T I C W 3$ or $O I C W 3$ equals one during the 2004-2006 period, zero otherwise. In columns 3 and 4, TICW equals the firm-level value of TICW3 during the period 2004-2006.

The intercept in the regression represents tax aggressive firms that do not disclose an ICW or a tax ICW, respectively at the firm-level. $I C W / T I C W^{*} T A G$ are interaction variables that represent tax aggressive firms that disclose any ICW or a tax ICW, respectively, at the firm-level. $I C W / T I C W^{*} N O N \_T A G$ are also interaction variables that represent non-tax aggressive firms that disclose any ICW or a tax ICW, respectively, at the firm-level. ICS $/ T I C S^{*} N O N \_T A G$ are interaction variables that represent non-tax aggressive firms that do not disclose a general ICW or a tax ICW, respectively, at the firm-level (i.e. TICSC reflects strong internal control). The $M R F, S M B, H M L$ and $U M D$ variables are the Fama-French (1993) factor loadings representing the excess market return, the size premium, the book-to-market premium and the momentum premium, respectively. $* * * * * *$ refer to significance at the $10 \%, 5 \%$ and $1 \%$ levels, respectively. Significance for all variables is calculated using a twotailed test. Post-estimation F-tests are presented in the table below to examine Hypotheses 4 and 5. 


\begin{tabular}{|c|c|c|c|c|c|c|c|c|}
\hline \multirow{3}{*}{$\frac{\text { VARIABLE }}{\text { INTERCEPT }}$} & \multicolumn{8}{|c|}{ DEPENDENT VARIABLE $=\mathrm{R}=$ EXCESS RETURN $(\mathrm{RET}-\mathrm{RF})$} \\
\hline & \multicolumn{2}{|c|}{$\begin{array}{l}\text { IN-SAMPLE } \\
\text { CASH_ETR5 - ICW }\end{array}$} & \multicolumn{2}{|c|}{$\begin{array}{l}\text { OUT-OF-SAMPLE } \\
\text { CASH_ETR5 - ICW }\end{array}$} & \multicolumn{2}{|c|}{$\begin{array}{l}\text { IN-SAMPLE } \\
\text { CASH_ETR5 - TICW }\end{array}$} & \multicolumn{2}{|c|}{$\begin{array}{l}\text { OUT-OF-SAMPLE } \\
\text { CASH_ETR5 - TICW }\end{array}$} \\
\hline & $\begin{array}{l}0.0069 \\
(0.0011)\end{array}$ & $* * *$ & $\begin{array}{l}0.0066 \\
(0.0011)\end{array}$ & $* * *$ & $\begin{array}{l}0.0066 \\
(0.0010)\end{array}$ & $* * *$ & $\begin{array}{l}0.0058 \\
(0.0010)\end{array}$ & $* * *$ \\
\hline ICW/TICW*TAG & $\begin{array}{l}-0.0054 \\
(0.0030)\end{array}$ & $*$ & $\begin{array}{l}-0.0061 \\
(0.0029)\end{array}$ & $* *$ & $\begin{array}{l}-0.0091 \\
(0.0043)\end{array}$ & $* *$ & $\begin{array}{l}-0.0040 \\
(0.0047)\end{array}$ & \\
\hline ICW/TICW*NON_TAG & $\begin{array}{l}-0.0054 \\
(0.0016)\end{array}$ & $* * *$ & $\begin{array}{l}-0.0061 \\
(0.0017)\end{array}$ & $* * *$ & $\begin{array}{l}-0.0094 \\
(0.0022)\end{array}$ & $* * *$ & $\begin{array}{l}-0.0091 \\
(0.0024)\end{array}$ & $* * *$ \\
\hline ICS/TICS*NON_TAG & $\begin{array}{l}-0.0025 \\
(0.0011)\end{array}$ & $* *$ & $\begin{array}{l}-0.0032 \\
(0.0011)\end{array}$ & $* * *$ & $\begin{array}{l}-0.0022 \\
(0.0011)\end{array}$ & $* *$ & $\begin{array}{l}-0.0024 \\
(0.0011)\end{array}$ & $* *$ \\
\hline MRF & $\begin{array}{l}1.0031 \\
(0.0257)\end{array}$ & $* * *$ & $\begin{array}{l}0.9835 \\
(0.0270)\end{array}$ & $* * *$ & $\begin{array}{l}1.0031 \\
(0.0257)\end{array}$ & $* * *$ & $\begin{array}{l}0.9835 \\
(0.0270)\end{array}$ & $* * *$ \\
\hline SMB & $\begin{array}{l}0.5796 \\
(0.0300)\end{array}$ & $* * *$ & $\begin{array}{l}0.5555 \\
(0.0316)\end{array}$ & $* * *$ & $\begin{array}{l}0.5796 \\
(0.0299)\end{array}$ & $* * *$ & $\begin{array}{l}0.5556 \\
(0.0316)\end{array}$ & $* * *$ \\
\hline HML & $\begin{array}{l}0.0387 \\
(0.0307)\end{array}$ & & $\begin{array}{l}0.0485 \\
(0.0319)\end{array}$ & & $\begin{array}{l}0.0387 \\
(0.0307)\end{array}$ & & $\begin{array}{l}0.0485 \\
(0.0319)\end{array}$ & \\
\hline UMD & $\begin{array}{l}-0.0344 \\
(0.0223)\end{array}$ & & $\begin{array}{l}-0.0401 \\
(0.0235)\end{array}$ & $*$ & $\begin{array}{l}-0.0343 \\
(0.0223)\end{array}$ & & $\begin{array}{l}-0.0401 \\
(0.0234)\end{array}$ & $*$ \\
\hline $\begin{array}{l}\text { F-tests for Hypotheses } 4 \text { \& } 5 \\
\text { F-stat } \\
\text { (Probability) }\end{array}$ & $\begin{array}{l}H 4 \\
6.218 \\
(0.002)\end{array}$ & $\begin{array}{l}H 5 \\
0.000 \\
(0.991)\end{array}$ & $\begin{array}{l}H 4 \\
7.336 \\
(0.001)\end{array}$ & $\begin{array}{l}H 5 \\
0.000 \\
(0.986)\end{array}$ & $\begin{array}{l}H 4 \\
10.232 \\
(0.000)\end{array}$ & $\begin{array}{l}H 5 \\
0.005 \\
(0.944)\end{array}$ & $\begin{array}{l}H 4 \\
7.273 \\
(0.001)\end{array}$ & $\begin{array}{l}H 5 \\
0.996 \\
(0.318)\end{array}$ \\
\hline $\begin{array}{l}\text { Adjusted } \mathrm{R}^{2} \\
\text { Total firm-year observations }\end{array}$ & $\begin{array}{l}13.30 \% \\
48477 \\
\end{array}$ & & $\begin{array}{l}13.60 \% \\
40363\end{array}$ & & $\begin{array}{l}13.30 \% \\
48477 \\
\end{array}$ & & $\begin{array}{l}13.60 \% \\
40363 \\
\end{array}$ & \\
\hline
\end{tabular}


TABLE 17

\section{Analysis of Abnormal Stock Returns Conditional on Tax AgGRESSIVENESS AND COMPANY-LEVEL TAX-RELATED INTERNAL CONTROL QUALITY (12 MONTHS PRECEDING AND FOLLOWING 2004-2006 SOX PERIOD)}

Equation (4) is estimated as follows:

$$
\begin{aligned}
& R_{i t}=\beta_{0}+\beta_{1} T I C W C^{*} T A G_{i}+\beta_{2} T I C W C^{*} N O N_{-} T A G_{i}+\beta_{3} T I C S C * N O N_{-} T A G_{i}+b M R F_{t}+s S M B_{t}+ \\
& h H M L_{t}+w U M D_{t}+\varepsilon_{i t}
\end{aligned}
$$

$R$ is measured with $X R E T$, a firm's monthly stock return less the monthly risk-free rate observed during the twelve months prior to the firm's 2004 fiscal year-end (for column 1) and the twelve months following the firm's 2006 fiscal year-end (for column 2). Tax aggressiveness is determined by ranking firms according to their value of $C A S H_{-} E T R 5$. TAG is a dichotomous variable representing tax aggressiveness, equal to 1 if a firm's $C A S H_{-} E T R 5$ estimate is in the bottom quintile, 0 otherwise. NON_TAG represents “control firms” that are not highly tax aggressive and is coded as 1 if a firm's $C A S \bar{H}_{-} E T R 5$ estimate is not in the bottom quintile, 0 otherwise. CASH_ETR5 (out-of-sample) equals the five-year sum of taxes paid divided by the five-year sum of income less special items, estimated based on the firm-level value as at 2003. TICWC equals the firm-level value of TICW5_COMP5 during the period 2004-2006.

The intercept in the regression represents tax aggressive firms that do not disclose a company-level tax ICW at the firm-level. TICWC*TAG is an interaction variable that represents tax aggressive firms that disclose a company-level tax ICW at the firm-level. TICWC*NON_TAG is also an interaction variable that represents non-tax aggressive firms that disclose a company-level tax ICW at the firm-level. $T I C S C^{*} N O N_{-} T A G$ is an interaction variable that represents non-tax aggressive firms that do not disclose a company-level tax ICW at the firm-level (i.e. TICSC reflects strong internal control). The $M R F, S M B$, $H M L$ and $U M D$ variables are the Fama-French (1993) factor loadings representing the excess market return, the size premium, the book-to-market premium and the momentum premium, respectively. ${ }^{*} * *$ $* * *$ refer to significance at the $10 \%, 5 \%$ and $1 \%$ levels, respectively. Significance for all variables is calculated using a two-tailed test. Post-estimation F-tests are presented in the table below to examine Hypotheses 4 and 5. 


\begin{tabular}{|c|c|c|c|c|}
\hline \multirow[b]{2}{*}{ VARIABLE } & \multicolumn{4}{|c|}{$\frac{\text { DEPENDENT VARIABLE }=\mathrm{R}=\text { EXCESS RETURN }}{\underline{(\mathrm{RET}-\mathrm{RF})}}$} \\
\hline & \multicolumn{2}{|c|}{$\begin{array}{l}\text { OUT-OF-SAMPLE } \\
\text { CASH_ETR5 - } 12 \\
\text { MONTHS PRIOR }\end{array}$} & \multicolumn{2}{|c|}{$\begin{array}{l}\text { OUT-OF-SAMPLE } \\
\text { CASH_ETR5 - } 12 \\
\text { MONTHS AFTER }\end{array}$} \\
\hline INTERCEPT & $\begin{array}{l}-0.0004 \\
(0.0024)\end{array}$ & & $\begin{array}{l}0.0045 \\
(0.0019)\end{array}$ & \\
\hline TICWC*TAG & $\begin{array}{l}0.0165 \\
(0.0098)\end{array}$ & $*$ & $\begin{array}{l}-0.0022 \\
(0.0091)\end{array}$ & \\
\hline TICWC*NON_TAG & $\begin{array}{l}-0.0034 \\
(0.0051)\end{array}$ & & $\begin{array}{l}0.0009 \\
(0.0052)\end{array}$ & \\
\hline TICSC*NON_TAG & $\begin{array}{l}-0.0029 \\
(0.0024)\end{array}$ & & $\begin{array}{l}0.0002 \\
(0.0020)\end{array}$ & \\
\hline MRF & $\begin{array}{l}1.2053 \\
(0.0480)\end{array}$ & & $\begin{array}{l}0.9789 \\
(0.0280)\end{array}$ & $* * *$ \\
\hline SMB & $\begin{array}{l}0.5191 \\
(0.0515)\end{array}$ & $* * *$ & $\begin{array}{l}0.5376 \\
(0.0695)\end{array}$ & $* * *$ \\
\hline HML & $\begin{array}{l}0.0418 \\
(0.0768)\end{array}$ & & $\begin{array}{l}0.4225 \\
(0.0790)\end{array}$ & $* * *$ \\
\hline UMD & $\begin{array}{l}0.0717 \\
(0.0298)\end{array}$ & $* *$ & $\begin{array}{l}-0.1360 \\
(0.0357)\end{array}$ & $* * *$ \\
\hline $\begin{array}{l}\text { F-tests for Hypotheses } 4 \text { \& } 5 \\
\text { F-stat } \\
\text { (Probability) }\end{array}$ & $\begin{array}{l}H 4 \\
1.779 \\
(0.169)\end{array}$ & $\begin{array}{l}H 5 \\
3.550 \\
(0.060)\end{array}$ & $\begin{array}{l}H 4 \\
0.047 \\
(0.954)\end{array}$ & $\begin{array}{l}H 5 \\
0.093 \\
(0.760)\end{array}$ \\
\hline $\begin{array}{l}\text { Adjusted } \mathrm{R}^{2} \\
\text { Number of total observations }\end{array}$ & $\begin{array}{l}13.93 \% \\
11749 \\
\end{array}$ & & $\begin{array}{l}11.13 \% \\
12876 \\
\end{array}$ & \\
\hline
\end{tabular}


TABLE 18

\section{Analysis of Abnormal Stock Returns Conditional on Alternative TaX Aggressiveness Proxies and Company-LeVel TAX-Related InTERnal CONTROL QUALiTY}

Equation (4) is estimated as follows:

$$
\begin{aligned}
& R_{i t}=\beta_{0}+\beta_{1} T I C W C^{*} T A G_{i}+\beta_{2} T I C W C^{*} N O N_{-} T A G_{i}+\beta_{3} T I C S C * N O N_{-} T A G_{i}+b M R F_{t}+s S M B_{t}+ \\
& h H M L_{t}+w U M D_{t}+\varepsilon_{i t}
\end{aligned}
$$

$R$ is measured with $X R E T$, a firm's monthly stock return less the monthly risk-free rate during the period 2004-2006. Tax aggressiveness is determined by ranking firms according to their annual value of BTD1 or PROB_TS. BTD1 is the Manzon-Plesko (2002) BTD measure, also estimated annually, equal to [US domestic pre-tax income - (current US domestic tax expense / US statutory rate) - state income taxes - other income taxes - equity in earnings] / lagged assets. PROB_TS is the predicted probability that a firm engages in tax sheltering, based on Wilson's (2009) tax shelter prediction model. Values of $P R O B \_T S$ range from 0 to 1 . Additional description of Wilson's (2009) tax shelter prediction model is available in subsection 6.2.1 of this dissertation. In the regressions, $T A G$ is a dichotomous variable representing tax aggressive firms, equal to 1 if a firm's BTDI or PROB_TS estimate is in the top quintile, 0 otherwise. NON_TAG represents "control firms" that are not highly tax aggressive and is coded as 1 if a firm's $B T D 1$ or $P R O B \_T S$ estimate is not in the top quintile, 0 otherwise. For purposes of ranking tax aggressiveness, $B T D 1$ and $P R O B \_T S$ are estimated for each available firm-year observation in the period 2004-2006. TICWC equals the firm-year value of TICW_COMP during the period 2004-2006.

The intercept in the regression represents tax aggressive firms that do not disclose a company-level tax ICW at the firm-year level. TICWC ${ }^{*} T A G$ is an interaction variable that represents tax aggressive firms that disclose a company-level tax ICW at the firm-year level. TICWC*NON_TAG is also an interaction variable that represents non-tax aggressive firms that disclose a company-level tax ICW at the firm-year level. TICSC*NON_TAG is an interaction variable that represents non-tax aggressive firms that do not disclose a company-level tax ICW at the firm-year level (i.e. TICSC reflects strong internal control). The $M R F, S M B, H M L$ and $U M D$ variables are the Fama-French (1993) factor loadings representing the excess market return, the size premium, the book-to-market premium and the momentum premium, respectively. $* * * * * *$ refer to significance at the $10 \%, 5 \%$ and $1 \%$ levels, respectively. Significance for all variables is calculated using a two-tailed test. Post-estimation F-tests are presented in the table below to examine Hypotheses 4 and 5. 


\begin{tabular}{|c|c|c|c|c|}
\hline \multirow[b]{2}{*}{ VARIABLE } & \multicolumn{4}{|c|}{$\frac{\text { DEPENDENT VARIABLE }=\mathrm{R}=\text { EXCESS RETURN }}{(\mathrm{RET}-\mathrm{RF})}$} \\
\hline & \multicolumn{2}{|c|}{ IN-SAMPLE BTD1 } & \multicolumn{2}{|c|}{ IN-SAMPLE PROB_TS } \\
\hline INTERCEPT & $\begin{array}{l}0.0059 \\
(0.0012)\end{array}$ & $* * *$ & $\begin{array}{l}0.0044 \\
(0.0013)\end{array}$ & $* * *$ \\
\hline TICWC*TAG & $\begin{array}{l}-0.0008 \\
(0.0063)\end{array}$ & & $\begin{array}{l}-0.0033 \\
(0.0048)\end{array}$ & \\
\hline TICWC*NON_TAG & $\begin{array}{l}-0.0095 \\
(0.0024)\end{array}$ & $* * *$ & $\begin{array}{l}-0.0056 \\
(0.0036)\end{array}$ & \\
\hline TICSC*NON_TAG & $\begin{array}{l}-0.0015 \\
(0.0012)\end{array}$ & & $\begin{array}{l}-0.0007 \\
(0.0014)\end{array}$ & \\
\hline MRF & $\begin{array}{l}1.0051 \\
(0.0298)\end{array}$ & $* * *$ & $\begin{array}{l}1.1168 \\
(0.0407)\end{array}$ & $* * *$ \\
\hline SMB & $\begin{array}{l}0.6081 \\
(0.0348)\end{array}$ & $* * *$ & $\begin{array}{l}0.6518 \\
(0.0472)\end{array}$ & $* * *$ \\
\hline HML & $\begin{array}{l}-0.0096 \\
(0.0359)\end{array}$ & & $\begin{array}{l}-0.1919 \\
(0.0497)\end{array}$ & $* * *$ \\
\hline UMD & $\begin{array}{l}-0.0363 \\
(0.0258)\end{array}$ & & $\begin{array}{l}-0.0378 \\
(0.0354)\end{array}$ & \\
\hline $\begin{array}{l}\text { F-tests for Hypotheses } 4 \text { \& } 5 \\
\text { F-stat } \\
\text { (Probability) }\end{array}$ & $\begin{array}{l}H 4 \\
8.024 \\
(0.000)\end{array}$ & $\begin{array}{l}\text { H5 } \\
1.678 \\
(0.195)\end{array}$ & $\begin{array}{l}H 4 \\
1.421 \\
(0.242)\end{array}$ & $\begin{array}{l}\text { H5 } \\
0.157 \\
(0.692)\end{array}$ \\
\hline $\begin{array}{l}\text { Adjusted } \mathrm{R}^{2} \\
\text { Number of total observations }\end{array}$ & $\begin{array}{l}13.33 \% \\
37296\end{array}$ & & $\begin{array}{l}15.23 \% \\
20843\end{array}$ & \\
\hline
\end{tabular}

